\title{
Playback surveys and breeding habitat characteristics of golden- winged warblers (Vermivora chrysoptera) on high-elevation pasturelands on the Monongahela National Forest, West Virginia
}

Kyle Ray Aldinger

West Virginia University

Follow this and additional works at: https://researchrepository.wvu.edu/etd

\section{Recommended Citation}

Aldinger, Kyle Ray, "Playback surveys and breeding habitat characteristics of golden-winged warblers (Vermivora chrysoptera) on high-elevation pasturelands on the Monongahela National Forest, West Virginia" (2010). Graduate Theses, Dissertations, and Problem Reports. 3045.

https://researchrepository.wvu.edu/etd/3045

This Thesis is protected by copyright and/or related rights. It has been brought to you by the The Research Repository @ WVU with permission from the rights-holder(s). You are free to use this Thesis in any way that is permitted by the copyright and related rights legislation that applies to your use. For other uses you must obtain permission from the rights-holder(s) directly, unless additional rights are indicated by a Creative Commons license in the record and/ or on the work itself. This Thesis has been accepted for inclusion in WVU Graduate Theses, Dissertations, and Problem Reports collection by an authorized administrator of The Research Repository @ WVU. For more information, please contact researchrepository@mail.wvu.edu. 
Playback Surveys and Breeding Habitat Characteristics of Golden-winged Warblers (Vermivora chrysoptera) on High-Elevation Pasturelands on the Monongahela National Forest, West Virginia

Kyle Ray Aldinger

Thesis submitted to the Davis College of Agriculture, Natural Resources, and Design at West Virginia University in partial fulfillment of the requirements for the degree of

Master of Science

in

Wildlife and Fisheries Resources

\author{
Petra B. Wood, Ph.D., Chair \\ James T. Anderson, Ph.D. \\ Rob Tallman, M.S.
}

Division of Forestry and Natural Resources

Morgantown, West Virginia

2010

Keywords: Breeding habitat; classification tree; early succession; Golden-winged Warbler; grazing; Monongahela National Forest; nest; pasture; playback survey; point count; scale; song; territory; Vermivora chrysoptera 


\begin{abstract}
Playback Surveys and Breeding Habitat Characteristics of Golden-winged Warblers (Vermivora chrysoptera) on High-Elevation Pasturelands on the Monongahela National Forest, West Virginia
\end{abstract}

\author{
Kyle Ray Aldinger
}

Across the breeding range of the Golden-winged Warbler (Vermivora chrysoptera), significant population declines have been documented even before the implementation of the North American Breeding Bird Survey (BBS) and continue as such today. The plight of this species has been blamed on the loss and degradation of early successional habitat, interactions with the closely related Blue-winged Warbler (Vermivora pinus), and Brown-headed Cowbird (Molothrus ater) brood parasitism. Most breeding Golden-winged Warblers are found in the upper Midwest and Great Lakes regions of the United States, but there are considerable populations persisting at higher elevations $(>600 \mathrm{~m})$ in the central Appalachian region. States in this part of the range are witnessing some of the steepest population declines. In West Virginia, a state that is predominantly forested, Golden-winged Warblers breed on actively grazed highelevation pasturelands composed of a matrix of grasses, forbs, Rubus, shrubs, few saplings and trees, and a forest edge. The habitats in this study are unique to the published literature on Golden-winged Warblers because they remain in a suitable state due to annual low-intensity (1.2-2.4 ha usable forage/animal unit) livestock grazing, require little additional management, and Blue-winged Warblers and hybrids are rare or absent. My primary objectives were to 1) test the effectiveness of using two types of Golden-winged Warbler song playback surveys at different times of day and season to monitor known populations and 2) quantify breeding habitat characteristics of this species on high-elevation pasturelands on the Monongahela National Forest, West Virginia.

In 2008 and 2009 on the Monongahela National Forest, I conducted point counts with Golden-winged Warbler song playback on grazing allotments where the number of territorial males was known. I used the proportion of males detected during song playback surveys (detection probability) as a measure of the effectiveness of each survey type. Behavioral responses were noted to further assess the value of playback. Results have implications for monitoring efforts and recent attempts to estimate absolute population size for this species.

I measured habitat characteristics at Golden-winged Warbler nests, territories, and random points associated with each. Habitat characteristics were grouped and analyzed using classification trees at the microhabitat, macrohabitat, and global (all variables) scales.

Regardless of song type or season, more Golden-winged Warbler males were detected during morning surveys than evening surveys. Detection probability was higher during playback of type 2 songs, associated with territorial interactions, than with type 1 songs, associated with mate attraction. Season did not have a significant effect on detection probability, although we 
only detected $40 \%$ of the known male population using 3-min passive point counts during the season that coincided with the BBS. In most instances, playback elicited behavioral responses that would allow positive identification between Golden-winged Warblers, Blue-winged Warblers, and their hybrids; however, with regards to detection probability, playback surveys performed similarly to passive point counts. Morning point counts with 1-1.3 mins of Goldenwinged Warbler song playback followed by passive listening conducted from 22 May to 2 June can maximize detection probability for this species on pasturelands in West Virginia. Because detection rates were low, attempts to estimate absolute abundance from point count data will underestimate population size for this species.

Classification trees correctly identified nests, territories, and random plots at a rate better than would be expected at random. Vegetation density, microhabitat-scale woody ground cover, and macrohabitat-scale grass cover all emerged in multiple models as important explanatory variables. Most nests had woody vegetation supporting the nest or were built less than one meter from a shrub stem. The remaining nests were characterized by greater Rubus and herbaceous cover. Global classification trees combined variables from microhabitat and macrohabitat scales; however, no final global models incorporated variables from both scales. Thus, microhabitat and macrohabitat may be the important scales for categorizing nests and territories, respectively. Characteristics such as woody, grass, and vine cover, height of the shrub layer, and aspect may predispose a nest to success or failure. Low intensity livestock grazing can be used to manage habitat for Golden-winged Warblers breeding on high-elevation sites in West Virginia and perhaps elsewhere. 


\section{ACKNOWLEDGMENTS}

First and foremost, I would like to thank God for the opportunity to work on such a wonderful and rewarding project. There are many people who have made contributions to this project, to all of which I am grateful. My major advisor, Dr. Petra Wood, gave me the opportunity to do research at WVU. Her advice, comments, expertise, patience (especially when I was injuring myself playing ultimate frisbee), and promptness were greatly appreciated. My graduate committee members Dr. Jim Anderson and Rob Tallman provided support, guidance, and suggestions, and I should have taken advantage of them more often during this process. Rob has been a great example of a field biologist and a vital part of the field component of my research. My entire graduate committee provided valuable assistance in the completion of this manuscript and project. I have to acknowledge Dr. Carol Bocetti, who instilled in me a love of the avian world and the desire to continue my education and professional development well beyond California University of Pennsylvania.

I have had such a great time doing field work with Mandy Weston, Jerry Kreiser, Daniel Ware, Andy Newman, Liz Stout, and Carolyn Sedgwick. I owe a special thanks to Mandy and Jerry for their multiple years of work, dedication to this project, and all of the adventures we had. Mandy was extremely supportive of me during my entire Master's career at WVU. Dr. Greg George is partly responsible for getting my foot in the door at WVU, and I could list several accomplishments under his direction, including obtaining a bird banding subpermit. Matt Shumar, Molly McDermott, Josh Vance and other graduate students at WVU provided assistance in the field and elsewhere on this project. Dave Gibson, Dr. Cathy Johnson, Jim McCormick, and Andy Stump were our extremely accommodating liaisons with the USFS.

So many members of the Golden-winged Warbler Working Group have contributed directly or indirectly to this study, through publications, meetings, conference calls, protocols, advice, and general knowledge of the species. Jake Kubel and John Confer provided valuable insight for the playback survey portion of the project. I would like to thank Dr. George Merovich for his continuing willingness to provide statistical assistance to myself and so many other graduate students in the Division of Forestry and Natural Resources.

Funding for this project was granted by the WV Division of Natural Resources Wildlife Diversity Program, U.S. Fish and Wildlife Service Migratory Bird Program, U.S. Forest Service Monongahela National Forest, and the National Fish and Wildlife Foundation. Logistic and administrative support was provided by the USGS West Virginia Cooperative Fish and Wildlife Unit and the Division of Forestry and Natural Resources at West Virginia University, with a special thanks to Becky Nestor, who keeps the WVCFWRU afloat. Housing was provided by the WVDNR Elkins Operation Center. The Littlefield family graciously let us borrow their popup camper for the Pocahontas County study area and the USFS allowed us access to the study sites. 


\section{TABLE OF CONTENTS}

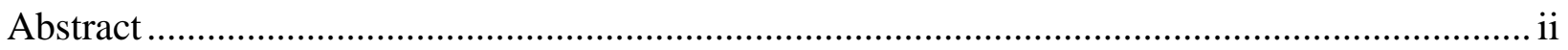

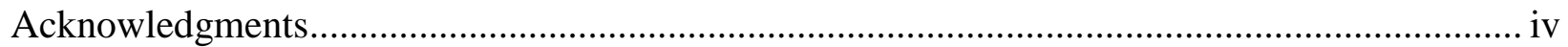

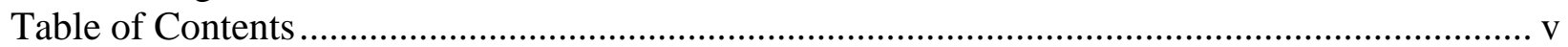

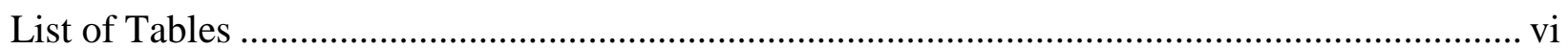

List of Figures ................................................................................................................... vii

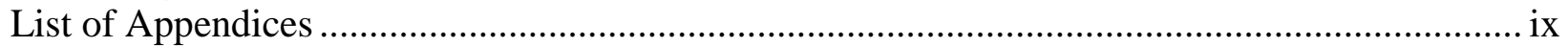

Chapter 1: Literature review of playback surveys and breeding habitat characteristics of Golden-winged Warblers (Vermivora chrysoptera)

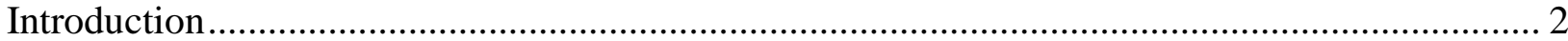

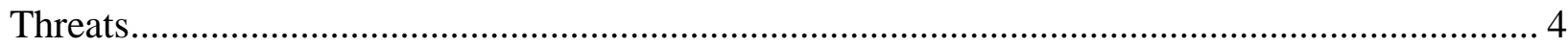

Golden-winged Warbler Monitoring ….............................................................................. 7

Golden-winged Warbler Breeding Ecology......................................................................... 10

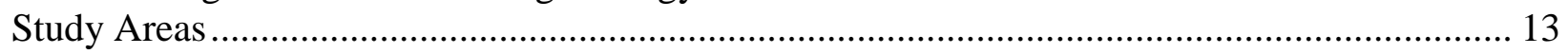

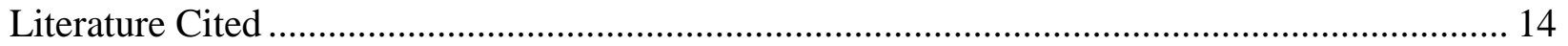

Chapter 2: Effect of time of day, season, song type, and playback duration on detection probability and behavioral response of Golden-winged Warblers

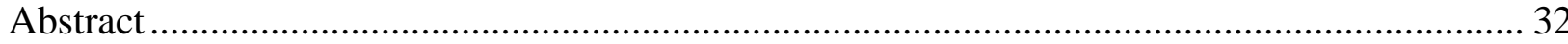

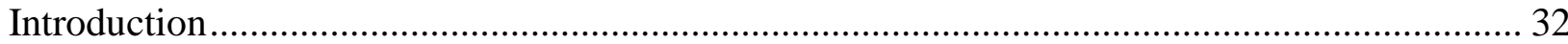

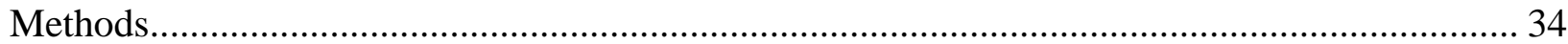

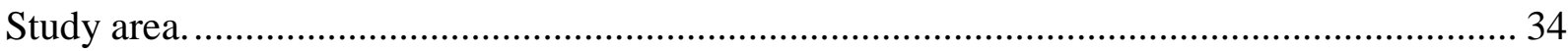

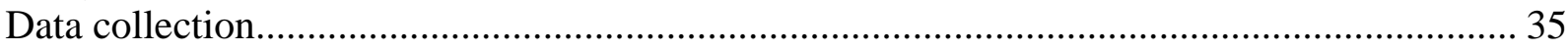

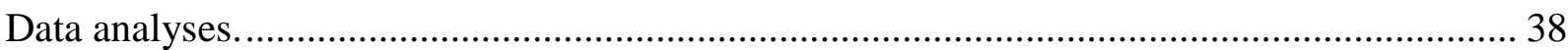

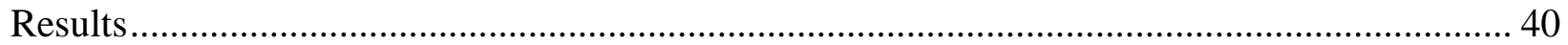

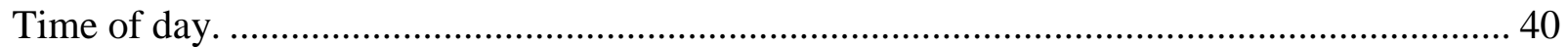

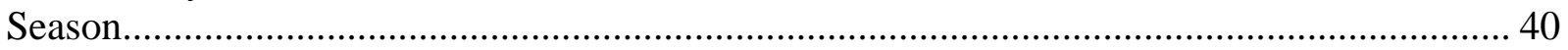

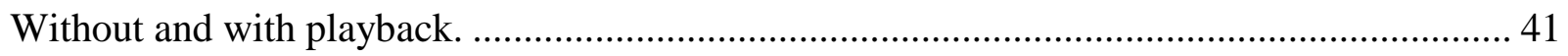

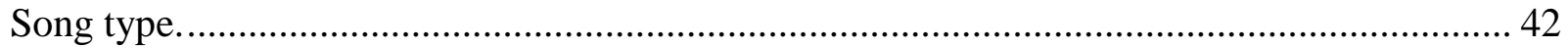

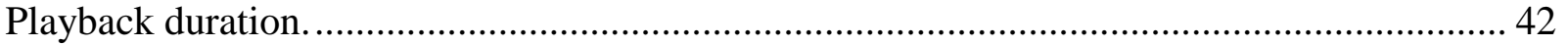

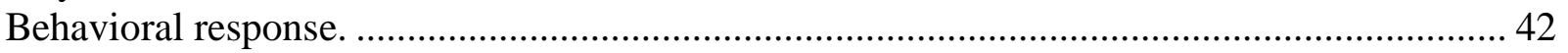

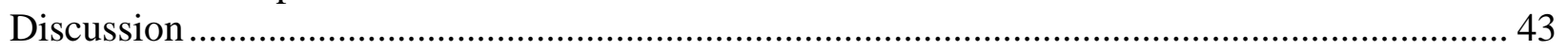

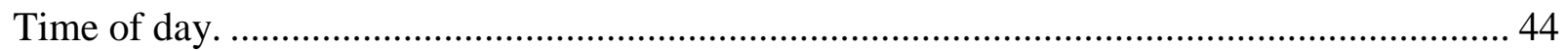

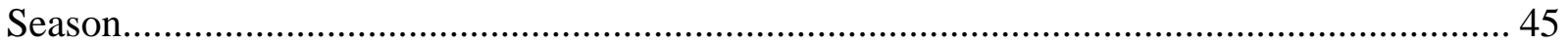

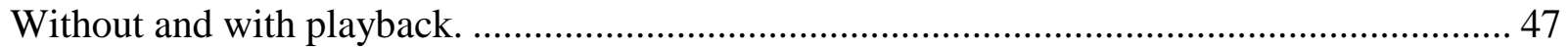

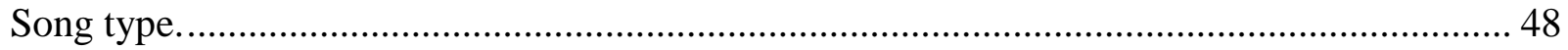

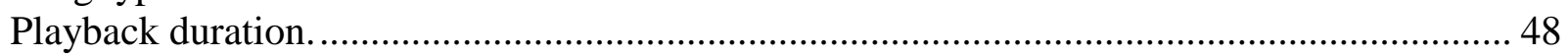

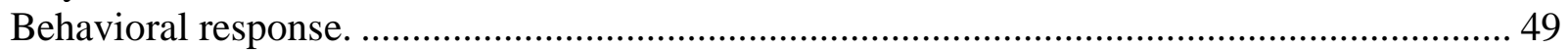

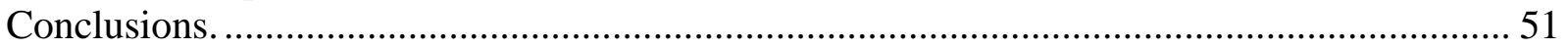

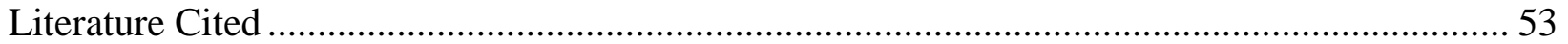

Chapter 3: Breeding habitat characteristics of Golden-winged Warblers on high-elevation pasturelands on the Monongahela National Forest, West Virginia

Abstract 66 


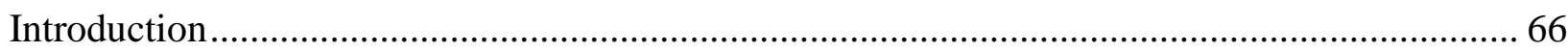

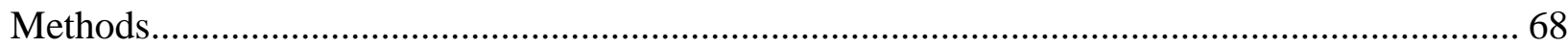

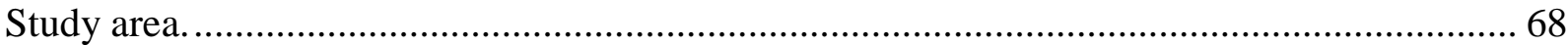

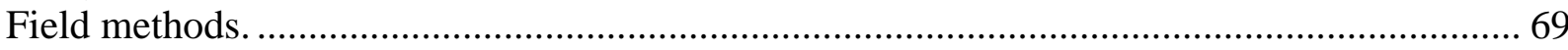

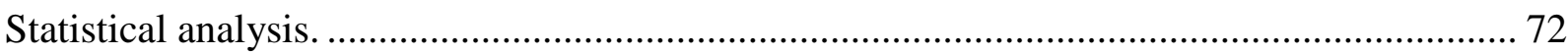

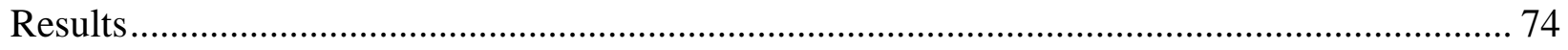

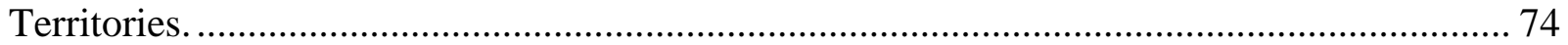

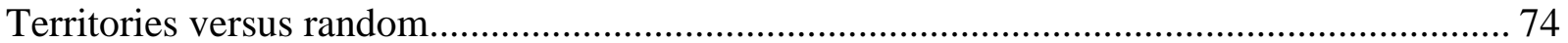

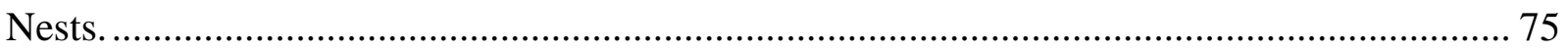

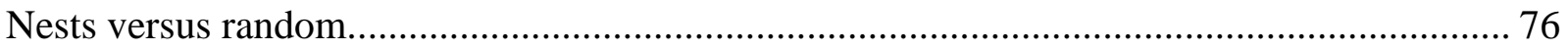

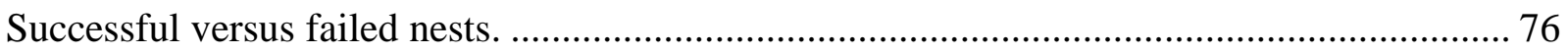

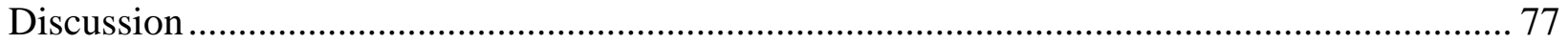

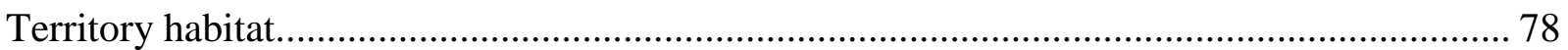

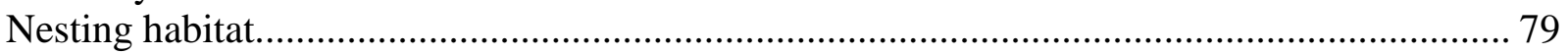

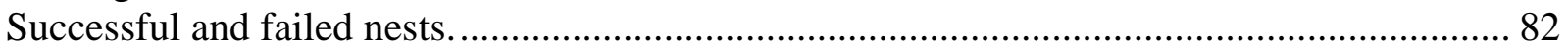

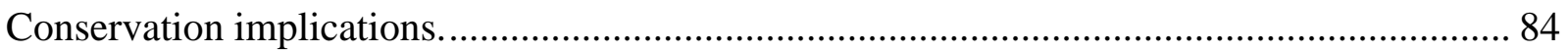

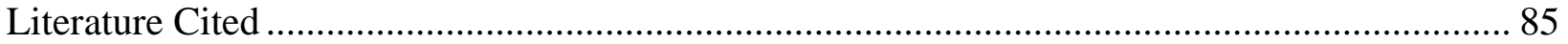

\section{Chapter 1:}

LIST OF TABLES

Table 1. Summary statistics of Golden-winged Warbler nesting parameters................................ 21

\section{Chapter 2:}

Table 1. Repeated measures ANOVA table comparing mean detection probability across the 6min survey period with song type, season, and year as main effects............................................. 57

Table 2. Mean detection probability (\% of known territorial male population) in AM versus PM surveys in 2008 on grazing areas on the Monongahela National Forest, West Virginia............... 58

Table 3. Mean detection probability with and without playback during AM surveys using type 1 and 2 song in 2008 and 2009 on grazing areas on the Monongahela National Forest, West

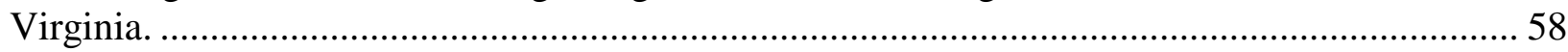

Table 4. Mean detection probability using type 1 and 2 song considering pre-playback and playback periods independently. Data were collected during AM surveys in 2008 and 2009 on grazing areas on the Monongahela National Forest, West Virginia.............................................. 59

Table 5. Total numbers of responses of male Golden-winged Warblers to 3 mins of type 1 and type 2 song in three time periods (Early $=10-21$ May, Middle $=22$ May-2 June, Late $=3-15$ June) during surveys of grazing areas on the Monongahela National Forest, West Virginia in 2008 and 2009.

\section{Chapter 3:}

Table 1. Summary of Golden-winged Warbler nesting demographics

Table 2. Classification tree models by scale and variables included in initial models using data from 2008-2009 in Randolph and Pocahontas counties, WV.... 
Table 3. Means and standard errors for vegetation variables measured during 2008-2009 in Randolph and Pocahontas counties, WV.

Table 4. Means and standard errors for nest microhabitat characteristics collected at nests $(\mathrm{n}=21)$ and paired nest points $(\mathrm{n}=21)$ during 2008-2009 in Randolph and Pocahontas counties, WV.... 93

\section{LIST OF FIGURES}

\section{Chapter 1:}

Figure 1. Golden-winged Warbler (Vermivora chrysoptera) male (top), female (bottom left), and

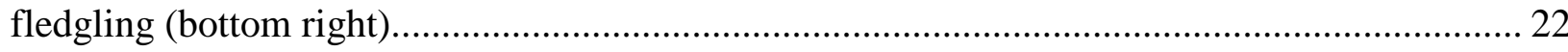

Figure 2. Map of Golden-winged Warbler breeding, migratory, and winter ranges. .................. 23

Figure 3. Aerial photographs (NRCS 2007) of intensively monitored study sites in Randolph and Pocahontas Counties with grazing allotment boundaries in black and treatment areas in red. McAllister, which is located less than $2 \mathrm{~km}$ to the northwest of Hoover, is not shown because Golden-winged Warblers were not present.

Figure 4. The ungrazed section of Coberly Sods North with evidence of brush-hogging to the right and left of the Golden-winged Warbler nest site in the center. 25

Figure 5. The grazed section of Coberly Sods North (behind road) ....................................... 25

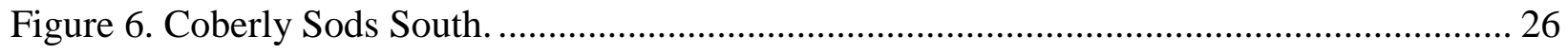

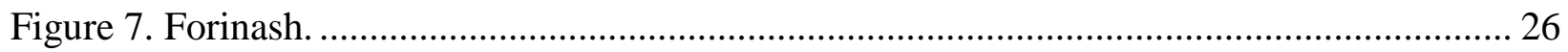

Figure 8. Washout: the privately owned abandoned pasture.............................................. 27

Figure 9. The ungrazed section of Coberly Sods North during treatment in November 2008

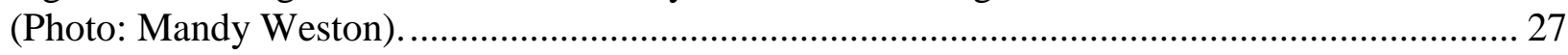

Figure 10. Ten months post-treatment on the ungrazed section of Coberly Sods North. This area was previously a homogeneous patch of Rubus. ............................................................. 28

Figure 11. Forinash a few days post-treatment in September 2008...................................... 29

Figure 12. Hoover with barn remaining from previous land owner. ........................................ 29

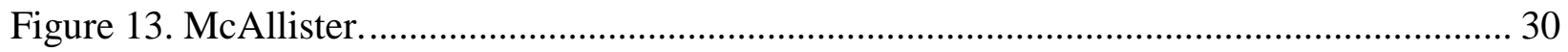

Figure 14. A 4.05 ha clearcut (upper right) adjacent to the Hoover grazing allotment (bottom). 30

\section{Chapter 2:}

Figure 1. Mean detection probability ( \pm SE) using type 1 and type 2 song playback during AM surveys in 2008 and 2009 on grazing areas on the Monongahela National Forest, West Virginia. Detection probability is based on the 6-min survey (3 mins of passive listening and 3 mins of 
song playback) during the early (May 10-21), middle (May 22-June 2), and late (June 3-15) seasons.

Figure 2. Difference in detection probability by site $(\mathrm{CN}=\mathrm{Coberly}$ Sods North, $\mathrm{CS}=$ Coberly Sods South, FO=Forinash, WA=Washout, GS=Gay/Sharp, HO=Hoover) between 10-min type 2 surveys and 10-min passive point counts. Y-axis values represent the difference in detection probability (Type 2 - Passive). The difference was not significant (paired $t=0.9, \mathrm{df}=9, P=0.39$ ).

Figure 3. Mean cumulative detection probability $( \pm \mathrm{SE})$ by min during the middle season using type 1 and 2 surveys and passive point counts in 2008 and 2009 on grazing areas on the Monongahela National Forest. Data were pooled across sites and detection probability is the mean of the 2 years. The first 2 mins of the passive point count were grouped as one interval when data were collected.

Figure 4. Mean cumulative detection probability ( \pm SE) by min using type 1 and 2 song playback during AM surveys in 2008 and 2009 on grazing areas on the Monongahela National Forest, West Virginia. Data were pooled across sites and seasons and detection probability is the mean of the 2 years.

Figure 5. Frequency distribution of distances within which Golden-winged Warblers approached survey stations in response to 3 mins of type 1 or type 2 song playback on grazing areas on the Monongahela National Forest, West Virginia. Data were pooled across season and year. Individuals that did not approach were excluded.

\section{Chapter 3:}

Figure 1. Classification tree for microhabitat characteristics at Golden-winged Warbler territories $(n=63)$ and paired territory plots $(n=63)$ during 2008-2009 in Randolph and Pocahontas counties, West Virginia. Letters below the histogram at each terminal node for all trees signify the dominant type (e.g., PT=paired territory, T=territory center) and values represent the number of cases for that type at each node (\#PT/\#T).

Figure 2. Classification tree for macrohabitat characteristics at Golden-winged Warbler territories (T; n=63) and paired territory plots (PT; n=63) during 2008 and 2009 in Randolph and Pocahontas counties, West Virginia.

Figure 3. Classification tree for microhabitat characteristics at nests $(N ; n=21)$ and their associated random plots (PN; $n=21$ ) during 2008-2009 in Randolph and Pocahontas counties, WV.

Figure 4. Classification tree for macrohabitat characteristics at nests $(\mathrm{N} ; \mathrm{n}=21)$ and their associated random plots (PN; $\mathrm{n}=21$ ) during 2008-2009 in Randolph and Pocahontas counties, WV. 
Figure 4. Classification tree for macrohabitat characteristics at nests $(\mathrm{N} ; \mathrm{n}=21)$ and their associated random plots (PN; $n=21$ ) during 2008-2009 in Randolph and Pocahontas counties, WV.

Figure 5. Classification tree for microhabitat characteristics at nests $(n=21)$ during 2008-2009 in Randolph and Pocahontas counties, WV. Letters below histograms signify successful (S) and failed (F) nests.

Figure 6. Classification tree for macrohabitat characteristics at successful $(\mathrm{S} ; \mathrm{n}=11)$ and failed nests $(\mathrm{F} ; \mathrm{n}=10)$ during 2008-2009 in Randolph and Pocahontas counties, WV. We selected the tree with the minimum CV error rather the smallest tree within 1-SE of the minimum CV error.

\section{List OF APPENDICES}

\section{Chapter 2:}

Appendix 1. Observations of male Golden-winged Warblers with the GOWAP (Type 1) protocol.

Appendix 2. Observations of male Golden-winged Warblers with the Type 2 protocol. 


\section{Chapter 1}

Literature review of playback surveys and breeding habitat characteristics of Golden-winged Warblers (Vermivora chrysoptera) 


\section{INTRODUCTION}

Golden-winged Warblers (Vermivora chrysoptera, Figure 1, henceforth referred to as Golden-wings) are small, Neotropical migrant birds that have experienced significant declines across most of their range for over 40 years based on the North American Breeding Bird Survey (BBS; annual average decline: $-2.8 \%$ year $^{-1}, \mathrm{P}<0.01, \mathrm{n}=276$ routes, Sauer et al. 2008). In West Virginia, Golden-wing populations have experienced even greater declines over the same time period $\left(-10.3 \%\right.$ year $^{-1}, \mathrm{P}<0.001, \mathrm{n}=31$ routes, Sauer et al. 2008); recent declines are even larger (1996-2007, -28.7 year $\left.{ }^{-1}, \mathrm{P}<0.001, \mathrm{n}=6\right)$. Estimating modern population trends using BBS data in West Virginia is problematic though, because Golden-wings occur on so few routes. Another long-term dataset from Massachusetts noted significant declines before the implementation of the BBS (1937-89, -1.4\% year ${ }^{-1}, \mathrm{P}<0.01$, Hill and Hagan 1991).

Population assessments in the United States (e.g., Buehler et al. 2007) and Canada (e.g., COSEWIC 2006) generally have described the status of the Golden-wing as imperiled. It is listed as "threatened" by the Committee on the Status of Endangered Wildlife in Canada, a "species of management concern" in the United States (USFWS 2002), a member of the Partners-in-Flight Continental Watch List (Rich et al. 2004), "global conservation concern (Red)" on the Audubon Society's Watch List (National Audubon Society 2007), and a global ranking of G4 (apparently secure - uncommon but not rare) by NatureServe. Several states have listed populations as "endangered", "threatened", and "of management concern" in response to declining populations and dramatic range contraction (Buehler et al. 2007). The US Fish and Wildlife Service (USFWS) recently received a petition to list Golden-wings as a threatened or endangered species under the federal Endangered Species Act (Sewell 2010). An ongoing conservation initiative, of which this project is part, is aimed at strategically increasing global populations of Golden-wings and, in turn, other early successional associates.

A reasonable amount of data exist concerning recent population trends of Golden-wings (Hill and Hagan 1991, Sauer et al. 2008); however, little is known about populations prior to European colonization of eastern North America. Morse (1989) commented on a population explosion of some disturbance dependent avian species, including Golden-wings, as a result of abundant early successional habitats during the late 1800s and early 1900s (Lorimer 2001). Chestnut-sided Warblers (Dendroica pensylvanica), commonly found in the same habitats as Golden-wings, supposedly were so rare that John James Audubon encountered the species only 
once during expeditions in the early 1800s (Bent 1953). Abundance trends of some early successional species over the past 300 years may be explained by a successional wave passing through the forests of eastern North America (figure 6 in Litvaitis 1993). Therefore, present day populations of Golden-wings and some early successional vertebrate species may be returning to pre-settlement conditions as forest maturation occurs (Litvaitis 1993). Regardless of viewpoints on natural population sizes for early-sere dependent species, recent declines should cause legitimate concern because habitat conversion, fragmentation, alteration, and urbanization are widespread.

Golden-wings breed across eastern North America as far south as Georgia and northeast to New York and Ontario, then stretching west over the Great Lakes region to Minnesota (Figure 2). Considerable numbers of Golden-wings are now being found in Manitoba (C. Artuso, pers. comm.). Densities seem to be highest in parts of Minnesota, Michigan, Wisconsin, Pennsylvania, New York, West Virginia, and southern Ontario (Confer 1992) with scattered populations elsewhere (e.g., Virginia, Wilson et al. 2007). The breeding range has changed notably in the past 130 years; contraction is the general trend with expansion in the north and northwest limits (Confer 1992). Populations are, or may be in danger of, becoming disjunct, notably the Appalachian and Great Lakes populations (Buehler et al. 2006).

Breeding habitat is described as early successional, and typically is characterized by patches of forbs, shrubs, brush, few trees, and a forested edge (Frech and Confer 1987, Klaus and Buehler 2001, Martin et al. 2007) in a patchy and structurally complex distribution (Rossell et al. 2003). Although this species is sometimes considered a habitat specialist (Confer and Knapp 1981), especially when compared to its sister species the Blue-winged Warbler (V.pinus, henceforth referred to as Blue-wing), Golden-wings are known to use a variety of early successional habitats across their range, including meadows, power line rights-of-way (ROWs, Kubel and Yahner 2007, 2008), wetlands (Confer and Tupper 2000), aspen (Populus spp.) clearcuts, and swamps (Martin et al. 2007).

Little information is known or has been compiled concerning the migration of Goldenwings (see Confer 1992). Males begin to arrive in the central Appalachians in late April and early May (Hall 1983) followed by females several days later (Will 1986). Departure for the wintering grounds peaks in late August to early September in the eastern United States (Confer 1992). Winter range covers southern Central America and northern South America (Confer 
1992); however, disagreement of results in some sources (Keast 1980, Rappole et al. 1983, Ridgley and Tudor 1989) suggests boundaries are not well known.

\section{THREATS}

Golden-wings face numerous threats to their population, the most commonly cited factors being loss and degradation of breeding and/or winter habitat, Brown-headed Cowbird (Molothrus ater) parasitism, and hybridization, genetic introgression, and competition with Blue-wings (Confer 1992). Habitat loss perhaps is one of the most formidable threats facing Golden-wing populations, and may be intricately tied to other threats such as hybridization with Blue-wings and Brown-headed Cowbird parasitism. Maintaining sufficient tracts of early successional habitat presents a unique challenge to land managers, as there have been drastic changes in disturbance regimes of forests in the northeastern United States (Lorimer 2001). Abandonment and reversion of farmlands, fire suppression, and a general reestablishment of second-growth forests throughout much of the northeast has altered the abundance, character, and distribution of these ephemeral habitats (Askins 2001, Trani et al. 2001). At one point late in the nineteenth century, due largely to anthropogenic influences, "young forest" habitat made up 55-60\% of the forest cover in eastern North America (Lorimer 2001). Since then, these early successional habitats have declined to $20 \%$ or less of the forest cover in many regions (Lorimer 2001) and many habitats classified as "young forest" are probably not all suitable for Golden-wings. As a result, a number of disturbance-dependent avian species have seen dramatic declines (Hunter et al. 2001). Despite the needs of species that depend almost entirely on early successional habitats (74 out of 126 species of Neotropical migrant songbirds in the northeast, Smith et al. 1993), Trani et al. (2001) also state that "young forests" cover only 16\% of the northeastern region of the United States.

Although Golden-wings use a variety of anthropogenic habitats, these areas might not be suitable for successful breeding. Kubel and Yahner (2008) found that nesting success and productivity were lower on relatively narrow utility ROWs (15\% of nests successful and 0.57 young fledged per nest) compared to patch clearcuts (58\% and 2.38). Other researchers have cautioned against the use of utility ROWs for sustaining populations, because almost complete nesting failure occurs in some years (J. Confer, pers. comm.). Further complicating issues of habitat suitability, Golden-wings exhibit area-sensitivity and usually avoid patches less than 2 ha while increasing in occupancy and density in patches greater than 12 ha (Hunter et al. 2001). 
Bigger is not always better, though, since expansive shrub-scrub habitats ( $>40$ ha) may lack a forested edge toward the interior of the patch. In such a case, leaving 10-20\% residual canopy cover after a clearcut, for example, can remediate the upper end of area sensitivity (Huffman 1997). This silvicultural technique, coined "legacy tree retention," is being investigated in Michigan with promising results (A. Roth, unpubl. data).

Some debate has arisen concerning the status of Golden-wings on their wintering grounds. Rappole and McDonald (1994, 1998) argue that Golden-wings have seen such drastic declines because of "differential winter survival." In effect, they argue that Golden-wing populations have been reduced because they use winter habitat that has been altered considerably, whereas Blue-wing populations are not declining as precipitously because their winter habitat is not threatened. As a result, the less abundant Golden-wings are forced to pair with the more abundant Blue-wings. This hypothesis has been challenged (Latta and Baltz 1997, Confer and Larkin 1998). Confer and Larkin (1998) argue that timelines of winter habitat loss and range expansion/decline of the Golden-wing do not coincide; therefore, the differential winter survival hypothesis has been deemed not valid. Furthermore, some studies have shown relatively high return rates among adults (76\% of males in Murray and Gill 1976, 30\% of males in Confer and Knapp 1979, 54\% of males and 10\% of females combined in Will 1986, 48\% in Confer 1992, and 50-76\% of males and 33-35\% of females in Vallender et al. 2007b), but less so among yearlings (0\% in Will 1986, 0\% in Canterbury et al. 1996), suggesting Golden-wings may not be experiencing low survival on the wintering grounds. In a meta-analysis of site-fidelity of shrubland and forest birds, Schlossberg (2009) found return rates of $40 \%$ and less than $1 \%$ for adult and yearling Golden-wings, respectively. Nevertheless, winter habitat loss should not be discarded as a reason for decline, although its role may not be as drastic as Rappole and McDonald (1994, 1998) describe.

Hybridization between Golden-wings and Blue-wings occurs almost range-wide and the hybrid zone is shifting northward (Vallender et al. 2007a, 2009). It is thought that populations of Golden-wings and Blue-wings historically were allopatric until the early 1900s when widespread abandonment of agricultural fields across eastern North America created an abundance of early successional breeding habitat used by both species (Gill 1980). Mating of Golden-wings and Blue-wings produces two fertile, stereotyped hybrid phenotypes, the Brewster's (F1 generation) and Lawrence's (F2 generation) Warblers (Parkes 1951), although hybrids often exhibit 
considerable variation in plumage characteristics (Short 1963, 1969). Locating allopatric, genetically pure populations of either species is difficult and they may only exist at the extreme peripheries of ranges or in areas where segregation due to elevation occurs (Gill 1987, Welton 2003, Buehler et al. 2007, Vallender et al. 2007a, 2009). Golden-wings generally occur on sites higher than $600 \mathrm{~m}$ and Blue-wings below this elevation. Vallender et al. (2007a, 2009) suggest that the only remaining genetically pure populations of Golden-wings may be located in Manitoba and the only genetically pure populations of Blue-wings exist in Kentucky. Gill (1980) suggested a pattern of replacement of Golden-wings by Blue-wings 50 years after initial contact; however, this pattern is not applicable across the entire zone of contact. A unique situation exists at Sterling Forest in southern New York, where Golden-wings and Blue-wings have existed in sympatry for over 100 years (Confer et al. 1998, Confer and Tupper 2000). Genetically, Golden-wings and Blue-wings are similar, and recent research has investigated genetic introgression in the hybrid complex (e.g., Gill 1997, Shapiro et al. 2004, Dabrowski et al. 2005, Vallender et al. 2007a, 2007b, 2009). Gill (1997) suggests that genetic introgression is rapid and asymmetric, thus Golden-wings are being "swamped" by Blue-wings. However, Shapiro et al. (2004) and Vallender et al. (2007a, 2009) found that introgression is more symmetrical. Although we do not fully understand how hybridization directly affects Goldenwing demographics, there seems to be a general consensus that introgression is bidirectional (Vallender et al. 2009), which raises concern for populations of Golden-wings and Blue-wings. Still, interactions between the two species generally end in local extirpation for the Goldenwings (Gill 1980, Confer and Knapp 1981, Confer 1992).

Another potential mechanism in the decline of Golden-wings is competition with Bluewings. Again there is some debate as to which species exhibits competitive dominance. Confer and Larkin (1998) found that interactions between Golden-wings and Blue-wings were rare, with most adjacent males ignoring each other. When interactions did occur, Golden-wings dominated the majority of them, but did not expand into vacated Blue-wing territories. Will (1986) also found that rates of dominance interactions between the two species were extremely low, but the frequencies of intraspecific and interspecific interactions were essentially identical, suggesting that Golden-wings and Blue-wings treat each other as conspecifics. Clutch size in Golden-wings has been shown to decline in the presence of Blue-wings, suggesting a competitive interaction between the two species (Confer et al. 2003). Mean clutch size is about 5 (e.g., Will 1986, 
Confer 1992). Culling of Blue-wings in areas of sympatry with Golden-wings is not justifiable since Blue-wing populations also have significant declines (Confer 1992, annual average decline in WV: $-3.1 \%$ year $^{-1}, \mathrm{P}=0.04, \mathrm{n}=40$ routes, Sauer et al. 2008 ).

Brown-headed Cowbird parasitism is common among nesting Golden-wings. A study in north central New York found that cowbirds parasitized $30 \%$ of nests, reducing the number of Golden-wings fledged by $17 \%$ (Confer et al. 2003). This is a considerable decrease in reproductive output if representative of the entire range. The authors also found that Goldenwings nesting in early stages of succession (the preferred nesting habitat across much of the range, Confer 1992) correlated with greater cowbird parasitism. Essentially, Golden-wings nesting in "preferred" habitat may be more vulnerable to cowbird parasitism. One of the Golden-wings' favored haunts, shrub-scrublands created by past and/or present agricultural activity, may be somewhat of an ecological trap since cowbirds tend to be more abundant in agricultural settings (Thompson et al. 2000).

\section{GOLDEN-WINGED WARBLER MONITORING}

Golden-wings have been the subject of widespread monitoring and population status assessments (e.g. COSEWIC 2006, Wilson et al. 2007, Buehler et al. 2007). The GoldenWinged Warbler Atlas Project (GOWAP) is a range-wide initiative to "determine the population status and habitat and area requirements of the Golden-winged Warbler and the Blue-winged Warbler as well as their hybrids" (CLO 2008). It was first conducted in 1999 and continues to evolve as new members join and new protocols are adopted. Main objectives of GOWAP are to develop a distribution map of Golden-wing populations so that future management can target high-density areas and to create a hybrid index map to examine spatial aspects of the Goldenwing x Blue-wing hybrid complex. Most recently, several universities (e.g, University of Tennessee, West Virginia University, Indiana University of Pennsylvania) and wildlife agencies (e.g., Wisconsin/West Virginia DNR, USFS, USFWS) have collaborated to examine the effects

of different habitat management strategies on populations of Golden-wings. Golden-wings have received so much attention because valuable long-term monitoring has shown dramatic declines; however, some monitoring techniques are not without their shortcomings.

The North American Breeding Bird Survey, which uses a series of 50 three minute point counts along roadside survey routes, is the most extensive (across time and space) index of population trends for North American breeding landbird species. As discussed, BBS data 
suggest that Golden-wings have experienced significant declines survey-wide (Sauer et al. 2008). However, the BBS has come under scrutiny from researchers concerned with how representative routes are of the regional landscape (Bart et al. 1995, Keller and Scallan 1999), biases resulting from differences between observers (Sauer et al. 1994), limitations of roadside surveys (Bibby et al. 2000), and detection rates (Hutto et al. 1995). In a study of the effectiveness of three minute (BBS style) point counts with and without the use of playback, Kubel and Yahner (2007) found that detection probabilities of Golden-wings without playback were $23 \%$ in a clearcut area and $61 \%$ on powerline rights-of-way (ROWs). Use of playback resulted in $7 \%$ and $19 \%$ net increases in detection rates at the clearcut area and ROWs, respectively. Detection rate or probability was the proportion of the true population of Goldenwings detected during a survey. These results suggest that using BBS results to estimate population size may be underestimating populations of Golden-wings due to their cryptic nature. Similarly, in a literature review and field investigation, Johnson et al. (1981) found 51 species, including six Parulidae warblers, which were responsive to playback recordings as a census technique.

Despite drawbacks to the BBS, the data are extremely valuable for monitoring trends and for some species it may be possible to accurately estimate population size. The North American Landbird Conservation Plan (Rich et al. 2004) is a "continental synthesis of priorities and objectives that will guide landbird conservation actions at national and international scales." Population estimates, which are derived from BBS data, are based on methods described in Rosenberg and Blancher (2005). Thogmartin et al. (2006) provide a thorough review and critique of the population estimation methods, while encouraging field tests. Three assumptions are made: BBS routes are (1) randomly distributed, (2) representative of the landscape, and (3) $100 \%$ of males are detected within a maximum detection distance. Correction factors accounting for females, time of day, and maximum detection distance are applied to population estimates. Already these methods have come under fire on the basis of a trial wherein Golden-wings were one of the focal species (Confer et al. 2008). Within 200 meters of survey points (the distance within which $100 \%$ of Golden-wings should be detected, Rosenberg and Blancher 2005), only $3 \%$ of Golden-wings and 7\% of Vermivora spp. (Golden-wings, Blue-wings, and their hybrids pooled) were detected using BBS style point counts. Thus, no studies were able to, on average, detect even close to $100 \%$ of the true population of male Golden-wings within 200 meters during 
a BBS style point count (Kubel and Yahner 2007, Confer et al. 2008). These findings suggest that current population estimates are much lower than reality. Vallender et al. (2009) provide anecdotal evidence to substantiate this claim. Partners in Flight estimated that less than $1 \%$ of the global breeding population of Golden-wings can be found within the provincial borders of Manitoba each year, based on BBS data (Rich et al. 2004, Rosenberg and Blancher 2005), but more intensive surveys indicate that this may be an underestimate $(\mathrm{C}$. Artuso pers. comm. in Vallender et al. 2009). In a broader sense, error in prioritization of landbirds based on these estimated population sizes could mean more conservation effort for some (underestimated cryptic species) and less for others (overestimated conspicuous species).

A number of studies have either examined the effectiveness of playback (e.g., Ficken and Ficken 1973, Highsmith 1989, Kubel and Yahner 2007) or used playback to determine the presence of Golden-wings (e.g., Klaus and Buehler 2001, Roth and Lutz 2004). Ficken and Ficken (1973) found after altering length and structure of type 1 songs that Golden-wings are most responsive to a form consisting of an introductory zee not followed by three lower frequency bee notes. However, to our knowledge there are no published data on the effectiveness of using type 2 songs for playback or manipulating the duration of playback. Type 1 song is defined as an introductory zee note followed by a variable number of lower frequency bee notes, most commonly three (Highsmith 1989). Alternatively, type 2 songs, which are similar for Golden-wings and Blue-wings, typically contain three to five syllable types and end with a buzzy note, although there can be considerable variation (Highsmith 1989). This secondary song is typically associated with pre-dawn singing bouts or territorial interactions (Highsmith 1989). The supposed territorial nature of type 2 songs may elicit stronger responses from males. It is important to determine which type of playback (type 1 vs. type 2) and at what duration is most effective for detecting Golden-wings, as studies use playback to increase detection rates of this cryptic species (Kubel and Yahner 2007) and population monitoring efforts include point counts with playback (GOWAP, CLO 2008).

Counts occurring early in the morning and at the peak of the breeding season have long been accepted as most effective for monitoring populations of breeding birds (Ralph et al. 1995, Bibby et al. 2000). Given the variation in peak breeding times for different species and often overloaded schedules of state and federal biologists, it is valuable to recognize optimal times for surveying. This is especially true for species of conservation concern (e.g., Golden-winged 
Warblers) where surveys may be supplemental (e.g., Golden-winged Warbler Atlas Project) rather than essential (e.g., Breeding Bird Survey) for the agency involved. Conducting surveys at different (unconventional) times of day or season could be considered as alternatives if benefits outweigh costs and detection rate tradeoffs are understood. For Golden-wings, peak survey times are relatively well understood (e.g., Kubel and Yahner 2007), but the consequences of delaying surveys or using different types and durations of song playback should receive more attention. Ultimately, a firmer grasp of the detectability of this species could guide supplemental survey times and be applied as a correction factor when estimating populations.

\section{GOLDEN-WINGED WARBLER BREEDING ECOLOGY}

Golden-wings nest on or near the ground usually associated with a micro-edge where dense vegetation transitions into a more open area (Confer 1992). Nest sites might occur along forest-field edges, small forest openings, trails, or paths (Confer 1992). Clusters of goldenrod (Solidago sp.) and blackberry/raspberry (Rubus sp.) often support the nest, although grasses and woody substrates are sometimes used. Regardless of the nest substrate(s), most nests feature a taller, sturdier stem among the supporting vegetation which is grasped by adults when accessing the nest (Confer 1992).

Mean clutch size is about 5 eggs (see Confer 1992, Table 1). Double-brooding has not been documented among Golden-wings, but second clutches occur frequently when the first nest is destroyed (Confer 1992). Second clutches may be smaller in size and more vulnerable to cowbird parasitism (Confer 1992). Fledging rate, nest success, and cowbird parasitism vary over time, space, and habitat (Table 1). Demmons (2000) reported 43\% of nests were successful in an agriculture-forest matrix in southern Ontario. Interestingly, $47 \%$ of nests placed directly on an edge and only $17 \%$ of nests placed elsewhere were successful (Demmons 2000). Kubel and Yahner (2008) compared patch clearcuts to utility ROWs in central Pennsylvania and found significantly higher nest success and productivity in clearcuts $(58 \%$ nests successful and 2.38 fledglings/nest) compared to ROWs (15\% and 0.57). Nest success on utility ROWs may vary considerably from year to year in synchrony with mast production and small mammal populations, sometimes resulting in complete nesting failure (Confer, unpubl. data). Parasitism from cowbirds ranges from nonexistent (Canterbury et al. 1996, Klaus and Buehler 2001) to intermediate (Kubel 2005) to high levels (Will 1986, Confer 1992, Confer et al. 2003) across time, space, and habitat. Parasitism decreases the mean number of Golden-wings fledged per 
nest as well as the percent of nests successfully fledging young (Confer 1992, Confer et al. 2003). Confer et al. (2003) suggested that cowbird parasitism could reduce production of fledglings by $17 \%$ in north-central New York.

Several studies have attempted to identify common characteristics of Golden-wing nests, particularly successful nests (e.g., Demmons 2000, Klaus and Buehler 2001, Bulluck and Buehler 2008). Confer et al. (2003) provided one of the most in depth investigations of factors that affect reproduction of Golden-wings. Herb and shrub cover were positively correlated with Golden-wing clutch size, but also with more cowbird eggs (Confer et al. 2003). Bulluck and Buehler (2008) found that herbaceous vegetation cover was greater at nest sites and woody vegetation cover was greater at random sites and nests with a woody stem in the substrate had lower nest-survival rates. Klaus and Buehler (2001) also found nest sites had more herbaceous vegetation than surrounding unoccupied habitat. Within a Golden-wing territory, there tended to be more saplings and canopy cover than directly at the nest site (Klaus and Buehler 2001). In a study of nests and random points placed directly on edges, Demmons (2000) discovered that edge shape was more gradual and stem density higher at nest sites. Successful nests generally were more visible and surrounded by more goldenrod stems compared to depredated nests (Demmons 2000). These studies are not in total agreement, but there are some common features (e.g., high herbaceous cover surrounding nests, specifically goldenrod). A standardized protocol for measuring reproductive and nest site parameters may be needed to better understand the nesting ecology of Golden-wings.

Currently, researchers from academia, state and federal wildlife agencies, nongovernmental organizations, and industry as part of the Golden-winged Warbler Conservation Initiative are measuring attributes of nest sites with the goal of discovering range-wide characteristics that maximize reproductive success of Golden-wings. Because Golden-wings occupy a variety of different early successional habitat types, this task may prove to be difficult. Results should be applicable to best management practices within habitat types (e.g., abandoned farmland, clearcuts), states (e.g., Michigan, West Virginia), or even regions (e.g., central Appalachians, Great Lakes), if not range-wide.

A complex matrix of herbaceous and woody vegetation cover has repeatedly emerged as a defining characteristic of Golden-wing breeding habitat, linked with nest survival (Bulluck and Buehler 2008), clutch size, Brown-headed Cowbird (Molothrus ater) parasitism rates, and 
number of fledglings produced (Confer et al. 2003). Nests, territories, and the surrounding habitat may vary in regards to their respective habitat characteristics (Klaus and Buehler 2001). The studies of Golden-wing breeding habitat differ in some regards, probably because Goldenwings use a variety of early successional habitat types, but there are some common features, including high herbaceous cover (specifically goldenrod, Demmons 2000), few large canopy trees, many shrubs (Klaus and Buehler 2001, Confer et al. 2003), and structurally complex, patchy vegetation (Confer 1992, Rossell et al. 2003). Suitable habitat must be spatially complex to facilitate all of the requirements of breeding, including tall song perches (Rossell 2001), transitional edges for nesting (Confer 1992, Demmons 2000), forest edges (Ficken and Ficken 1968, Frech and Confer 1987), and shrubs and trees for foraging (Ficken and Ficken 1968, Confer 1992).

I am aware of no published studies of Golden-wing nest success, cowbird parasitism rates, or habitat characteristics, from actively grazed pasturelands. The habitats studied here may be important for several reasons. First, federal ownership ensures that grazing areas will be maintained under the current land use and at a sustainable grazing intensity for a long period of time. Consistency of land use and low grazing intensity provides a somewhat stable, long-term refuge for Golden-wings and other early successional associates (“arrested succession”, Niering and Goodwin 1974). Furthermore, a relatively low stocking density (the number of livestock) allows for a structurally complex habitat able to host a wider variety of avian species. Livestock are not able to graze the pasture to homogeneous grassland, so it develops into a matrix of grasses, forbs, shrubs, saplings, and few trees transitioning to a forested perimeter. This is especially valuable in West Virginia, a state that is predominantly forested. Studies have investigated the response of avian communities to grazing, and results typically vary by species, grazing intensity, and landscape context (Popotnik and Giuliano 2000, Baldi et al. 2005, Martin and McIntyre 2007). There seems to be some agreement that low intensity grazing can be used under certain conditions (e.g., avoid riparian zones, Popotnik and Giuliano 2000) to manage complex early successional habitats beneficial to some species (Martin and McIntyre 2007).

This thesis is organized into three chapters. The first chapter introduces the ecology and conservation of Golden-wings and reviews literature relevant to population monitoring and breeding habitat of this species. Chapter 2 is a comparison of the effectiveness of two monitoring protocols varying type and duration of Golden-wing song playback at different times 
of day and season. Chapter 3 is an investigation of breeding habitat characteristics of Goldenwings at high-elevation grazing areas on Monongahela National Forest, West Virginia, where all data collection took place.

\section{STUDY AREAS}

Four study areas monitored in 2008 and 2009 included grazed pasturelands near Elkins, Randolph County, West Virginia ranging in elevation from about 800 to 1,100 meters (Figure 3). All areas have consistently harbored territorial male Golden-wings (R. Tallman pers. comm.), mostly roadside observations of single singing males or pairs. Grazing allotments on the Monongahela National Forest generally were active pastures when the land was acquired by the U.S. Forest Service and remain as such today, primarily managed for grazing, wildlife habitat, visual diversity, and dispersed recreation. The Forest Service leases grazing allotments to the public for low intensity grazing of livestock (1.2-2.4 ha usable forage/animal unit [AU], C. Johnson pers. comm.) from 15 May to 1 October, thus they are maintained at the current stage of succession by grazing and intermittent mowing. Officials with the Forest Service may choose to allow or deny grazing permits based on the impact of grazing during the previous year(s). Allotments are comprised of pasture grasses and herbaceous vegetation with shrub-scrub habitat (predominantly hawthorn [Crataegus sp.] and autumn olive [Elaeagnus umbellata]) primarily towards the fenced edges transitioning into surrounding forests. Coberly Sods North (40.6 ha) is divided into ungrazed (23.1 ha, Figure 4) and grazed (17.5 ha, 18 AUs in 2009, Figure 5) sections; the ungrazed section was fenced in 1991. Coberly Sods South (30.2 ha, 21 AUs in 2009, Figure 6) is separated from Coberly Sods North by a gravel Forest Service road. Forinash (21.8 ha, 7 AUs in 2009, Figure 7) was ungrazed from 1993 to 2006, but mowing and grazing continued in 2007. After the ungrazed period, about 5 ha of the allotment were fenced and reverted to forest. One study site, "Washout" (5.9 ha, Figure 8) is a privately-owned abandoned pasture. Habitat on Washout is similar to the federally owned allotments, although it has not been grazed for about 40 years (W. Tolin pers. comm.), so the vegetation is denser and taller in some areas. During autumn 2008, 10.8 ha on Coberly Sods North (Figure 9-10), 2.1 ha on Coberly Sods South, and 3.1 ha on Forinash (Figure 11, 16 ha total) were treated with brush hogging and selective tree harvest to restore or improve habitat conditions for Golden-wings.

In 2009, the Hoover (179 ha, Figure 12), Gay/Sharp (56 ha), and McAllister (107 ha, Figure 13) allotments on Monongahela National Forest were added to the list of intensively 
monitored sites. Hoover and Gay/Sharp shared 70 AUs in 2009 and are only separated by a cattle fence with McAllister located $2 \mathrm{~km}$ to the northwest. Adjacent to the Hoover allotment are two 10 year old 4.05 ha clearcuts (Figure 14) that also were monitored in 2009. The allotments, located in Pocahontas County, WV, are larger and higher in elevation (960-1,200 m) than grazing allotments near Elkins. As part of an early successional habitat initiative, the Forest Service implemented additional mowing and brush-hogging on the Hoover, Gay/Sharp, McAllister, and other nearby allotments in 2009. Management actions avoided areas occupied by Golden-wings and attempted to create suitable habitat elsewhere.

If the study sites (Figure 3 ) are representative of the 51 grazing allotments $(\sim 2,719$ ha) managed by the Forest Service on the Monongahela National Forest, there may be about 1,023 ha of suitable or near-suitable Golden-wing habitat on grazing allotments. The estimate is based on the amount of suitable or near-suitable habitat on 12 allotments (six with Golden-wings present and six with Golden-wings absent) delineated using GIS software and intimate knowledge of the allotments. Grazing allotments on the Monongahela National Forest may be of great importance to the conservation of Golden-wings and some other early-successional associates, as they provide a somewhat stable source of habitat for the birds, isolation from Bluewings, grazing opportunities for local farmers, and an opportunity for the Forest Service to accomplish multiple-use objectives on their lands. Further, brush or shrub lands only comprise about 3,642 ha (1.0\%) of the Monongahela National Forest (371,906 ha) and open areas with grasses, forbs, or other herbaceous ground cover comprise about 8,094 ha (2.2\%, USFS 2006). Conversely, 356,933 ha (96.0\%) of the land is forested, of which, few stands are less than 15 years of age (2\%), while the majority are over 60 years old (84\%, USFS 2006), illustrating the importance of grazing allotments to early successional species on federal lands and statewide.

\section{LiterATURE CITED}

Askins, R.A. 2001. Sustaining biological diversity in early successional communities: The challenge of managing unpopular habitats. Wildlife Society Bulletin 29:407-412.

Baldi, A., P. Batary, and S. Erdos. 2005. Effects of grazing intensity on bird assemblages and populations of Hungarian grasslands. Agriculture, Ecosystems and Environment 108:251263.

Bart, J., M. Hofschen, and B.G. Peterjohn. 1995. Reliability of the Breeding Bird Survey: effects of restricting surveys to roads. Auk 112: 758-761. 
Bent, A.C. 1953. Life histories of North American wood warblers. Bulletin of the United States National Museum 203:1-734.

Bibby, C.J., N.D. Burgess, D.A. Hill, and S.H. Mustoe. 2000. Bird census techniques. $2^{\text {nd }}$ ed. Academic Press, London, UK.

Buehler, D. A., J.L. Confer, R.A. Canterbury, T.C. Will, W.C. Hunter, R. Dettmers, and D. Demarest. 2006. Status assessment and conservation plan for the Golden-winged Warbler, Vermivora chrysoptera, in the United States. U. S. Department of the Interior, Fish and Wildlife Service Biological Technical Publication FWS/BTP-R6XXX-2006, Washington, D.C.

Buehler, D.A., A.M. Roth, R. Vallender, T.C. Will, J.L. Confer, R.A. Canterbury, S.B. Swarthout, K.V. Rosenberg, and L.P. Bulluck. 2007. Status and conservation priorities of Golden-winged Warbler (Vermivora chrysoptera) in North America. Auk 124:14391445.

Bulluck, L.P., and D.A. Buehler. 2008. Factors influencing Golden-winged Warbler (Vermivora chrysoptera) nest-site selection and nest survival in the Cumberland Mountains of Tennessee. Auk 125:551-559.

Canterbury, R.A., D.M. Stover, and J.J. Kotesovec Jr. 1996. Population ecology of Goldenwinged Warblers in southern West Virginia. West Virginia Division of Natural Resources, Elkins.

Confer, J.L. 1992. Golden-winged Warbler (Vermivora chrysoptera). In: The Birds of North America, no. 20 (Poole, A., P. Steenheim, and F. Gill, Eds.). Academy of Natural Sciences, Philadelphia, PA and American Ornithologists' Union, Washington, D.C.

Confer, J.L. 2006. Secondary contact and introgression of golden-winged warblers (Vermivora chrysoptera): documenting the mechanism. Auk 123:958-961.

Confer, J.L., J. Gebhards, and J. Yrizarry. 1998. Golden-winged and Blue-winged Warblers at Sterling Forest: a unique circumstance. Kingbird 39:50-55.

Confer, J.L., and K. Knapp. 1981. Golden-winged Warblers and Blue-winged Warblers: the relative success of a habitat specialist and a generalist. Auk 98:108-114.

Confer, J.L., and J.L. Larkin. 1998. Behavioral interactions between Golden-winged and Bluewinged Warblers. Auk 115:209-213.

Confer, J.L., J.L. Larkin, and P.E. Allen. 2003. Effects of vegetation, interspecific competition, and brood parasitism on Golden-winged Warbler (Vermivora chrysoptera) nesting success. Auk 120:138-144.

Confer, J.L., R.E. Serrell, M. Hager, and E. Lahr. 2008. Field tests of the Rosenberg-Blancher method for converting point counts to abundance estimates. Auk 125:932-938.

Confer, J.L., and S.K. Tupper. 2000. A reassessment of the status of Golden-winged and Bluewinged Warblers in the Hudson Highlands of southern New York. Wilson Bulletin 112:544-546. 
CLO. 2008. Golden-winged Warbler Atlas Project. Cornell Laboratory of Ornithology. Available at: http://www.birds.cornell.edu/gowap/.

COSEWIC. 2006. COSEWIC assessment and status report on the Golden-winged Warbler Vermivora chrysoptera in Canada. Committee on the Status of Endangered Wildlife in Canada. Ottawa, Ontario. vii +30 pp. Available at: www.sararegistry.gc.ca/status/status_e.cfm.

Dabrowski A.K., R. Fraser, J.L. Confer, I.J. Lovette. 2005. Geographic variability in mitochondrial introgression among hybridizing populations of Golden-winged (Vermivora chrysoptera) and Blue-winged (V. pinus) Warblers. Conservation Genetics 6:843-853.

Demmons, T.D. 2000. Nest site selection and nest predation patterns at forest-field edges. M.S. thesis, Kingston, Ontario, Canada, Queen's University.

Ficken, M.S., and R.W. Ficken. 1968. Ecology of Blue-winged Warblers, Golden-winged Warblers, and some other Vermivora. American Midland Naturalist 79:311-319.

Ficken, M.S., and R.W. Ficken. 1973. Effect of number, kind and order of song elements on playback responses of the Golden-winged Warbler. Behaviour 46:114-127.

Frech, M.H., and J.L. Confer. 1987. The Golden-winged Warbler: competition with the Bluewinged Warbler and habitat selection in portions of southern, central, and northern New York. Kingbird 37:65-72.

Gill, F.B. 1980. Historical aspects of hybridization between Blue-winged and Golden-winged Warblers. Auk 97:1-18.

Gill, F.B. 1987. Allozymes and genetic similarity of Blue-winged and Golden-winged Warblers. Auk 104: 444-449.

Gill, F.B. 1997. Local cytonuclear extinction of the Golden-winged Warbler. Evolution 51:519525.

Hall, G.A. 1983. West Virginia Birds. Special Publication, No. 7, Carnegie Museum of Natural History, Pittsburgh, Pennsylvania.

Highsmith, R.T. 1989. The singing behavior of Golden-winged Warblers. Wilson Bulletin 101: $36-50$.

Hill, N.P., and J.M Hagan III. 1991. Population trends of some northeastern North American landbirds: a half-century of data. Wilson Bulletin 103:165-182.

Huffman, R. 1997. Bird communities along a successional gradient in aspen clearcuts in Tamarac National Wildlife Refuge, Minnesota, with an emphasis on the Golden-winged Warbler and other non-game migrant birds. M.S. thesis, West Virginia University, Morgantown, WV. 
Hunter, W.C., D.A. Buehler, R.A. Canterbury, J.L. Confer, and P.B. Hamel. 2001. Conservation of disturbance dependent birds in eastern North America. Wildlife Society Bulletin 29: 440-455.

Hutto, R.L., S.J. Hejl, J.F. Kelly, and S.M. Pletschet. 1995. A comparison of bird detection rates derived from on-road versus off-road point counts in northern Montana. In: Monitoring Bird Populations by Point Counts (Ralph, C.J., J.R. Sauer, and S. Droege, Eds.), pp. 103110. USDA Forest Service General Technical Report PSW-GTR-149. Albany, CA.

Johnson, R.R., B.T. Brown, L.T. Haight, and J.M. Simpson. 1981. Playback recordings as a special avian censusing technique. In: Estimating numbers of terrestrial birds (Ralph, C.J. and J. M. Scott, Eds.), pp. 68-75. Studies in Avian Biology No. 6.

Keast, A. 1980. Spatial relationships between migratory parulid warblers and their ecological counterparts in the Neotropics. In: Migrant birds in the Neotropics/ecology, behavior, distribution and conservation (Keast, A. and E.S. Morton, Eds.), pp. 109-130. Smithson Inst. Press, Washington, D.C.

Keller, C.M.E., and J.T. Scallan. 1999. Potential roadside biases due to habitat changes along Breeding Bird Survey routes. Condor 101:50-57.

Klaus, N.A., and D.A. Buehler. 2001. Golden-winged Warbler breeding habitat characteristics and nest success in clearcuts in the southern Appalachian Mountains. Wilson Bulletin 113:297-301.

Kubel, J.E. 2005. Breeding ecology of Golden-winged Warblers in managed habitats of central Pennsylvania. M.S. thesis, Pennsylvania State University, University Park, PA.

Kubel, J.E., and R.H. Yahner. 2007. Detection probability of Golden-winged Warblers during point counts with and without playback recordings. Journal of Field Ornithology 78:195205.

Kubel, J.E., and R.H. Yahner. 2008. Quality of anthropogenic habitat for Golden-winged Warblers in Central Pennsylvania. Wilson Journal of Ornithology 120:801-812.

Latta, S.C., and M.E. Baltz. 1997. Population limitation in Neotropical migratory birds: Comments on Rappole and McDonald (1994). Auk 114:754-762.

J.A. Litvaitis. 1993. Response of early succesional vertebrates to historic changes in land use. Conservation Biology 7:866-873.

Lorimer, C.G., 2001. Historical and ecological roles of disturbance in eastern North American forests: 9000 years of change. Wildlife Society Bulletin 29: 425-439.

Martin, K.J., R.S. Lutz, and M. Worland. 2007. Golden-winged Warbler habitat use and abundance in northern Wisconsin. Wilson Journal of Ornithology 119:523-532.

Martin, T.G., and S. McIntyre. 2007. Impacts of livestock grazing and tree clearing on birds of woodland and riparian habitats. Conservation Biology 21:504-514.

Mayfield, H. 1961. Nesting success calculated from exposure. Wilson Bulletin 73:255-261. 
Morse, D.H. 1989. American warblers. Harvard University Press, Cambridge, MA.

National Audubon Society. 2007. Audubon Watch list 2007. An early warning system for bird conservation. [Online.] Available at: www.audubon.org/bird/watchlist/

Niering, W.A., and R.H. Goodwin. 1974. Creation of relatively stable shrublands with herbicides: arresting "succession" on rights-of-way and pastureland. Ecology 55:784-795.

Parkes, K.C. 1951. The genetics of the Golden-winged x Blue-winged Warbler complex. Wilson Bulletin 63:5-15.

Popotnik, G.J., and W.M. Giuliano. 2000. Response of birds to grazing of riparian zones. Journal of Wildlife Management 64:976-982.

Ralph, C.J., J.R. Sauer, and S. Droege, Eds. 1995. Monitoring bird populations by point counts. General Technical Report. PSW-GTR-149. Pacific Southwest Research Station, Forest Service, U.S. Department of Agriculture, Albany, CA.

Rappole, J.H., and M.V. McDonald. 1994. Cause and effect in population declines of migratory birds. Auk 111:652-660.

Rappole, J.H., and M.V. McDonald. 1998. Response to Latta and Baltz (1997). Auk 115:246251.

Rappole, J.H., E.S. Morton, T.E. Lovejoy, and J.L. Ruos. 1983. Nearctic avian migrants in the Neotropics. U.S. Fish and Wildlife Service.

Reed, L.P, R. Vallender, and R.J. Robertson. 2007. Provisioning rates by Golden-winged Warblers. Wilson Journal of Ornithology 119:350-355.

Rich, T.D., C.J. Beardmore, H. Berlanga, P.J. Blancher, M.S. W. Bradstreet, G.S. Butcher, D.W. Demarest, E.H. Dunn, W.C. Hunter, E.E. Iñigo-Elias, J.A. Kennedy, A.M. Martell, A.O. Panjabi, D.N. Pashley, K.V. Rosenberg, C.M. Rustay, J.S. Wendt, and T.C. Will. 2004. Partners in Flight North American Landbird Conservation Plan. Cornell Lab of Ornithology. Ithaca, NY.

Ridgely, R.S., and G. Tudor. 1989. The birds of South America, Vol. 1. University of Texas Press, Austin, TX.

Rosenberg, K.V., and P.J. Blancher. 2005. Setting numerical population objectives for priority landbird species. In: Bird conservation and implementation in the Americas: proceedings of the third international Partners in Flight Conference, vol.1 (C.J. Ralph and T.D. Rich, Eds.), pp. 57-67. U.S. Department of Agriculture, Forest Service, General Technical Report PSW-GTR-191.

Rossell, C.R., S.C. Patch, and S.P. Wilds. 2003. Attributes of Golden-winged Warbler territories in a mountain wetland. Wildlife Society Bulletin 31:1099-1104.

Roth, A.M., and R.S. Lutz. 2004. Relationships between territorial male Golden-winged Warblers in managed aspen stands in northern Wisconsin, USA. Forest Science 50:153161. 
Sauer, J.R., J.E. Hines, and J. Fallon. 2008. The North American Breeding Bird Survey, Results and Analysis 1966 - 2007. Version 5.15.2008. USGS Patuxent Wildlife Research Center, Laurel, MD.

Sauer, J.R., B.G. Peterjohn, and W.A. Link. 1994. Observer differences in the North American Breeding Bird Survey. Auk 111:50-62.

Schlossberg, S. 2009. Site fidelity of shrubland and forest birds. Condor 111:238-246.

Sewell, A. 2010. Petition to list the Golden-winged Warbler (Vermivora chrysoptera) as a threatened or endangered species under the U.S. Endangered Species Act. Available at: http://gwwa.org/resources/Petition\%20to\%20List\%20GWWA_comp.pdf.

Shapiro, L.H., R.A. Canterbury, D.M. Stover, and R.C. Fleischer. 2004. Reciprocal introgression between Golden-winged Warblers (Vermivora chrysoptera) and Blue-winged Warblers (V. pinus) in eastern North America. Auk 121:1019-1030.

Short, L.L., Jr. 1963. Hybridization in the wood warblers Vermivora pinus and V. chrysoptera. In: Proceedings XIII International Ornithological Congress (C.G. Sibley, Ed.), pp. 147160. American Ornithologists' Union, Washington, D.C.

Short, L.L., Jr. 1969. "Isolating mechanisms" in the Blue-winged Warbler X Golden-winged Warbler complex. Evolution 23:355-356.

Thogmartin, W.E., F.P. Howe, F.C. James, D.H. Johnson, E.T. Reed, J.R. Sauer, and F.R. Thompson III. 2006. A review of the population estimation approach of the North American Landbird Conservation Plan. Auk 123:892-904.

Thompson, F.R. III, S.K. Robinson, T.M. Donovan, J. Faaborg, D.R. Whitehead. 2000. Biogeographic, landscape, and local factors affecting cowbird abundance and host parasitism levels. In: Ecology and management of cowbirds (Cooke T., S.K. Robinson, S.I. Rothstein, S.G. Sealy, J.N.M. Smith, Eds.), pp. 271-279. University of Texas Press, Austin, Texas, USA.

Trani, M.K., R.T. Brooks, T.L. Schmidt,V.A. Rudis, and C.M. Gabbard. 2001. Patterns and trends of early-successional forests in the eastern United States. Wildlife Society Bulletin 29: 413-424.

USFS. 2006. Monongahela National Forest land and resource management plan. United States Department of Agriculture Forest Service, Monongahela National Forest, Elkins, WV.

USFWS. 2002. Birds of conservation concern 2002. United States Fish and Wildlife Service. Division of Migratory Bird Management, Arlington, VA.

Vallender, R., R.J. Robertson, V.L. Friesen, and I.J. Lovette. 2007a. Complex hybridization dynamics between Golden-winged and Blue-winged Warblers (Vermivora chrysoptera and Vermivora pinus) revealed by AFLP, microsatellite, intron and mtDNA markers. Molecular Ecology 16:2017-2029.

Vallender, R., V.L. Friesen, and R.J. Robertson. 2007b. Paternity and performance of Goldenwinged Warblers (Vermivora chrysoptera) and Golden-winged x Blue-winged Warbler 
(V.pinus) hybrids at the leading edge of a hybrid zone. Behavioral Ecology and Sociobiology 61:1797-1807.

Vallender, R., S.L. Van Wilgenburg, L.P. Bulluck, A. Roth, R. Canterbury, J. Larkin, R. Fowlds, and I.J. Lovette. 2009. Extensive rangewide mitochondrial introgression indicates substantial cryptic hybridization in the Golden-winged Warbler (Vermivora chrysoptera). Avian Conservation and Ecology 4:4. Available at: http://www.aceeco.org/vol4/iss2/art4/

Welton, M. 2003. Status and distribution of the Golden-winged Warbler in Tennessee. Migrant 74:61-82.

Will, T.C. 1986. The behavioral ecology of species replacements: Blue-winged and Goldenwinged Warblers in Michigan. Ph.D. dissertation, University of Michigan, Ann Arbor, MI.

Wilson, M.D., B.D. Watts, M.G. Smith, J.P. Bredlau, and L.W. Seal. 2007. Status Assessment of Golden-winged Warblers and Bewick's Wrens in Virginia. Center for Conservation Biology Technical Report Series, CCBTR-07-02. College of William and Mary, Williamsburg, VA. 


\section{TABLES AND FIGURES}

Table 1. Summary statistics of Golden-winged Warbler nesting parameters.

\begin{tabular}{|c|c|c|c|c|c|c|c|c|}
\hline State & Habitat & $\mathbf{N}$ & Year & $\begin{array}{c}\text { Nest } \\
\text { Success } \\
(\%)\end{array}$ & $\begin{array}{l}\text { Clutch } \\
\text { Size }\end{array}$ & Productivity $^{\mathrm{a}}$ & $\begin{array}{c}\% \\
\text { Parasitized }\end{array}$ & Authors \\
\hline MI & $\begin{array}{l}\text { Tamarack } \\
\text { swamps, } \\
\text { successional } \\
\text { fields, } \\
\text { overgrown } \\
\text { cuttings }\end{array}$ & 13 & $\begin{array}{l}1981- \\
1983\end{array}$ & $85^{\mathrm{b}}$ & 4.69 & 3.30 & 31 & Will 1986 \\
\hline NY & $\begin{array}{l}\text { Old fields, } \\
\text { young forests }\end{array}$ & 12 & $\begin{array}{l}1990- \\
1991\end{array}$ & -- & 4.80 & 2.00 & 35 & $\begin{array}{c}\text { Confer } \\
1992\end{array}$ \\
\hline WV & $\begin{array}{l}\text { Reclaimed } \\
\text { surface mines, } \\
\text { cutover forests }\end{array}$ & 347 & $\begin{array}{l}1987- \\
1996\end{array}$ & 61 & 4.80 & 3.22 & 0 & $\begin{array}{l}\text { Canterbury } \\
\text { et al. } 1996\end{array}$ \\
\hline $\mathrm{ON}$ & $\begin{array}{l}\text { Deciduous } \\
\text { forest mixed } \\
\text { with } \\
\text { agricultural } \\
\text { fields and } \\
\text { swamps }\end{array}$ & 49 & $\begin{array}{l}1998- \\
1999\end{array}$ & 44 & -- & -- & 2 & $\begin{array}{c}\text { Demmons } \\
2000\end{array}$ \\
\hline $\mathrm{NC}$ & $\begin{array}{l}\text { Forest } \\
\text { regeneration } \\
\text { areas }\end{array}$ & 23 & $\begin{array}{l}1997- \\
1998\end{array}$ & 73 & 4.50 & 3.65 & 0 & $\begin{array}{c}\text { Klaus and } \\
\text { Buehler } \\
2001\end{array}$ \\
\hline NY & $\begin{array}{l}\text { Old fields, } \\
\text { young forests }\end{array}$ & 69 & $\begin{array}{l}1988- \\
1994\end{array}$ & 38 & 4.39 & $1.00-2.30^{c}$ & 30 & $\begin{array}{l}\text { Confer et } \\
\text { al. } 2003\end{array}$ \\
\hline ON & $\begin{array}{l}\text { Abandoned } \\
\text { farmland, }\end{array}$ & 6 & 2004 & -- & 5.00 & -- & -- & $\begin{array}{l}\text { Reed et al. } \\
\quad 2007\end{array}$ \\
\hline $\mathrm{ON}$ & $\begin{array}{l}\text { swamps, } \\
\text { second growth } \\
\text { forest, rocky } \\
\text { outcrops }\end{array}$ & 55 & $\begin{array}{l}2001- \\
2003\end{array}$ & $56^{\mathrm{b}}$ & 5.06 & -- & -- & $\begin{array}{l}\text { Vallender } \\
\text { et al. } \\
2007 \mathrm{~b}\end{array}$ \\
\hline PA & $\begin{array}{c}\text { Patch } \\
\text { clearcuts, } \\
\text { utility ROWs }\end{array}$ & 39 & $\begin{array}{l}2002- \\
2003\end{array}$ & $\begin{array}{l}20- \\
46^{\mathrm{d}}\end{array}$ & 4.00 & $0.57-2.38^{d}$ & 15 & $\begin{array}{c}\text { Kubel and } \\
\text { Yahner } \\
2008\end{array}$ \\
\hline $\mathrm{TN}$ & $\begin{array}{c}\text { Reclaimed } \\
\text { surface mines }\end{array}$ & 102 & $\begin{array}{l}2003- \\
2006\end{array}$ & 49 & 4.30 & -- & 3 & $\begin{array}{l}\text { Bulluck } \\
\text { and } \\
\text { Buehler } \\
2008\end{array}$ \\
\hline
\end{tabular}

\footnotetext{
${ }^{\mathrm{a}}$ Average number of fledglings across all nests (successful or unsuccessful)

${ }^{b}$ Nest success is the proportion of successful nests, all other estimates are based on Mayfield (1961)

${ }^{\mathrm{c}}$ Lower number is from parasitized nests and higher number is from unparasitized nests

${ }^{d}$ Lower number is from utility ROWs and higher number is from patch clearcuts
} 


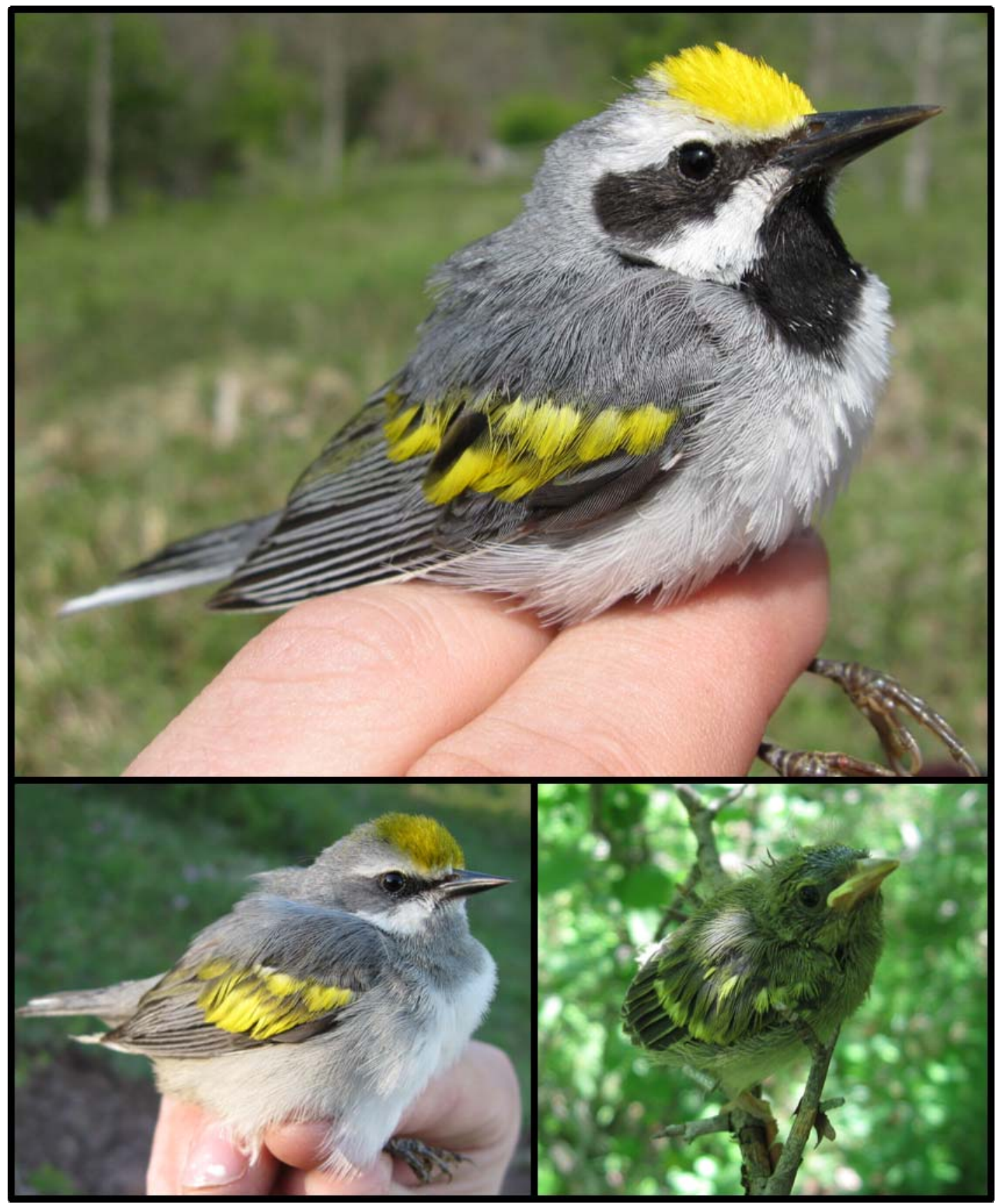

Figure 1. Golden-winged Warbler (Vermivora chrysoptera) male (top), female (bottom left), and fledgling (bottom right). 


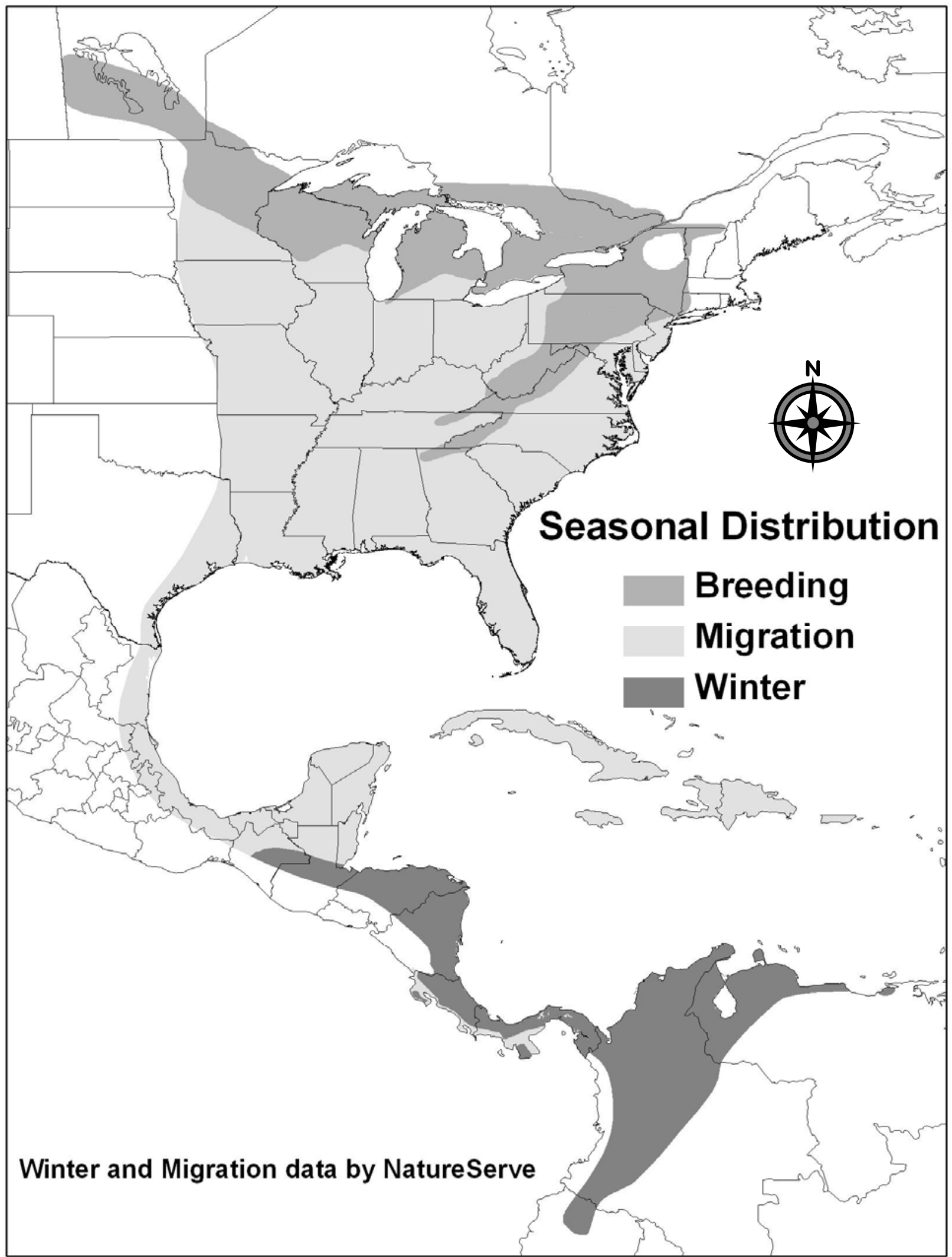

Figure 2. Map of Golden-winged Warbler breeding, migratory, and winter ranges. 


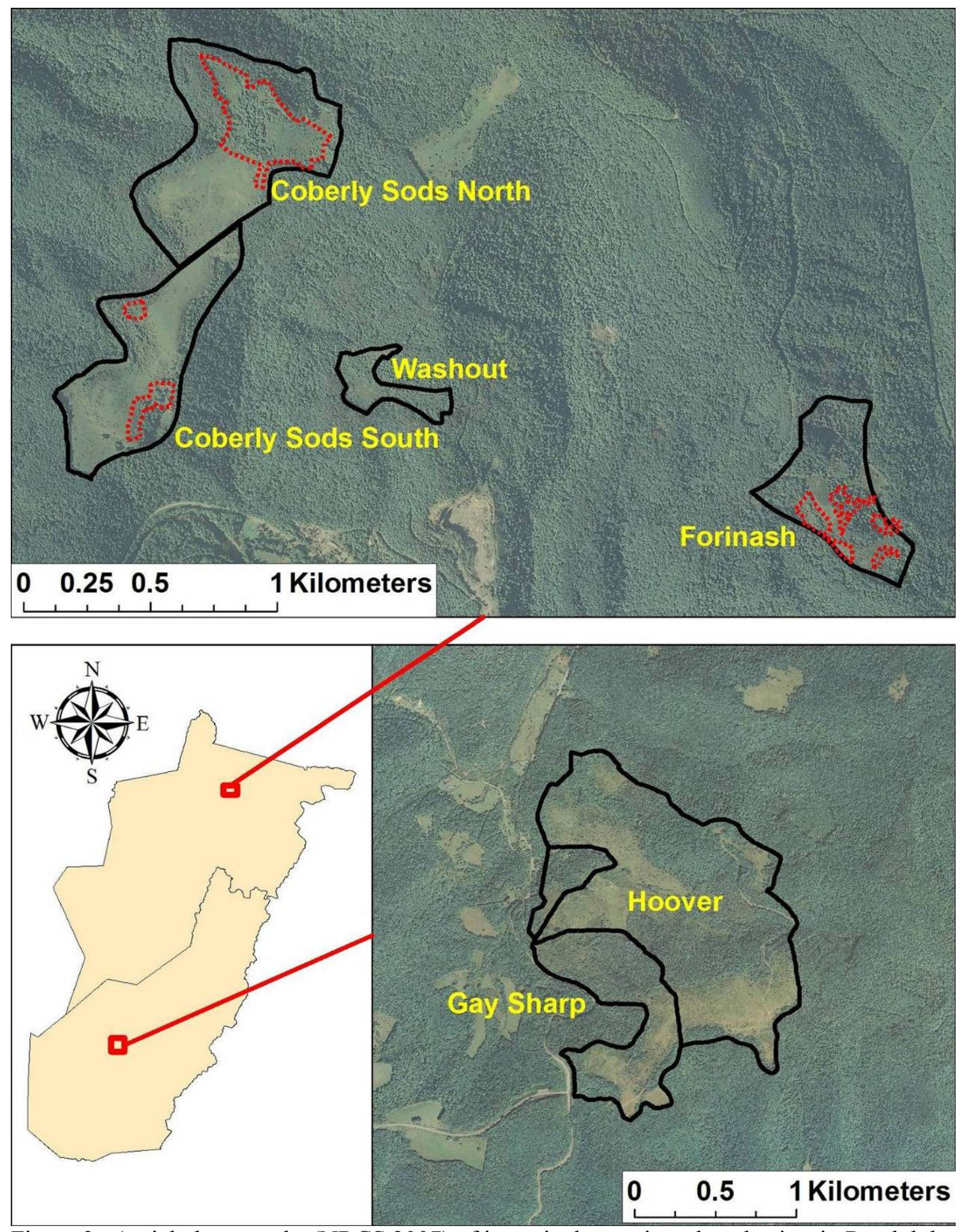

Figure 3. Aerial photographs (NRCS 2007) of intensively monitored study sites in Randolph and Pocahontas Counties with grazing allotment boundaries in black and treatment areas in red. McAllister, which is located less than $2 \mathrm{~km}$ to the northwest of Hoover, is not shown because Golden-winged Warblers were not present. 


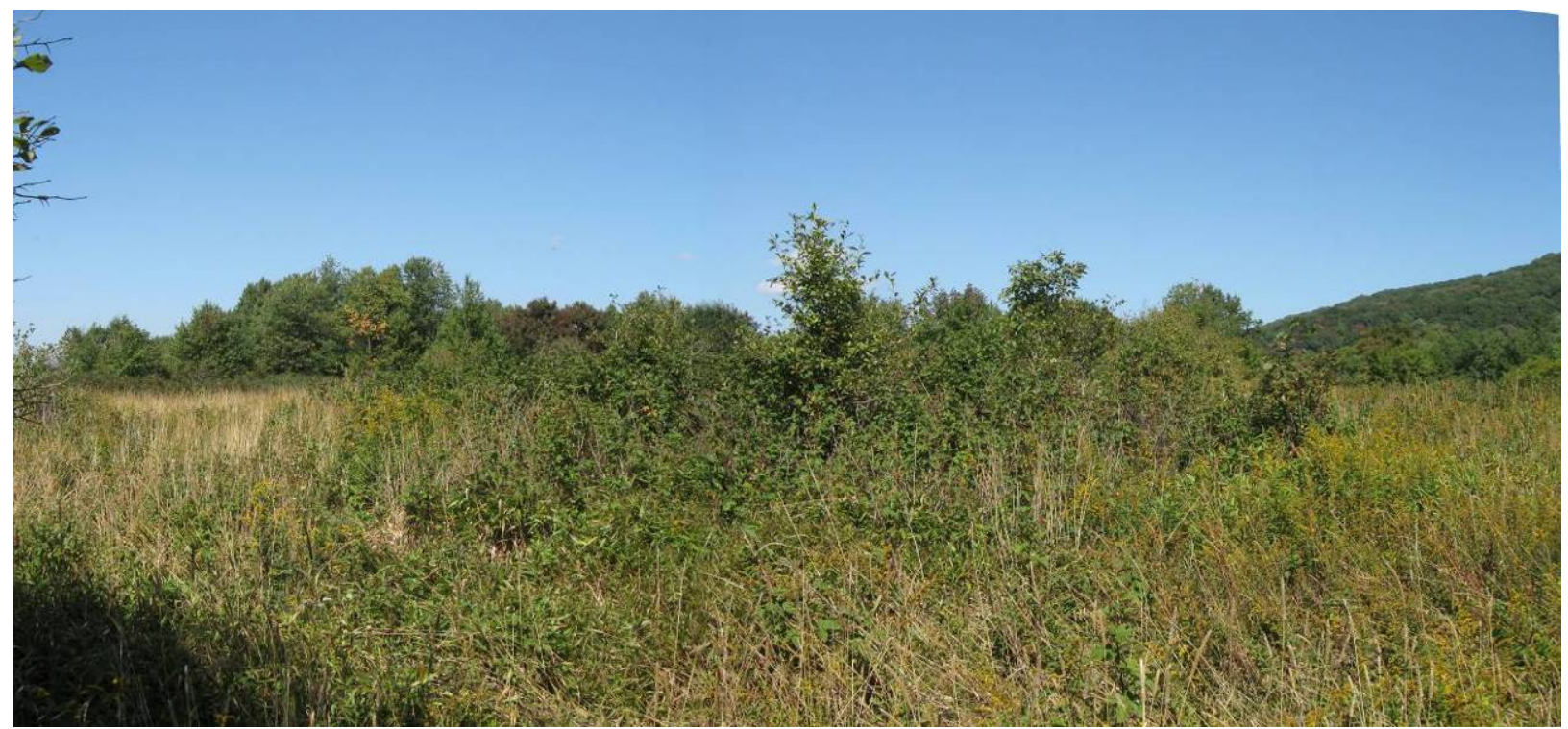

Figure 4. The ungrazed section of Coberly Sods North with evidence of brush-hogging to the right and left of the Golden-winged Warbler nest site in the center.

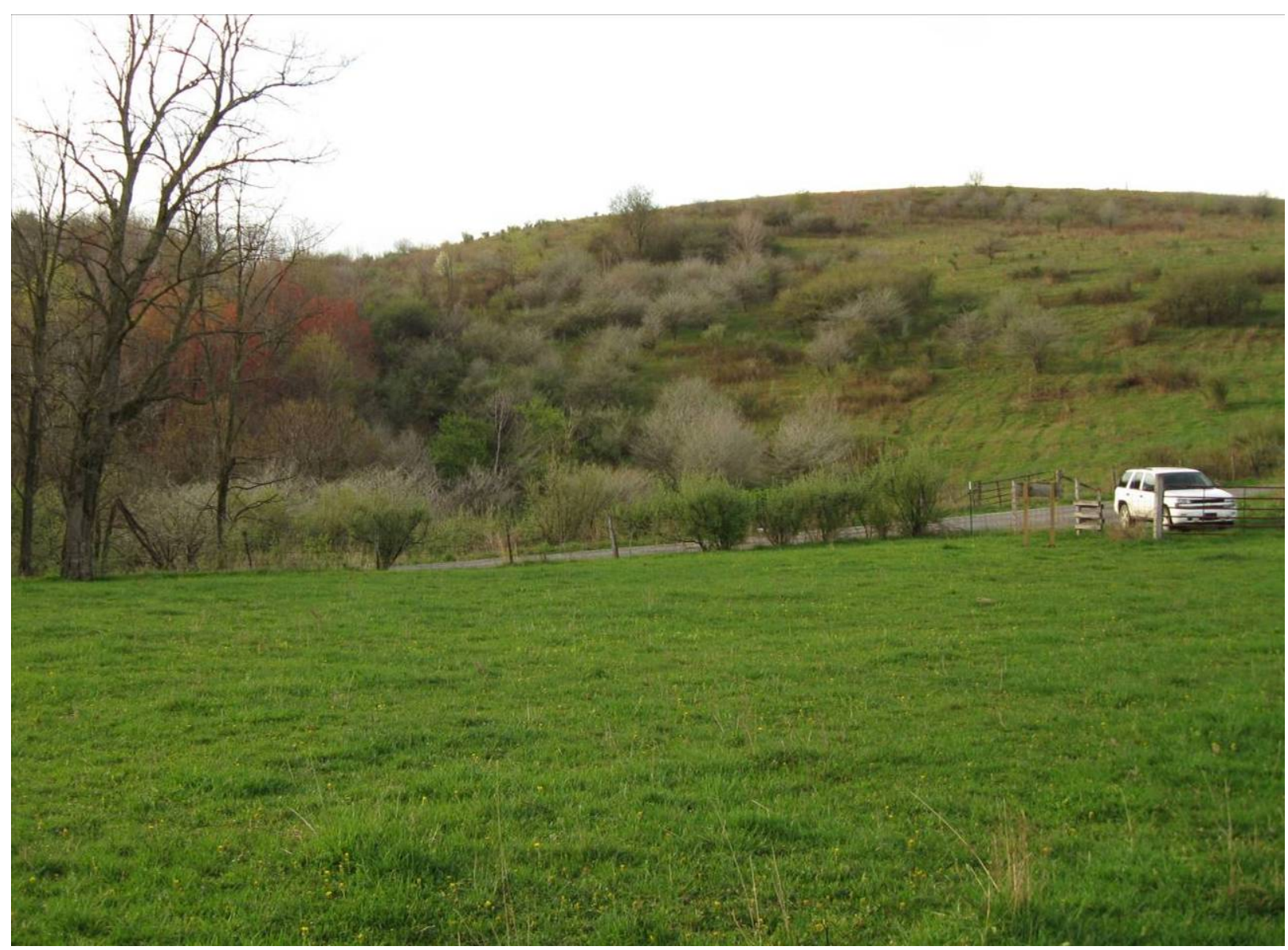

Figure 5. The grazed section of Coberly Sods North (behind road). 


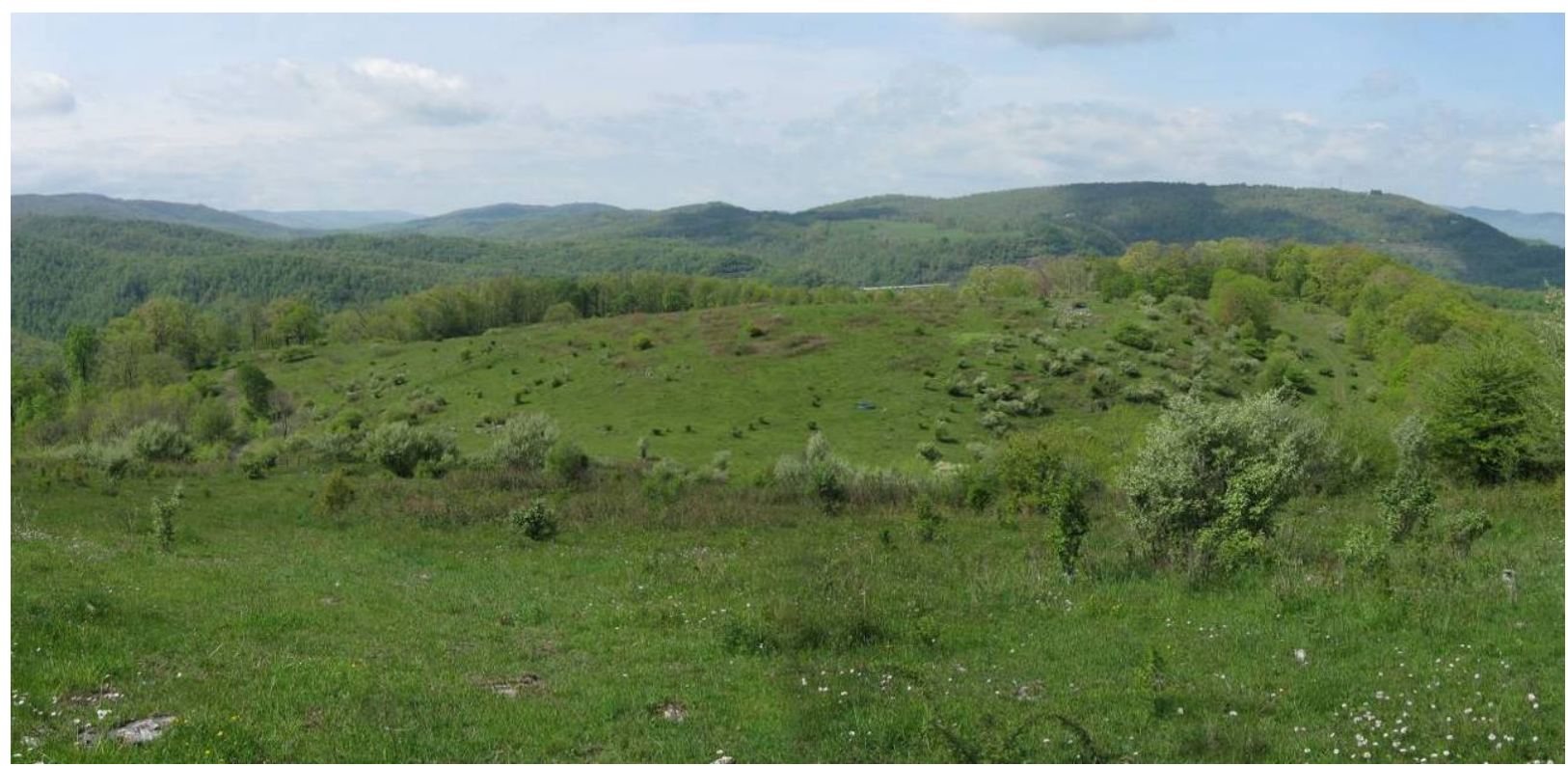

Figure 6. Coberly Sods South.

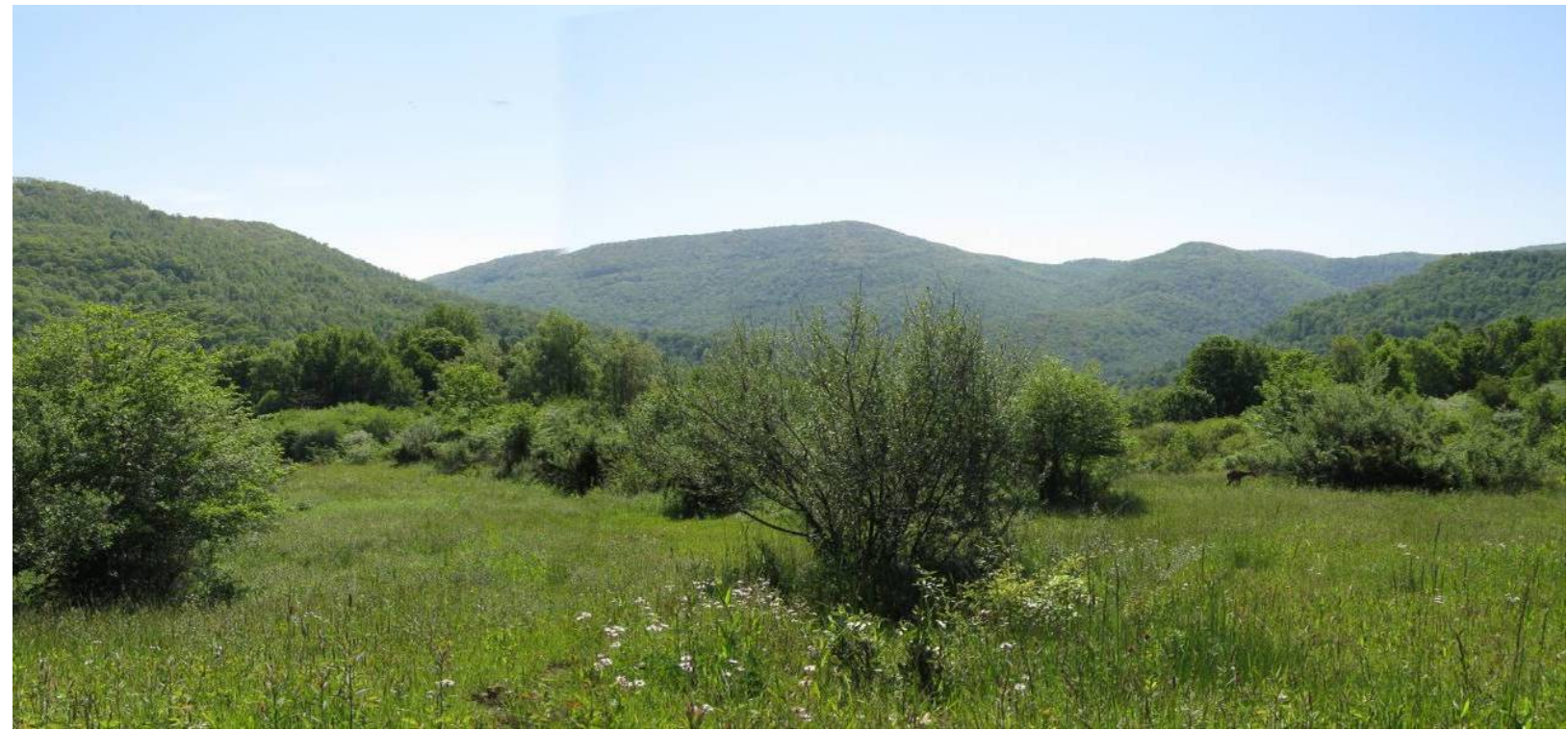

Figure 7. Forinash. 


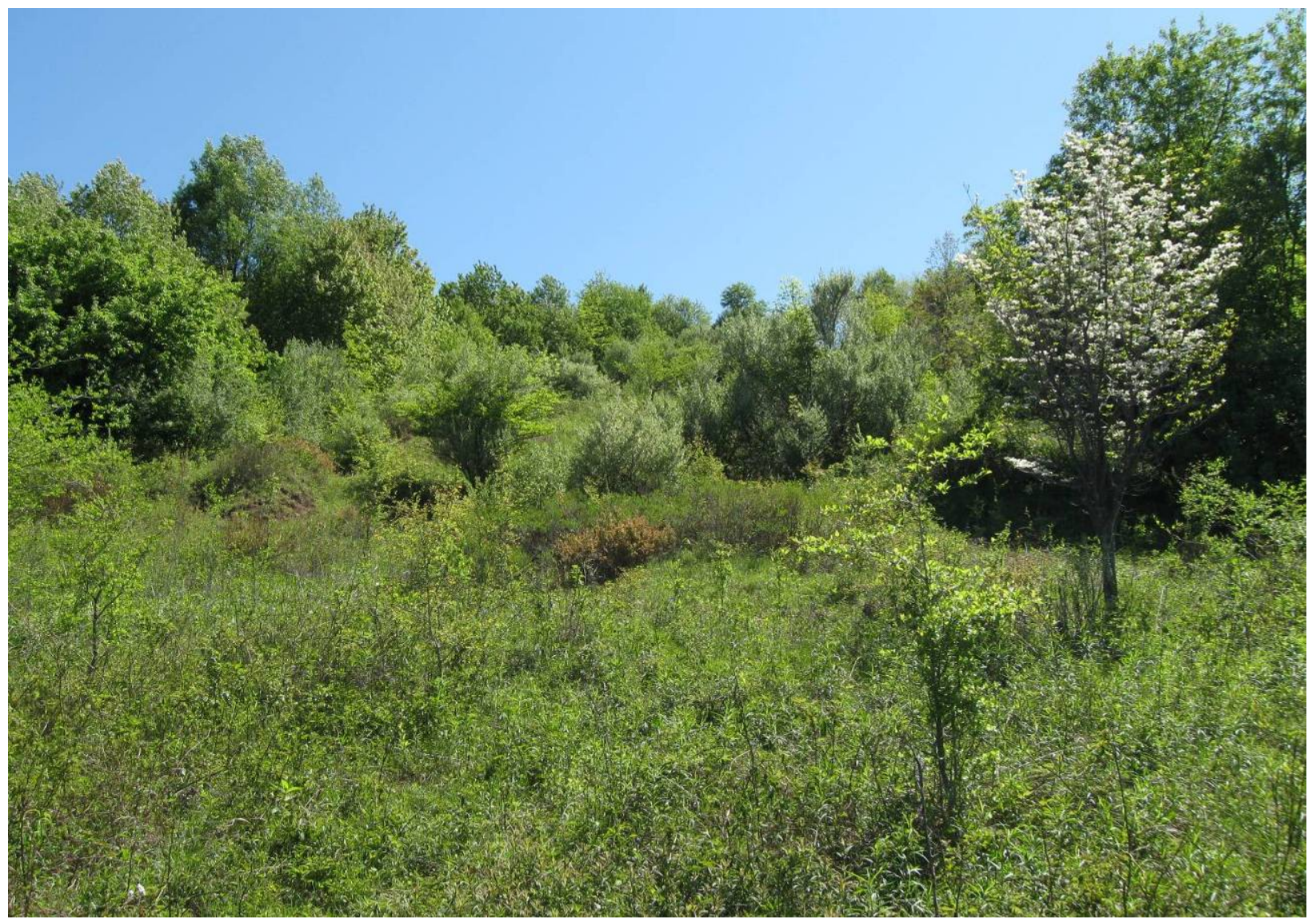

Figure 8. Washout: the privately owned abandoned pasture.

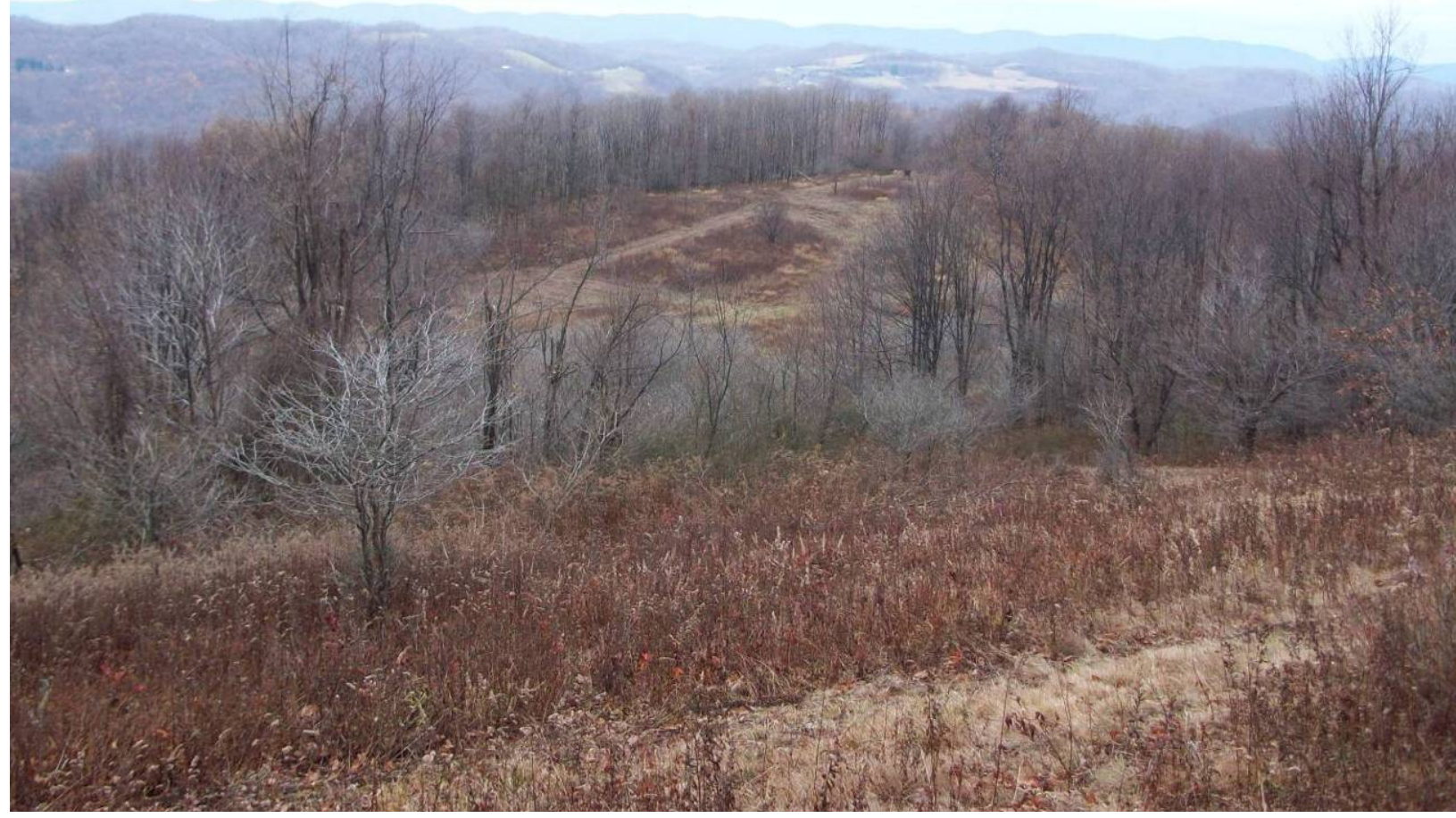

Figure 9. The ungrazed section of Coberly Sods North during treatment in November 2008 (Photo: Mandy Weston). 




Figure 10. Ten months post-treatment on the ungrazed section of Coberly Sods North. This area was previously a homogeneous patch of Rubus. 


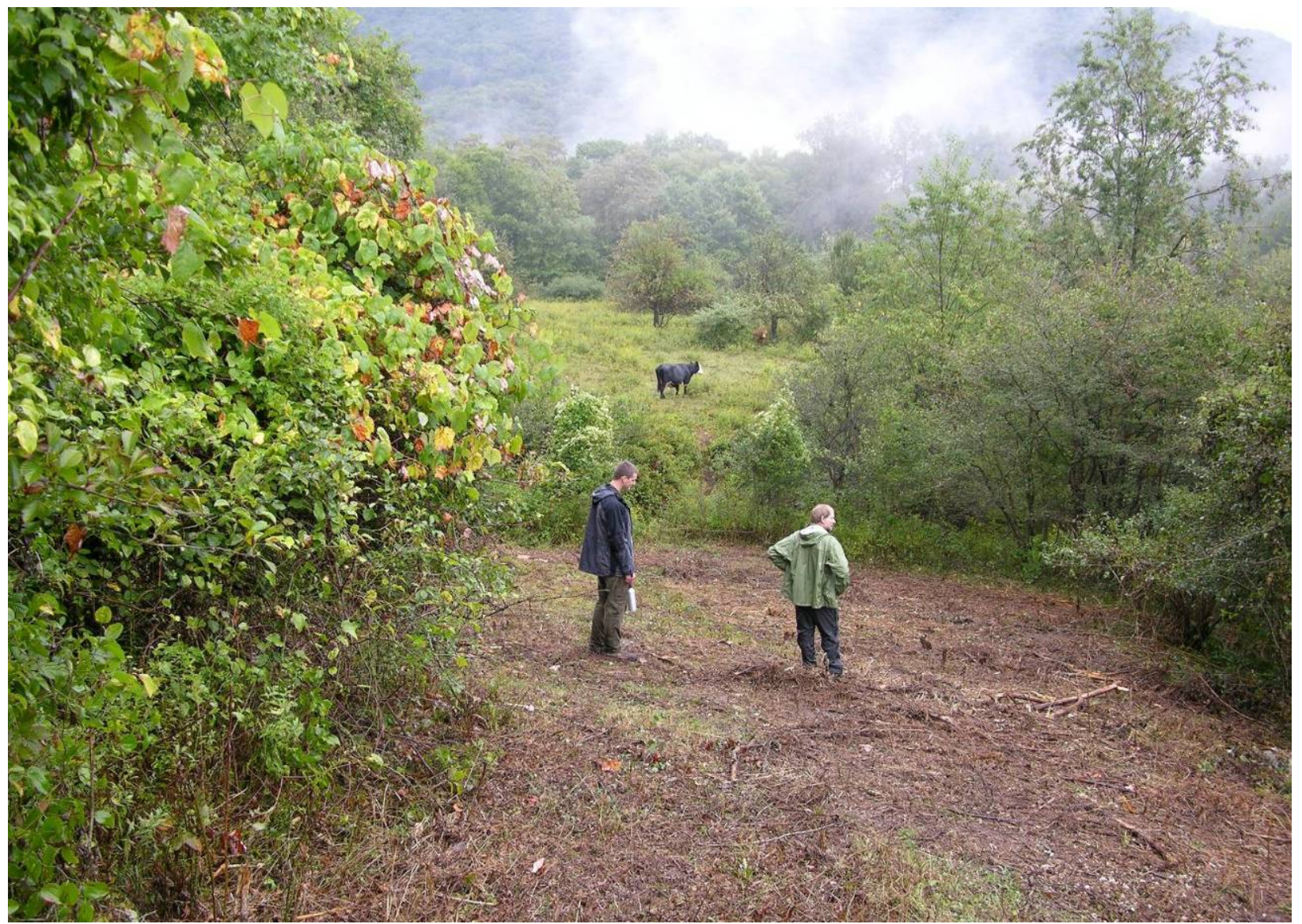

Figure 11. Forinash a few days post-treatment in September 2008.

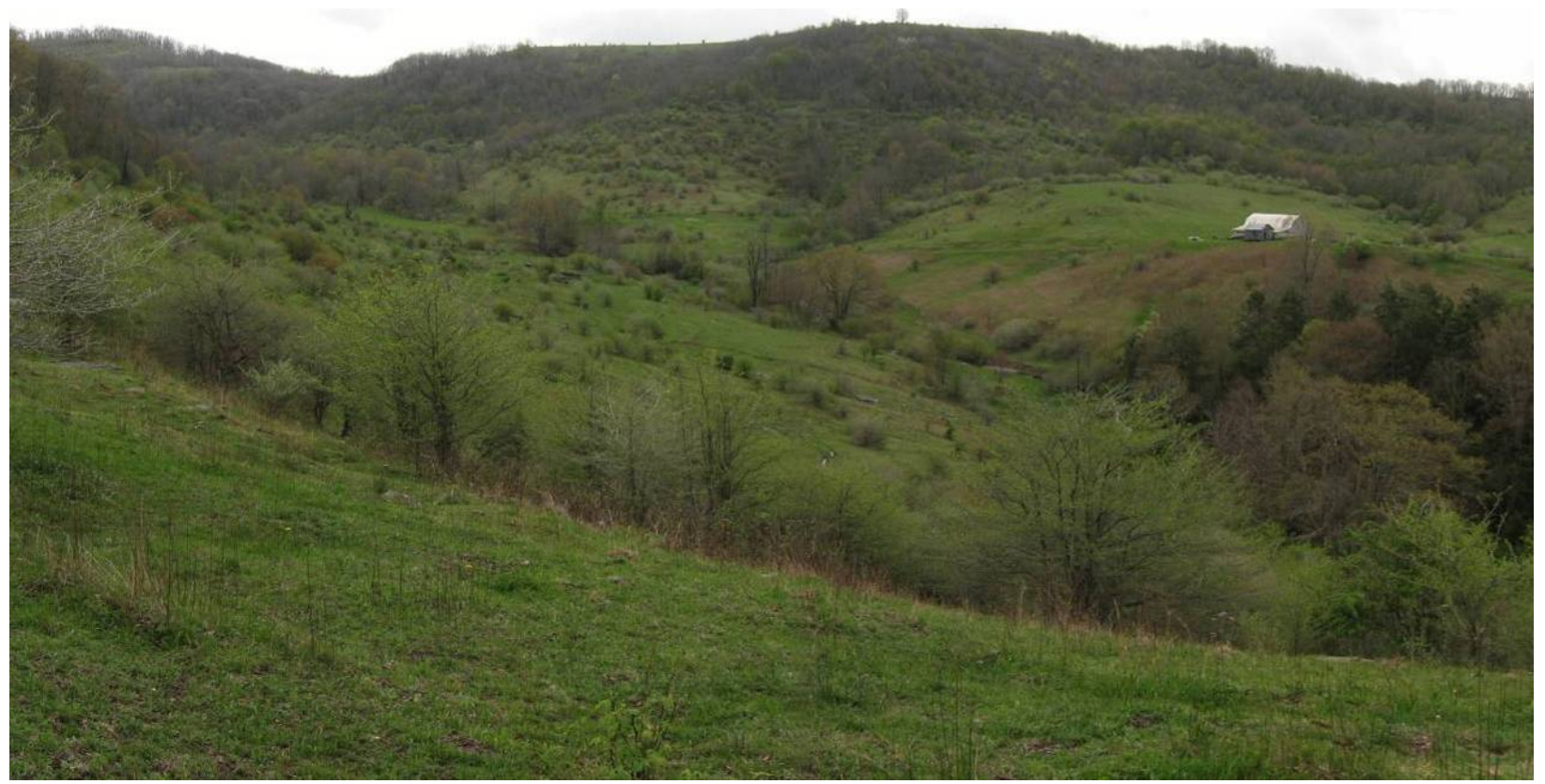

Figure 12. Hoover with barn remaining from previous land owner. 


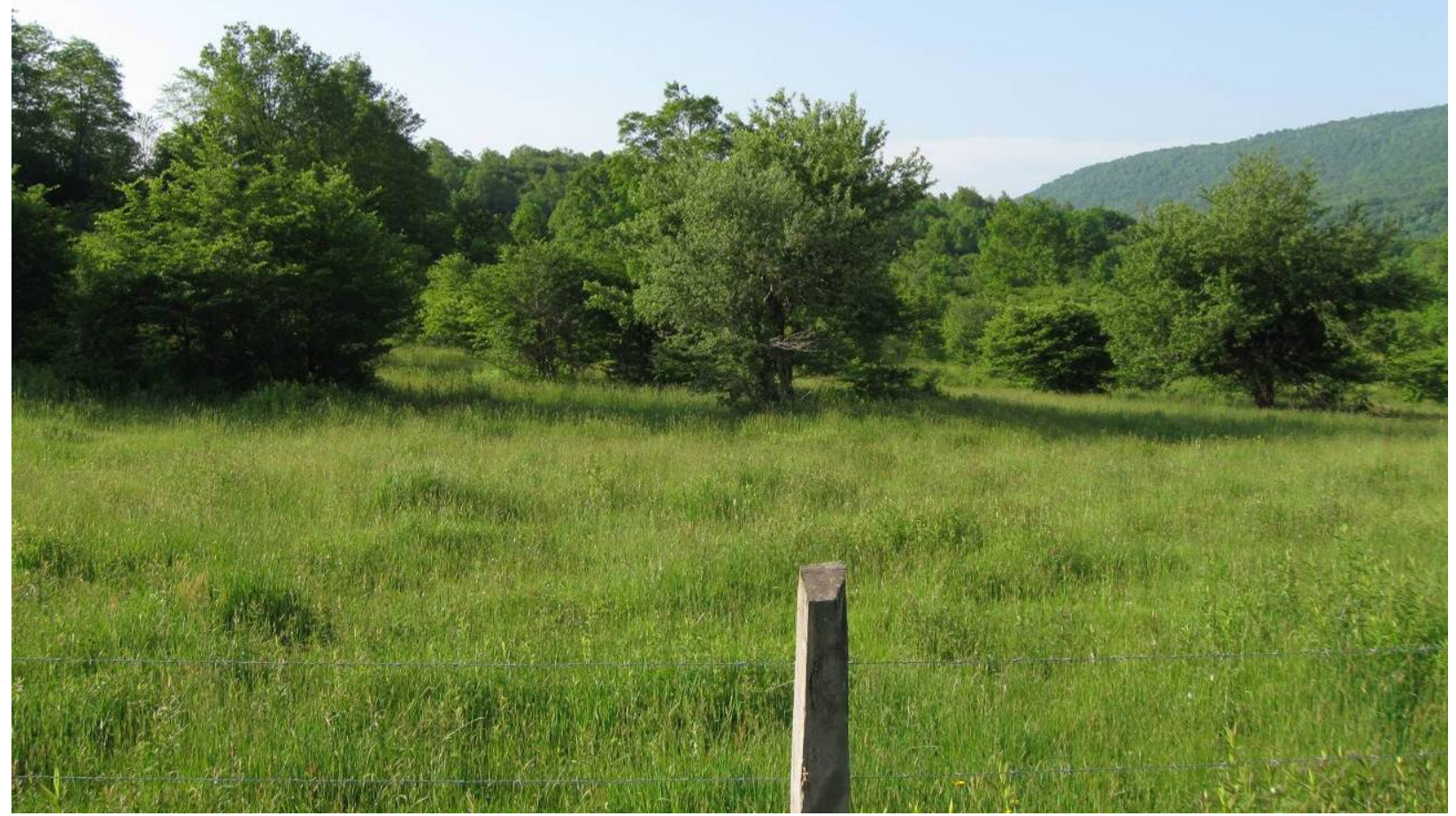

Figure 13. McAllister.

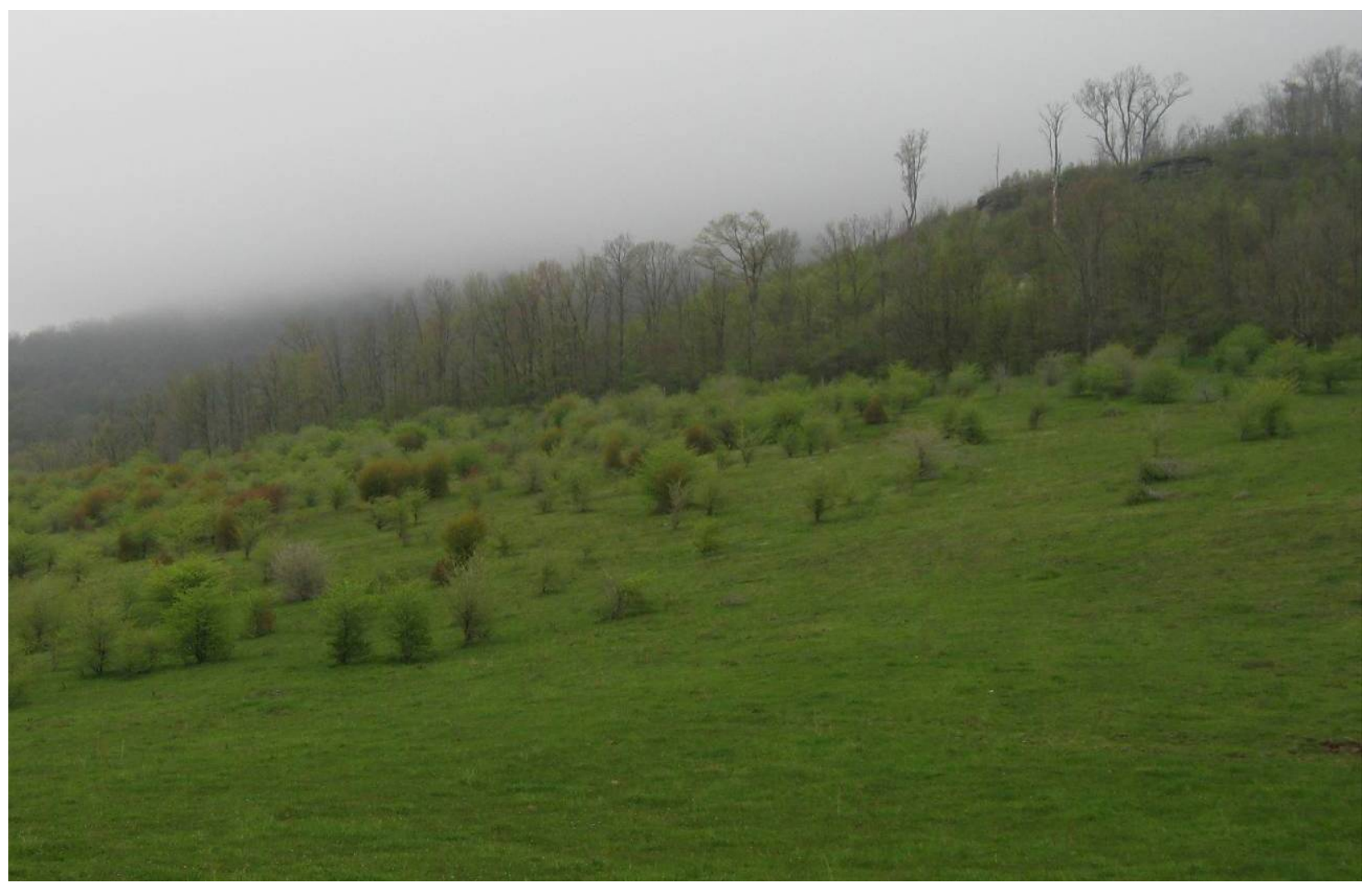

Figure 14. A 4.05 ha clearcut (upper right) adjacent to the Hoover grazing allotment (bottom). 


\section{Chapter 2}

\section{Effect of time of day, season, song type, and playback duration on detection probability and behavioral response of Golden-winged Warblers}

Formatted in the style of Journal of Field Ornithology 


\section{Abstract}

Golden-winged Warblers (Vermivora chrysoptera) are difficult to detect with point count surveys, and their inconspicuousness is exacerbated by temporal, habitat, and observer variability, among other factors. Population estimates, which affect conservation priorities, for this species are derived from North American Breeding Bird Survey data under the assumption that $100 \%$ of males $\leq 200 \mathrm{~m}$ from an observer during a 3-min count are detected. From 10 May to 15 June 2008-2009 on high-elevation grazing areas on the Monongahela National Forest, West Virginia, we estimated detection probability of Golden-winged Warblers at different times of day and season, without and with two types of song playback, and with a longer duration of song playback than previously reported in the literature. We also measured behavioral responses to playback. Detection probability was higher during morning (65\%) than evening surveys (27\%). Season did not significantly affect detection probability and our BBS-analogous counts detected $40 \%$ of the actual population. Although males often showed behavioral responses (initiating or altering vocalizations and territorial displays) to type $1(N=108)$ and type $2(N=94)$ song playback, detection probability was similar between point counts without playback and playback surveys. We detected significantly more males using type 2 playback surveys (61\%) than type 1 surveys (52\%), however. Approaching the observer, increasing singing rate, and initiating type 1 song made up $71 \%$ of responses for each song type. Morning surveys from 22 May to 2 June with 1-1.3 mins of playback followed by passive listening should maximize detection probability for Golden-winged Warblers on high-elevation grazing areas in WV. A single factor correcting population size estimates likely is not feasible due to variability among detection rates for this species.

\section{INTRODUCTION}

Golden-winged Warblers (Vermivora chrysoptera, hereafter Golden-wings) have been the subject of widespread monitoring and population status assessments (COSEWIC 2006, Wilson et al. 2007, Buehler et al. 2007), including a petition for listing under the federal Endangered Species Act (Sewell 2010), primarily because long-term monitoring has shown dramatic declines (1937-89, annual average decline: $-1.4 \%$ year $^{-1}, P<0.01$, Hill and Hagan 1991; North American Breeding Bird Survey, BBS, $-2.8 \%$ year $^{-1}, P<0.01, N=276$ routes, Sauer et al. 2008), with even steeper declines in West Virginia ( $-10.3 \%$ year $^{-1}, P<0.01, N=31$ routes, Sauer 
et al. 2008). BBS methods can produce low detection rates (Hutto et al. 1995), however, particularly for species such as Golden-wings, which sing infrequently after pairing and as the breeding season progresses (Ficken and Ficken 1967, Highsmith 1989) and have short breeding seasons (Confer 1992) that may not coincide well with the BBS survey period (Kubel and Yahner 2007). For example, Kubel and Yahner (2007) detected 23\% of the actual population of Golden-wing males in clearcuts and $61 \%$ on utility rights-of-way (ROWs) using BBS style counts; song playback increased detection rates 7-19\%. Consequently, surveys targeted at Golden-wings, whether to verify presence (Klaus and Buehler 2001, Roth and Lutz 2004) or for monitoring (Golden-winged Warbler Atlas Project, CLO 2008), often incorporate playback. Johnson et al. (1981) found that 51 species, including six Parulidae warblers, were responsive to playback recordings as a census technique.

Studies have examined the effect of song playback on Golden-wings with type 1 song (Ficken and Ficken 1969, 1973, Kubel and Yahner 2007). Responses to type 2 song also have been reported (Gill and Murray 1972, Highsmith 1989). Type 1 song, generally associated with mate attraction (Highsmith 1989), is defined as an introductory zee note followed by a variable number of lower frequency bee notes, most commonly three (Highsmith 1989). Ficken and Ficken (1973) found that Golden-wings were most responsive to the zee bee bee bee structure. Type 2 songs, which are similar for Golden-wings and Blue-winged Warblers ( $V$. pinus) to the point that interspecific discrimination is poor (Gill and Murray 1972), typically contain three to five syllable types and end with a buzzy note, although there can be considerable variation in the structure of trills and buzzes (Highsmith 1989). This secondary song, typically associated with pre-dawn singing bouts or aggressive territorial interactions (Highsmith 1989), may elicit stronger responses from males. To our knowledge no data are published on effectiveness of type 2 songs or playback duration to increase detection probability during point counts for this species. It is important to determine which type of playback (type 1 or type 2) and at what duration is most effective for detecting Golden-wings to refine playback methods and increase detection rates of this cryptic species (Kubel and Yahner 2007).

Counts early in the morning and at the peak of the breeding season have long been accepted as most effective for monitoring breeding bird populations (Ralph et al. 1995, Bibby et al. 2000). Given the variation in breeding times for different species and the often overloaded schedules of biologists, it is valuable to evaluate alternative times for surveying. Conducting 
surveys at unconventional times of day or season could be considered as alternatives if benefits outweigh costs and detection rate tradeoffs are understood. For Golden-wings, peak survey times are fairly well known (Ficken and Ficken 1967, Confer 1992, Kubel and Yahner 2007), but consequences of delaying surveys or using different types and durations of song playback could receive more attention. A firmer grasp of the detectability of this species could guide supplemental surveys and be applied as a correction factor when estimating population size.

Golden-wing population estimates, derived from BBS data and considered when prioritizing conservation efforts under the North American Landbird Conservation Plan (Rich et al. 2004, Panjabi et al. 2005), are based on methods described in Rosenberg and Blancher (2005) which assume that $100 \%$ of males are detected within $200 \mathrm{~m}$ of survey points. However, Confer et al. (2008) found that only 3\% of Golden-wings and 7\% of Vermivora spp. (Golden-wings, Blue-wings, and their hybrids) were detected using BBS style point counts. Neither Kubel and Yahner (2007) or Confer et al. (2008) were able to, on average, detect 100\% of the true population of male Golden-wings within $200 \mathrm{~m}$ during a BBS style point count. Thus, because detection probability varies among habitat types, we tested this assumption in high elevation grazing areas in West Virginia. Current population estimates for Golden-wings based on BBS data may be lower than reality.

Specifically, our study examined detection probability within $200 \mathrm{~m}$ and how it was influenced by 1) different times of day and season, 2) inclusion of song playback, 3) different types of song playback, and 4) a longer duration of playback than in Kubel and Yahner (2007). Behavioral responses to song types are considered, to assess which song type elicits a stronger response and because visual confirmation is needed to positively distinguish between Goldenwings, Blue-wings, and hybrids. These results compliment those found in Kubel and Yahner (2007) by addressing questions about type and duration of song playback needed to maximize detection rate.

\section{METHODS}

Study area. We conducted playback surveys on 6 grazing areas on the Monongahela National Forest, 4 near Elkins, Randolph County and 2 near Marlinton, Pocahontas County, West Virginia, ranging in elevation from about 800 to 1,200 m. Coberly Sods North (40.6 ha) is divided into ungrazed (23.1 ha) and grazed (17.5 ha) sections, the ungrazed section has been fenced off since 1991. Coberly Sods South (30.2 ha) is separated from Coberly Sods North by a 
gravel US Forest Service (USFS) road. Forinash (21.8 ha) was ungrazed from 1993 to 2006, but mowing and grazing resumed in 2007. One study site, "Washout" (5.9 ha) is a privately-owned abandoned pasture just outside of the national forest boundary. Washout has similar habitat as the federally owned sites, but is not currently grazed. These four sites were sampled in 2008 and 2009. Study areas in Pocahontas County, Hoover (179 ha) and Gay/Sharp (56 ha), were only sampled in 2009. Hoover and Gay/Sharp are adjacent and separated by a cattle fence. We also surveyed a $\sim 10$ year old, 9.2 ha clearcut directly adjacent to the Hoover site.

Grazing areas on the Monongahela National Forest generally were active pastures when the land was acquired by the USFS and remain as such today. The USFS leases grazing areas to the public for low intensity grazing of cattle and horses from 15 May to 1 October, so they are maintained at the current stage of succession primarily by livestock grazing and periodically by mowing. All sites are patchy and structurally complex, comprised of grasses, herbaceous vegetation, and shrub-scrub habitat with low basal area of trees. Most of the suitable Goldenwing habitat was located near the perimeters of the study areas. Sites were surrounded by extensive areas of mature forest (see Fig. 2 in Chapter 1). Topographically, the study areas are situated on ridge and mountaintops with gradual slopes, making it possible to detect Goldenwings at long distances from survey stations.

Data collection. To quantify the true population size of Golden-wings on each study site, we completed counts of territorial singing males in May and June using a thorough area search of the available habitat between dawn and approximately midday, although area searching continued further into the day if males remained active. Bibby et al. (2000) suggested that evening visits also may be helpful, so area searching occasionally occurred in the evening after the period of inactivity in the middle of the day. During visits to areas with territorial males, the location and behavior of males was monitored and recorded on high resolution aerial photographs with landmarks and point count stations for reference. Important territory characteristics such as song perches, nests, and courtship displays were noted. All available early successional habitats were searched extensively. In addition, most Golden-wings were banded with unique color combinations to help distinguish individuals. Territories were designated based on at least 8 locations for a male (Robbins 1970), although all males were observed more frequently and territorial boundaries were well defined. We are confident that $100 \%$ of all territorial males were detected and that all territories fell completely within study 
site boundaries. Sites were visited nearly every day for nest-searching, territory mapping, point counts, banding, and broadcast surveys, so we were familiar with all territories on each site.

We established sample points systematically on a $100 \mathrm{~m}$ by $100 \mathrm{~m}$ grid within patches of early successional habitat where a census of singing males had occurred. Points falling within unsuitable habitat were eliminated as well as points that were close enough to other stations that males might be detected at both locations (at least $250 \mathrm{~m}$ but no greater than $400 \mathrm{~m}$ between stations). This systematic approach was used because suitable habitat was irregularly distributed and it allowed us to survey all suitable habitat available. All suitable habitats on the study sites were within $200 \mathrm{~m}$ of a survey station and study sites were completely surrounded by intact forest, thus we assumed that all males were present and detectable within the maximum detection distance of $200 \mathrm{~m}$ (Rosenberg and Blancher 2005). The number of sample points per site depended on the amount of suitable habitat; the smallest site had two stations and the largest had 14. Across all study sites, we surveyed 12 playback stations in 2008 and 30 in 2009 . We tested playback equipment (Radio Shack Mini Amplifier-Speaker, catalogue \# 277-1008; TrekStor IBEAT CEBRAX FM 1GB MP3 PLAYER, catalogue \# TRIBC1GBQ; Centon moVex 2GB MP3 Player, catalogue \# 2GBMP3-003) in occupied Golden-wing habitat, a matrix of grasses, forbs, Rubus, shrubs, and few trees under good weather conditions (clear, low wind, etc.). Both type 1 and 2 song could be heard by field personnel to distances of about $120 \mathrm{~m}$.

Type 1 playback surveys were a subset (the first 6 mins) of the Golden-winged Warbler Atlas Project (GOWAP, CLO 2008) protocol. GOWAP surveys spanned 17 mins that included an initial 3-min passive listening period, 5 mins of type 1 Golden-wing song playback, 1 min of listening, 1 min of type 2 Golden-wing song, 1 min of silent observation, 5 mins of mobbing calls (Black-capped Chickadee [Poecile atricapillus], Eastern Screech Owl [Megascops asio], and Golden-wing vocalizations), ending with 1 min of silent listening. Silent periods between song playbacks were built directly into the sound file. The recording of type 1 song consisted of seven songs per min, two of which had four bee notes and the remaining had three. A single introductory zee note followed by three bee notes elicits a strong response from Golden-wings (Ficken and Ficken 1973). The type 2 song playback protocol survey consisted of a 3-min silent pre-playback period, followed by a type 2 song playback period of 3 mins, and ending with a silent post-playback period of 4 mins, to allow for standard 10-min counts. Playback consisted of 9 type 2 songs per min, provided by the Cornell Laboratory of Ornithology (Ithaca, NY). We 
were interested in detections occurring during the first 6 mins of a survey for direct comparison of song types.

In 2008 and 2009, six trained observers completed playback surveys on sites where they were responsible for territory mapping and nest searching. We conducted playback surveys from dawn/06:00 to 10:00 (AM survey) both years and 15:00 to 20:00 (PM survey) DST in 2008. At a site, survey stations were visited in different orders each visit to account for time of day temporal differences. To examine time of season, surveys were blocked into early (10-21 May), middle (22 May-2 June), and late (3-15 June) time periods to coincide with arrival of Goldenwings (earliest arrival date is May 5 for Randolph County, Hall 1983), survey dates of the Golden-winged Warbler Atlas Project (10 May to 15 June, CLO 2008), and the BBS which occurs during early June in most locations. We did not conduct playback surveys before males had established territories. Entire study sites were surveyed with the same protocol (determined by coin flip) in one day and the opposite protocol was implemented across the entire site in subsequent days. We did not conduct back-to-back surveys at the same point in one day to avoid carryover effects. In some cases, AM and PM playback surveys were conducted on the same day at the same point because there were at least five hours between surveys. Except for the early time period in 2008 where weather interfered with sampling efforts, AM and PM surveys were completed within a day or two of one another on the same site to avoid temporal effects within a time period. PM surveys at two sites (type 1 surveys at Forinash and type 2 surveys at Washout) were not completed during the early season in 2008 due to inclement weather. We dropped PM surveys in 2009 because of the low detection rates seen in 2008.

Because of the limited number of survey stations available, each playback protocol was repeated several times at each station. The type 1 and type 2 surveys were done at each station during each of the season intervals (early, middle, and late) both years. Each point was sampled during both times of day (AM and PM) with both protocols in 2008.

Playback survey techniques were adapted from Yahner and Ross (1995) and Kubel and Yahner (2007). At the beginning of each count, we recorded weather conditions including wind, cloud cover, precipitation, and temperature, but playback surveys were not conducted in weather that might lower detection rates. For each male Golden-wing located by sight or sound during a count, we recorded the estimated distance $(\mathrm{m})$ from the station to each individual at the time of initial detection. The minute during which the male was initially detected, along with all 
subsequent minutes wherein detection occurred, was recorded. We recorded if the individual was detected visually. Behavioral responses of individuals to playback were recorded if they occurred during the 3-min song playback interval. Response types were based on descriptions in Baird (1967), Ficken and Ficken (1967, 1969, 1973), Highsmith (1989), and Kubel and Yahner (2007) and included approaching the observer, initiating type 1, type 2, or chipping vocalizations, shortening, lengthening, or muting song, switching song type, increasing the rate of singing, or other territorial displays.

Phenotype (GWWA, BWWA, BRWA, LAWA, Introgressed) was recorded to assess possible differences in responsiveness to playback between phenotypically "pure" Golden-wings and introgressed individuals. Introgressed individuals were defined as individuals whose plumage characteristics were not consistent with descriptions of Golden-wings (GWWA), Bluewings (BWWA), Brewster's (BRWA), or Lawrence's Warblers (LAWA) from the literature (e.g, Parkes 1951).

We conducted 10-min passive point counts (Ralph et al. 1995) between dawn/0600 and 100030 May-2 June (bout 1) and 20-24 June (bout 2) at all of the survey stations both years. We recorded all individuals heard or observed within the 10-min span broken down into seven intervals $(2 \mathrm{~min}, 1,1,1,1,1,3)$. We noted the distance to each individual bird within several distance categories $(0-25 \mathrm{~m},>25-50 \mathrm{~m},>50-100 \mathrm{~m},>100 \mathrm{~m})$. Data from bout 1 were compared to the full 10-min type 2 protocol.

Data analyses. Only male Golden-wings were included in analyses for detection and response rates; females, Blue-wings, and hybrids were excluded because they were rarely encountered and our objective was to examine detection and response rates of Golden-wings. Individuals that were detected multiple times while surveying a site were only counted once, and we used the detection with a behavioral response or the shortest detection distance. Detection probability was defined as the proportion of the known population on each that was detected during broadcast surveys. We summed all detections of males at a site across survey points and divided by the known population at that site. Detection probability was broken down by site, year, time of season, time of day, and playback survey interval (Appendices 1 and 2). Overall detection probability was the mean detection probability across sites for a given time of day or season. Playback survey intervals included pre-playback, the initial 3 mins of silence before playback started, and playback, the 3 mins of either type 1 or 2 song playback. We determined 
the effect of playback on detection probability by summing the number of individuals that were first detected during song playback. Comparisons are limited to the first 6 mins of each protocol, unless otherwise stated, because the survey structure differed after this point.

Time of day comparisons were limited to data collected in 2008 because we did not conduct PM surveys in 2009. Data were not compared statistically because differences were large. All other comparisons included data collected during AM surveys in 2008 and 2009.

We used repeated measures analysis of variance (ANOVA) to test the equality of mean detection probabilities across each of the main effects and their interactions (Table 1). We used a repeated measures approach with song type nested within season nested within site as the repeated terms because detection probability was assessed at each site at under a variety of conditions. Detection probability was arcsine transformed to more closely approximate a normal distribution for these analyses (McDonald 2009).

The repeated measures ANOVA revealed if detection probability data could be pooled across season and year. We followed the ANOVA with $\chi^{2}$ goodness of fit tests to determine if the distribution of detections differed by season for each song type and a paired t-test to compare detection probability by song type. Another paired t-test was used to compare the detection probabilities across the entire 10-min type 2 survey and 10-min passive point count during the middle season. Paired t-tests were more powerful in these situations because each site was sampled using both treatments (McDonald 2009). Each site may be characterized by a different overall detection probability, so a paired analysis is appropriate to test whether song playback influences the detection probability of these patches of Golden-wings.

The Cochran-Mantel-Haenszel $\left(\mathrm{CMH}\right.$, test statistic $\left.=M^{2}\right)$ test with continuity correction (McDonald 2009) was used to test the independence of detections with and without playback by song type, accounting for season. $\mathrm{CMH}$ tests allowed us to test the independence of two variables while accounting for differences that may be the result of a third variable, reducing the chances of committing a type 1 statistical error (Zar 1999).

Pearson's $\chi^{2}$ test (test statistic $=\chi^{2}$ ) for count data and the CMH test were used to test the independence of behavioral responses from song type and season. To compare behavioral responses by song type, we summed responses across season and combined response types into three categories: initiate vocalization (initiate type 1, 2, and chipping), alter vocalization (increase singing rate, mute, shorten, or lengthen song, and switch song type), and territorial 
response (approach observer and territorial display). We grouped responses into the three categories because $\chi^{2}$ tests give inaccurate results if classes are too small (McDonald 2009). We used $\chi^{2}$ goodness of fit tests to test if the distribution of responses differed by season for both song types. All analyses were completed using package stats in the R Language and Environment for Statistical Computing Version 2.8.1 (R Development Core Team 2008). We considered differences significant at $\alpha=0.1$.

\section{RESULTS}

We identified 27 territorial males in 2008 and 38 in 2009 across all sites. At individual sites, number of males ranged from a low of 4 (Coberly Sods South in 2008) to a high of 13 (Hoover in 2009, Appendices 1 and 2). Sixty percent of males were observed with a female during the breeding season.

A total of 139 and 180 playback surveys were completed in 2008 and 2009, respectively. Summing detections from each protocol across all seasons and times of day, 150 males and nine females were detected using the GOWAP protocol, compared to 165 males and six females using the Type 2 protocol. These detections do not necessarily represent unique individuals, but the sum of observations made during different seasons or times of day. On two occasions, both using AM surveys in the middle season for the entire 10-min Type 2 protocol, we detected one more male than there were known territories at a site (Appendix 2). Male Brewster's Warbler hybrids were detected on four and two different occasions using the type 1 and type 2 surveys, respectively. One male Blue-wing was detected during a type 1 survey on 25 May 2008, but it was not found again. No individuals were labeled as introgressed.

Time of day. We detected a larger proportion of the known population of territorial Golden-wing males during AM (64.9 $\pm 3.1 \%)$ than PM surveys $(26.5 \pm 2.8 \%)$ averaging across song type and season. A similar pattern occurred within song types and seasons (Table 2). Detection probability ranged from $0 \%$ to $100 \%$ at a site across both times of day (Appendices 1 and 2). We were unable to detect $100 \%$ of the males at a site using PM surveys and four times we detected 0 males, all at Coberly Sods South. We detected at least one male per site on all AM surveys and twice we detected all of the known males (Appendices 1 and 2).

Season. Detections during 6 mins were distributed evenly across season for type 1 $\left(\chi_{2}^{2}=1.0, P=0.62\right)$ and type 2 surveys $\left(\chi_{2}^{2}=2.8, P=0.25\right.$; Table 3$)$. The distribution of observations across seasons did not differ by song type $\left(\chi_{2}^{2}=1.1, P=0.59\right)$. Based on a repeated 
measures ANOVA accounting for song type and year, season again did not have a significant effect on mean detection probability $\left(F_{2,8}=0.1, P=0.92\right.$; Table 1$)$. In general, as season progressed, detection probability did not show a dramatic decreasing trend as expected (Fig. 1). Ten-min passive point counts, however, did show a considerable decrease in detection probability between bout 1 (30 May-2 June, $72.2 \pm 0.2 \%$ ) and bout 2 (20-24 June, $23.1 \pm 7.7 \%$ ).

With playback, we detected over half of the known population of territorial Golden-wing males during all seasons and with both song types (Fig. 1, Table 3). The highest mean detection probability $(68.8 \pm 9.2 \%)$ occurred during the middle season using type 2 song playback, while the lowest mean detection probability $(50.4 \pm 8.6 \%)$ occurred during the late season using type 1 song. Standard error limits did not overlap for the middle and combined season comparisons of song type (Fig. 1).

The mean detection probability without playback during the late season $(40.4 \pm 6.0 \%)$ is analogous to a 3 -min BBS point count. We detected $100 \%$ of males using BBS analogous point counts at a site on two occasions (Appendices 1-2).

Without and with playback. Detection probability did not differ significantly between 10-min surveys with type 2 song playback $(80.2 \pm 6.8 \%)$ and 10-min passive point counts $(72.2$ $\pm 7.0 \%$ ) conducted during the middle season (paired $t_{9}=0.9, P=0.39$ ), although type 2 surveys often detected $\geq 20 \%$ more males (Fig. 2). Over the initial 6 mins, we detected slightly more Golden-wing males with type 2 surveys $(73.3 \pm 3.0 \%)$ compared to passive point counts $(66.0 \pm$ $8.1 \%)$ and type 1 surveys $(52.5 \pm 10.4 \%)$ during the middle season pooling detections across sites (Fig. 3).

We detected $100 \%$ of the known population at a site during the initial 3-min interval without playback only two times. When playback was added, detection probability was $100 \%$ at five additional sites, four of these used type 2 song. Accounting for season using the CMH test, the distribution of observations without and with playback was independent of song type $\left(M^{2}{ }_{1}=0.01, P=0.90 ;\right.$ Table 3).

If we consider pre-playback and playback as independent survey periods (Table 4), we detected a slightly smaller proportion of individuals during playback $(36.9 \pm 3.0 \%)$ compared to pre-playback $(43.3 \pm 2.0 \%)$ using type 1 surveys across all seasons. Pre-playback $(49.8 \pm 6.2 \%)$ and playback $(50.2 \pm 3.0 \%)$ were almost identical using type 2 surveys overall. This comparison 
suggests that although song playback may elicit responses from additional males, it can interfere with an observer's hearing.

Song type. Song type had a significant effect on mean detection probability based on the repeated measures ANOVA $\left(F_{1,14}=4.45, P=0.05\right.$; Table 1$)$. Because there was no effect of year or season on detection probability and no interactions, we also compared overall detection probability of type 1 and 2 surveys using a paired t-test (paired $t_{29}=-1.8, P=0.08$ ). We detected $51.8 \pm 1.2 \%$ using type 1 surveys and $60.9 \pm 4.1 \%$ using type 2 surveys, overall (Table 3 ). Across all AM surveys, type 2 song playback increased detection probability slightly more (11.1 $\pm 2.1 \%)$ than type 1 song playback $(8.5 \pm 2.1 \%)$, and the confidence intervals overlap.

If we consider just the 3 mins of playback (Table 4), we detected more Golden-wing males with type 2 song $(50.2 \pm 3.0 \%)$ than type 1 song $(36.9 \pm 3.0 \%)$ on average. This comparison may reveal information about song type and its effect on detection probability both in how birds respond and how songs interfere with an observer's hearing.

Playback duration. With type 1 song, mins 4, 5, and 6 (playback) increased overall detection probability by $1.1 \pm 0.2 \%, 3.8 \pm 1.2 \%$, and $4.2 \pm 0.7 \%$, respectively, while mins 4,5 , and 6 of type 2 song increased overall detection probability by $4.4 \pm 1.8 \%, 4.7 \pm 2.3 \%$, and $3.0 \pm$ $0.5 \%$, respectively (Fig. 4). Over the same mins of passive point counts but only during the middle season, overall detection probability increased by $3.7 \pm 3.7 \%, 5.0 \pm 2.4 \%$, and $5.3 \pm 5.3 \%$ (Fig. 3). The previous values are the increases in new individuals not detected during the initial 3-mins of each survey. Summing detections during each minute, we did detect a larger proportion of the actual population as duration of playback increased for type 1 (min-4=25.3 \pm $4.3 \%$, min- $5=30.1 \pm 8.2 \%$, min- $6=33.4 \pm 3.6 \%)$ and type 2 song $(34.2 \pm 5.3 \%, 38.6 \pm 0.9 \%, 41.9$ $\pm 5.0 \%$ ). These values are the sums of individuals detected during each minute.

Behavioral response. We visually detected $59(59 / 120=49.2 \%)$ and $41(41 / 136=30.1 \%)$ males using the entire GOWAP and Type 2 protocols during AM surveys, respectively. Thus, visual detections were dependent on protocol type $\left(\chi_{1}^{2}=8.9, P=0.003\right)$. Fifty-seven $(57 / 101=56.4 \%)$ and $64(64 / 122=52.5 \%)$ detections included a behavioral response to the 3-mins of type 1 and type 2 song playback, respectively, so occurrence of a response was not dependent on song type $\left(\chi_{1}^{2}=0.2, P=0.65\right)$. Of males that showed a behavioral response, multiple responses by a single male were more common than expected with type 1 song $\left(34 / 57=59.6 \%, \chi^{2}{ }_{1}=9.8\right.$, $P=0.002)$ compared to type 2 song $(19 / 64=29.7 \%)$. 
Approaching the observer, increasing rate of singing, and initiating type 1 song made up the majority of responses (71.3\%) elicited by each song playback type (Table 5). Responses summed across seasons for the three categories were not dependent on song type $\left(\chi_{2}^{2}=4.0\right.$, $P=0.14)$; nor were they when controlling for seasons with the CMH test $\left(M^{2}{ }_{2}=4.0, P=0.14\right)$. Sums of responses were not distributed evenly across seasons for type $1\left(\chi_{2}^{2}=20.2, P<0.001\right.$; Table 5) or type 2 song $\left(\chi_{2}^{2}=13.4, P=0.001\right.$; Table 5).

Mean first detection distances were $61.9 \pm 3.5 \mathrm{~m}$ and $61.3 \pm 3.7 \mathrm{~m}$ for type 1 and type 2 surveys, respectively, and the greatest detection distance was estimated at $190 \mathrm{~m}$. On average, individuals approaching the survey station moved from $52.6 \pm 4.7 \mathrm{~m}$ to $10.0 \pm 1.8 \mathrm{~m}$ in response to type 1 song and from $41.5 \pm 5.5 \mathrm{~m}$ to $12.3 \pm 1.7 \mathrm{~m}$ in response to type 2 song. The approach response tended to weaken in frequency (Table 5) and distance as season progressed (type 1: early $=10.6 \pm 2.9 \mathrm{~m}$, middle $=4.9 \pm 1.9 \mathrm{~m}$, late $=14.2 \pm 3.6 \mathrm{~m}$; type $2: 10.9 \pm 2.2 \mathrm{~m}, 13.0 \pm 3.1 \mathrm{~m}$, $14.6 \pm 4.9 \mathrm{~m}$ ), with the exception of the middle season using type $1 \mathrm{song}$. Most approaches were within $10 \mathrm{~m}$ for both type $1(66.7 \%)$ and type $2(60.5 \%)$ song playback (Fig. 5).

\section{DISCUSSION}

On two occasions during the middle time period, we detected more Golden-wing males than there were known territories at a site. Males were probably not double-counted because most individuals were banded, territory density was relatively low, and surveys at a site were completed rapidly in a single morning in most cases. It is unlikely that these were transient migrants because the middle season surveys started on 22 May. It is possible that the extra males were displaced or moved from a nearby patch of habitat (Murray and Gill 1976). On our study sites in 2009, there were several instances where males shifted or established a late territory, many times during the span of less than one week during late May. One male at Hoover was displaced by a late arriving male on 23 May and moved over a $\mathrm{km}$ to the north end of the study site. A male on the same site was banded on 22 May about a $\mathrm{km}$ away from where he began establishing a territory the next day. At Coberly Sods South, two males that established territories were first observed on 21 May. A male arrived at Coberly Sods North on 19 May and almost immediately was seen defending a territory and copulating with a female. These shifts and late arrivals do not explain the surplus of males though. It may be that the extra males were displaced or late arrivers but did not establish territories on the sites where they were detected; hence, they were not part of the known population for that site. 
Alternatively, there may have been a few inconspicuous individuals that did not establish territories, but "floated" among the population of territorial males (Brown 1969). Probst (1986) suggested that floaters could be present in a population of an even rarer species, the Kirtland's Warbler (Dendroica kirtlandii), although habitat is more limited in that case. Although not included in our analysis, we detected a Brewster's Warbler hybrid at the Hoover site on 3 June during a playback survey, the only occasion we observed this male. A male Golden-wing that sang a Blue-wing song spent the early part of each breeding season defending a territory before floating around Forinash attempting extra-pair fertilizations. He was captured and banded in 2008 visiting a nest site on another male's territory. We captured a second year (SY) Goldenwing male on 5 May 2009 that had been banded the previous year as a nestling. We made positive identification of this individual only one more time during the next few days, so he may have dispersed or was a cryptic floater. Either way, it could be possible that the unmated or floating population is mostly made up of young males or hybrids (Newton 1992, K. Aldinger pers. obs.). Of territorial males banded during 2008-2009, 30\% were SY males. Whether floating behavior in this species, if it occurs much at all, is driven by habitat or female availability (Marra and Holmes 1997) remains to be seen. Our evidence of floating male Golden-wings is limited and definite conclusions can not be made.

Time of day. Morning survey protocols are the norm for monitoring landbird populations (Ralph et al. 1995, Bibby et al. 2000). Published accounts of PM surveys for songbirds are rare, and this is the first study to report PM survey data for Golden-wings. Some studies have included PM surveys to augment detections for certain species, including Bicknell's Thrush (Catharus bicknelli; Rimmer et al. 1996), Sora (Porzana carolina) and Virginia Rail (Rallus limicola; Dobkin and Rich 1998), and Black Rail (Laterallus jamaicensis; Conway et al. 2004), or an entire avian community (Mažeika et al. 2009). Unless the study objective is to estimate the composition of the entire avian community, where some birds (e.g., owls, aerial insectivores, water-associated species) may be more detectable during the evening (Mažeika et al. 2009), AM surveys alone should suffice and generally are more effective than PM surveys. We suspected that this would be the case at the onset of our investigation, but we were curious to what extent we could detect Golden-wings during the evening on grazing areas in West Virginia, in case constraints limited survey efforts by researchers to nontraditional times. On average across the 2008 breeding season, almost 2.5 times more Golden-wings were detected on AM 
surveys compared to PM surveys regardless of playback type. A researcher conducting 6-min PM playback surveys on sites similar to ours could only expect to discover about a quarter of the true population of Golden-wings on average, compared to almost two-thirds with AM surveys.

Season. Several publications have asserted that Golden-wings sing less frequently (Ficken and Ficken 1967, Highsmith 1989, Confer 1992) or are less responsive to song playback (Kubel and Yahner 2007) as the breeding season progresses. We did see some evidence for a decrease in mean detection probability as season advanced; however, the difference between early, middle, and late seasons was not significant and detection probability peaked during the middle season for 3-min surveys without playback and 6-min type 2 surveys (Table 3 ). The difference may have been less obvious in our data because our last surveys were completed on 7 June, and we could have missed the time during which singing decreases markedly. Kubel and Yahner (2007), whose study area was over $200 \mathrm{~km}$ north of ours, conducted surveys up to 17 June and reported slight decreases in detection and response rates as time progressed. Mean detection rate during 3-min counts with playback showed a slight decreasing trend in the clearcut $(20-31$ May=39.0 $\pm 9.9 \%, 1-10$ June $=28.3 \pm 0.7 \%, 11-17$ June $=20.1 \pm 4.0 \%)$ and ROW habitat $(83.3 \pm 9.6 \%, 81.7 \pm 1.7 \%, 71.7 \pm 11.7 \%)$, although statistical analyses were not presented (Table 2 in Kubel and Yahner 2007). Ten-min passive point counts conducted beginning 20 June both years on our sites detected only about $23 \%$ of the known population of Golden-wing males, compared to $72 \%$ detected during an earlier bout beginning 30 May. Another reason the early season was not characterized by significantly higher detection probability is that a few males still were establishing and shifting territories up until about 23 May in 2009. Murray and Gill (1976) noted that 3 males in southern Michigan arrived on territory between 31 May and 7 June, perhaps because of local dispersal. Our survey dates were based on the Golden-winged Warbler Atlas Project (CLO 2008) and information in Hall (1983). Nest building behavior was observed as early as 5 May and first egg dates ranged from 13 May to 6 June, so we do not believe that survey times were too early during the breeding season. We did not include later surveys because one of our main objectives was to have results relevant to the BBS, which occurs in early June at most locations.

Our BBS comparable results from the late season interval suggest that an observer would only detect about $40 \%$ of the true population of male Golden-wings during surveys of grazing areas. This estimate should be a highly accurate representation of BBS results from our study 
sites because of the intensive study design involving two years of replication and repeated sampling within each year. Confer et al. (2008) reported much lower detection rates for Goldenwings (3\%) using BBS style counts. During their BBS comparable season (1-17 June), Kubel and Yahner (2007) observed mean detection probability of $18.3 \pm 3.1 \%$ and $58.3 \pm 8.3 \%$ using 3min passive point counts on clearcuts and utility ROWs, respectively; our sites fall in the middle of these. Incorporating a time of day correction factor of 1.32 (Rosenberg and Blancher 2005) did not yield detection probability of 100\% in Kubel and Yahner (2007) or Confer et al. (2008) and would not in our study. Grazing areas on the Monongahela National Forest in West Virginia are relatively open compared to Golden-wing habitat in other parts of the range (e.g., Roth and Lutz 2004, Kubel and Yahner 2008), yet we were still unable to detect 100\% of known population of males at a site during late season 3-min passive point counts. In fact, only two times across all surveys, times of day, and season were we able to detect the entire population of males at a site using the initial 3-min survey period.

The habitats studied on our grazing areas would seem to be ideal for affirming the $200 \mathrm{~m}$ maximum detection distance assumption in Rosenberg and Blancher (2005), as our study sites generally are located on ridge-tops, surrounded completely by intact forest, and interspersed with large unobstructed grassy areas. These habitat characteristics ensured that territorial males were present within $200 \mathrm{~m}$ of the sample point and that their songs generally would be unhindered by topography or vegetation. In fact, the study was designed to ensure that Golden-wings could be detected within $200 \mathrm{~m}$ of the sample point, a luxury not afforded by BBS routes. Therefore, detectability should have been high. However, data from surveys would underestimate the actual population size because we were unable to detect $100 \%$ of the males within $200 \mathrm{~m}$ of survey stations on average. As other authors have suggested (Kubel and Yahner 2007, Confer et al. 2008), estimating populations of Golden-wings from BBS data requires that distance assumptions are altered or additional correction factors applied beyond those of Rosenberg and Blancher (2005). Golden-wings face a variety of threats (Buehler et al. 2007) and populations have steadily declined (Sauer et al. 2008), but population estimates (Rosenberg and Blancher 2005) guiding conservation efforts for this and other species cannot be based on erroneous methods (Kubel and Yahner 2007, Confer et al. 2008). Fortunately, Rosenberg and Blancher (2005) encouraged refinement of their method (e.g., correction factors) and supplementary data (e.g., playback surveys) for more accurate estimates. 
Without and with playback. On average, we detected similar proportions of the actual population of Golden-wing males during the initial passive listening periods of both playback surveys. In one case during the middle season, we detected considerably more males during type 2 survey pre-playback $(62.0 \pm 8.3 \%)$ than type 1 survey pre-playback $(46.4 \pm 7.8 \%)$. We attempted to control for this by estimating the percent increase in detection probability with playback. Still, both types of song playback resulted in marginal increases in detection probability. Our comparison of the playback surveys to passive point counts suggested that the inclusion of song playback did not increase detection probability above what was seen during passive counts. In a study of winter singing behavior of Carolina Wrens (Thryothorus ludovicianus), a species that is permanently territorial, Strain and Mumme (1988) found that song playback did not significantly increase singing rate, although food availability and temperature may supersede intruder presence as a cause of vocal response. Further, we found no significant difference between the distribution of detections with and without playback between song types. Song playback is an effective survey technique for some bird species (Johnson et al. 1981, Conway and Gibbs 2005) and increases detection probability (Kubel and Yahner 2007) and singing activity (Highsmith 1989) for Golden-wings. To parallel the methods used in Kubel and Yahner (2007), with the entire 10-min type 2 survey we detected similar proportions of the known population during the 4-min post-playback period (53.2 $\pm 4.4 \%)$ and the 3 -min preplayback period $(49.8 \pm 5.6 \%)$, although the post-playback period was 1 min longer than the preplayback period. This playback effect comparison was not possible with the type 1 survey because there was no passive listening period after the 3 mins of playback. Kubel and Yahner (2007) found a larger difference between pre-playback (clearcut=23.3 $\pm 5.0 \%, \mathrm{ROW}=30.5 \pm$ $5.0 \%)$ and post-playback $(30.5 \pm 5.0 \%, 79.5 \pm 4.9 \%)$ than our study.

When we examined detection probability before and during playback independently, we found that detection probability was similar between the pre-playback and playback periods for type 2 surveys, and detection probability was greater during pre-playback than during the period of type 1 song. Type 1 song could, therefore, cause more aural interference than type 2 song, or type 2 song playback actually increased the detection probability of males more than type 1 song. Approaching the playback effectiveness question by considering pre- and post-playback periods independently is confounded first by the carry-over effect of males observed during pre-playback and second by the interference of playback on an observer's hearing. We do not downplay the 
usefulness of song playback for increasing detections of some species (Johnson et al. 1981, Kubel and Yahner 2007); however, there may be such a thing as too much song playback and we stress the importance of using passive listening after periods of playback.

Song type. Based on the results of the ANOVA $(P=0.05)$ and paired t-test $(P=0.08)$, the effect of song type on detection probability was significant, such that on average we detected $9.1 \%$ more of the known population using the 6-min type 2 survey than the type 1 survey. Highsmith (1989) found that in response to both song playback types, overall singing activity increased. If we considered just the 3-min playback periods, we detected more Golden-wing males with type 2 song compared to type 1 song. The disparity here could be due to differences in the way the two songs interfered with the observer's ability to hear; however, both song types were played at the same volume and the type 2 recording actually had two more songs per min than the type 1 recording. Type 2 song is usually repeated more frequently $(8.8 \pm 2.2$ [SD] songs/min) than type 1 song $(3.9 \pm 0.6[\mathrm{SD}]$ songs/min) by male Golden-wings (Highsmith 1989). Overall, the type 1 and 2 surveys performed differently in regards to detection probability, as might be expected because the two song types differ markedly in function (Ficken and Ficken 1967, 1969, 1973, Highsmith 1989). In areas where Blue-wings and hybrids are rare or absent, type 2 song playback may be more effective than type 1 song for increasing detection probability of Golden-wings. However, because type 2 songs are practically identical between Golden-wings and Blue-wings, in areas of sympatry using type 2 song playback could elicit strong responses from both species (Gill and Murray 1972) and further complicate aural identification.

Playback duration. It is difficult to assess how detection probability is dependent upon playback duration. There were no minute intervals during playback in which detection probability increased by more than $5 \%$ on average. When we broke down each survey by minute, increases in detection probability were quite similar regardless of song type or use of playback at all. The effect of a longer duration of playback may have been masked by the survey structure, because many of the males that responded to playback may have already been detected during earlier minutes and thus were not reflected as an increase of new individuals. We did detect more males as playback duration of both song types increased, potentially a result of males gradually approaching the observer or responding to the prolonged stimulus. So, detection 
probability showed an increasing trend with playback duration; however, many of these individuals were already detected during the initial 3-min listening period.

Kubel and Yahner (2007) used 1.3 mins of type 1 song playback and noted 7\% and 19\% net increases in clearcuts and utility ROWs, respectively. Our approach was slightly different, but if we compare pre- and post-playback as in Kubel and Yahner (2007), we detected similar proportions of the known population pre- and post-playback. Habitat structure and patch dimensions apparently have much to do with detection probability for this species (Kubel and Yahner 2007), with males being easier to detect in open linear habitats. The grazing areas we studied in West Virginia were characterized by relatively high detection probability without playback, similar to their utility ROWs, but playback did little to increase detection probability, similar to their clearcuts. Duration of playback may increase the potency of the song (Kroodsma 1986), but 3 mins of song playback may be too long. While we anticipated a longer duration of playback would elicit more and stronger responses, the tradeoff of not being able to hear as well during playback may not be worth it. This is evidenced by our data: overall mean detection probability was slightly higher using the 10-min type 2 protocol $(68.8 \pm 6.1 \%)$ compared to the 17-min GOWAP protocol $(60.5 \pm 1.1 \%)$. The type 2 protocol had 3 mins of playback and 7 mins of passive listening, while the GOWAP protocol had 11 mins of playback and 6 mins of passive listening. Even though the type 2 protocol was 7 mins shorter, we were able to detect more Golden-wing males on average, probably because there were 8 less mins of playback to interfere with hearing and more consecutive minutes of passive listening. Thus, we recommend using a relatively short duration of song playback (1-1.3 mins) followed by several consecutive minutes of passive listening, as most males seem to respond rapidly to conspecific song playback and observers need periods of silence to detect intermittently singing or weakly responding males.

Behavioral response. Across the entire survey period, we made visual confirmation of a significantly larger proportion of males detected using the GOWAP protocol than the type 2 protocol. The higher proportion of visual confirmation of males and females using the GOWAP protocol is likely due to the length of the protocol and the mobbing sequence which caused birds to approach the observer. Visual identification is important when surveying for Golden-wings, Blue-wings, and their hybrids because song interchange occurs in this complex (Gill and Murray 1972, Ficken and Ficken 1967, Confer 1992). We observed several Golden-wing males singing 
type 1 Blue-wing songs. One male on Forinash in 2008 sometimes added Golden-wing bee notes after his rendition of a Blue-wing song, but sang a more typical type 1 Golden-wing song when he returned to the same site in 2009. A male on Coberly Sods South sang a typical type 1 Golden-wing song until a Blue-wing male established an adjacent territory at which point the Golden-wing was heard singing a type 1 Blue-wing song.

Type 1 songs generally are associated with mate attraction, while type 2 songs are associated with male-male interactions, early morning singing bouts, and flight displays (Ficken and Ficken 1967, Highsmith 1989). Our data suggest that Golden-wings on grazing areas in West Virginia show similar behavioral responses to type 1 and 2 song recordings. Overall response rates and type of response did not differ by song type. The only statistically significant finding relating to song type was that the frequency of single and multiple responses from an individual was dependent on song type; type 1 song was skewed toward eliciting multiple responses. Perhaps an intruding male singing a mate attraction song is perceived as more of a threat, hence, the more involved response of the territorial male. Ficken and Ficken (1967) suggested that type 2 songs are given when there is a strong escape tendency. In other words, territorial Golden-wings might show a less elaborate response to type 2 song because they perceive the intruder in a subordinate escape position. Highsmith (1989) found that the percent of males singing type 2 song increased during periods of song playback and decreased during periods of silence, while the percent of males singing type 1 showed the opposite trend, regardless of playback type. Based on these results, we might expect to see a high proportion of type 2 song initiation and song type switching and a lower proportion of type 1 song initiation; however, the opposite occurred in our study. Further, in a study of four warbler species each with two different song types, Ficken and Ficken (1970) found that American Redstarts (Setophaga ruticilla), Black-throated Green Warblers (Dendroica virens), and Chestnut-sided Warblers (Dendroica pensylvanica) tended to sing relatively more songs of the type being broadcast; a trend not obvious in our data. Initiation of type 1 song may aid in positive identification of Golden-wings and Blue-wings, since type 2 songs of these species are similar.

Approaching the observer is a common response by Golden-wings to conspecific song playback (Ficken and Ficken 1969, 1973, Kubel and Yahner 2007). Regardless of song type, about $40 \%$ of all responses were approaches, approach distance generally weakened over time, and the majority of approaches were within $10 \mathrm{~m}$. Golden-wing responses were not evenly 
distributed across seasons, showing a decreasing trend as season progressed, similar to results of Kubel and Yahner (2007). Overall, we did observe similar behavioral responses as Kubel and Yahner (2007), except that increasing the rate of singing was more prominent in our data. Both our study and Kubel and Yahner (2007) used a repeated measures design, so while it is probable that the decreasing incidence of behavioral responses as season progressed is a legitimate finding, habituation to song playback is a possible explanation (Dong and Clayton 2009). However, Golden-wings do sing less frequently and generally are inconspicuous as season progresses (Ficken and Ficken 1967, Highsmith 1989, Confer 1992). In White-crowned Sparrows (Zonotrichia leucophrys), and likely in Golden-wings, responses to repeated song playback may be contingent on different stages of the breeding season (Petrinovich and Patterson 1979). Further, anecdotally, during GOWAP surveys of suitable habitats outside of the study sites where males had not been subjected to repeated bouts of song playback, we observed fewer and weaker responses near the end date of the survey period (15 June, KRA, pers. obs.).

Conclusions. Song playback can be a useful tool for eliciting responses from songbirds that may have otherwise gone undetected during passive counts (Johnson et al. 1981, Kubel and Yahner 2007). Surveys for Golden-wings should include a brief playback period coupled with passive listening. Lengthy periods of playback, although they may attract slightly more individuals than a shorter playback session, could inhibit an observer's ability to detect some males, especially those that display a weak response to playback or are near the maximum detection distance. If the objective of surveys is to maximize detection probability, the nominal gain of longer playback is probably not worth the lost ability to detect cryptic individuals. From our experience, most males respond to song playback almost immediately, so a playback period of 1-1.3 mins (Kubel and Yahner 2007), with 4-6 type 1 or 8-9 type 2 songs per min to reflect natural singing rates (Highsmith 1989) and maximize stimulus delivery, likely is sufficient. This playback period followed by at least 3 consecutive mins of passive listening affords an observer the opportunity to survey more habitat, albeit at a detection rate $<100 \%$, in a shorter time period than would be required to detect all males.

Six-min playback surveys during the morning between 10 May and 7 June revealed about $50-60 \%$ of the known population of Golden-wing males on our study sites, while BBS style counts in early June detected even fewer males (40\%). The optimal time within this window was mid- to late-May, being late enough to ensure that most males have arrived and dispersed locally 
but early enough to avoid a decrease in singing (Ficken and Ficken 1967, Highsmith 1989) or response rates (Kubel and Yahner 2007).

Studies have postulated that the two Golden-wing song types have different functions (Ficken and Ficken 1967, Highsmith 1989, Confer 1992). In terms of their effectiveness in playback surveys, detection probability was higher with type 2 than type 1 song, while behavioral responses were similar for both song types. Regardless of the increase in detection probability as a result of playback, broadcast surveys for this species caused individuals to respond in a way that made them visually identifiable in some cases. Visual confirmation is important because song interchange occurs between Golden-wings, Blue-wings, and their hybrids. Misidentification could cause problems when estimating population size in the rare case that a Golden-wing sings a Blue-wing song (or vise versa), or if a hybrid, which would legally not be considered a part of either population, was mistaken for one of the parent species.

We conclude that assuming an observer can detect 100\% of Golden-wings within $200 \mathrm{~m}$ is invalid at any time during the breeding season, as observed in other studies (Confer et al. 2008) even with the use of song playback (Kubel and Yahner 2007). Three studies now have contradicted this assumption, even given study designs to ensure that all detections within $200 \mathrm{~m}$ were possible and surveyors knew precisely where males should be detected during counts, advantages that BBS counters probably would not have. Potential revisions to the maximum detection distance assumption to 125 m (P. Blancher pers. comm. in Confer et al. 2008) should lessen the error in population estimates for Golden-wings, but observers are still unlikely to detect $100 \%$ of males (Confer et al. 2008). BBS style counts, and even 10 and 17-min point counts with playback, are insufficient for detecting all territorial males. While a single speciesspecific correction factor is an attractive solution to error associated with converting relative counts into absolute population estimates, variability in singing and, consequently, detection rates across time (Borror 1961, Highsmith 1989, Ficken and Ficken 1967), habitats (Kubel and Yahner 2007, our study), observers (Sauer et al. 1994), geographic range (Buskirk and McDonald 1995, Confer et al. 2008), and weather conditions (Huffman 1997), complicates this objective considerably. Complex models incorporating these sources of variation may be needed if conservation priorities continue to partly be based on BBS-derived population estimates. 


\section{Literature Cited}

Bibby, C. J., N. D. Burgess, D. A. Hill, And S. H. Mustoe. 2000. Bird Census Techniques. $2^{\text {nd }}$ ed. Academic Press, London, UK.

BORROR, D. J. 1961. Intraspecific variation in passerine bird songs. Wilson Bulletin 73:57-78.

BRown, J. L. 1969. Territorial behavior and population regulation in birds: a review and reevaluation. Wilson Bulletin 81:293-329.

Buehler, D. A., A. M. Roth, R. Vallender, T. C. Will, J. L. Confer, R. A. Canterbury, S. B. Swarthout, K. V. RosenberG, And L. P. Bulluck. 2007. Status and Conservation Priorities of Golden-winged Warbler (Vermivora chrysoptera) in North America. Auk 124:1439-1445.

BUSKIRK, W. H., AND J. L. MCDONALD. 1995. Comparison of point count sampling regimes for monitoring forest birds. In: Monitoring Bird Populations by Point Counts (C. J. Ralph, J. R. Sauer, and S. Droege, Eds.), pp. 25-34. USDA Forest Service General Technical Report PSW-GTR-149, Albany, CA.

CONFER, J. L. 1992. Golden-winged Warbler (Vermivora chrysoptera). In: The Birds of North America, no. 20 (Poole, A., P. Steenheim, and F. Gill, Eds.). Academy of Natural Sciences, Philadelphia, PA and American Ornithologists’ Union, Washington, D.C.

Confer, J. L., R. E. SERrell, M. HAGer, AND E. LAHR. 2008. Field tests of the RosenbergBlancher method for converting point counts to abundance estimates. Auk 125:932-938.

CLO. 2008. Golden-winged Warbler Atlas Project. Cornell Laboratory of Ornithology. Available at: http://www.birds.cornell.edu/gowap/.

COSEWIC. 2006. COSEWIC assessment and status report on the Golden-winged Warbler Vermivora chrysoptera in Canada. Committee on the Status of Endangered Wildlife in Canada. Ottawa, Ontario. vii + 30 pp. Available at: www.sararegistry.gc.ca/status/status_e.cfm.

Conway, C. J., C. Sulzman, And B. E. RAulston. 2004. Factors affecting detection probability of California Black Rails. Journal of Wildlife Management 68:360-370.

CONWAY, C. J., AND J. P. GiBBS. 2005. Effectiveness of call-broadcast surveys for monitoring marsh birds. Auk 122:26-35.

DoBKIN, D. S., AND A. C. Rich. 1998. Comparison of line-transect, spot-map, and point-count surveys for birds in riparian habitats of the Great Basin. Journal of Field Ornithology 69:430-443.

Dong, S., AND D. F. CLAYTON. 2009. Habituation in songbirds. Neurobiology of Learning and Memory 92:183-188.

FICKEN, M. S., AND R. W. FICKEN. 1967. Singing behavior of Blue-winged and Golden-winged Warblers and their hybrids. Behaviour 28:149-181. 
FICKEN, M. S., AND R. W. FICKEN. 1969. Responses of Blue-winged Warblers and Goldenwinged Warblers to their own and the other species' song. Wilson Bulletin 81:69-74.

FICKEN, M. S., AND R. W. FICKEN. 1970. Responses of four warbler species to playback of their two song types. Auk 87:296-304.

FICKEN, M. S., AND R. W. FICKEN. 1973. Effect of number, kind and order of song elements on playback responses of the Golden-winged Warbler. Behaviour 46:114-127.

GiLl, F. B., AND B. G. MurRAY. 1972. Discrimination behavior and hybridization of the Bluewinged and Golden-winged Warblers. Evolution 26:282-293.

Hall G. A. 1983. West Virginia Birds. Special Publication, no. 7, Carnegie Museum of Natural History, Pittsburgh, PA.

Highsmith, R. T. 1989. The singing behavior of Golden-winged Warblers. Wilson Bulletin 101: 36-50.

HiLl, N.P., AND J.M HAGAN III. 1991. Population trends of some northeastern North American landbirds: a half-century of data. Wilson Bulletin 103:165-182.

HufFMAn, R. 1997. Bird communities along a successional gradient in aspen clearcuts in Tamarac National Wildlife Refuge, Minnesota, with an emphasis on the Golden-winged Warbler and other non-game migrant birds. M.S. thesis, West Virginia University, Morgantown, WV.

Hutto, R. L., S. J. HeJl, J. F. Kelly, And S. M. Pletschet. 1995. A comparison of bird detection rates derived from on-road versus off-road point counts in northern Montana. In: Monitoring bird populations by point counts (Ralph, C. J., J. R. Sauer, and S. Droege, Eds.), pp. 103-110. USDA Forest Service General Technical Report PSW-GTR-149, Albany, CA.

Johnson R. R., B. T. Brown, L. T. HAight, AND J. M. Simpson. 1981. Playback recordings as a special avian censusing technique. In: Estimating numbers of terrestrial birds (Ralph, C. J. and J. M. Scott, Eds.), pp. 68-75. Studies in Avian Biology No. 6.

KLAus, N. A., AND D. A. BueHLER. 2001. Golden-winged Warbler breeding habitat characteristics and nest success in clearcuts in the southern Appalachian Mountains. Wilson Bulletin 113:297-301.

KROODSMA, D. E. 1986. Design of song playback experiments. Auk 103:640-642.

KuBEL, J. E., AND R. H. YAHNER. 2007. Detection probability of Golden-winged Warblers during point counts with and without playback recordings. Journal of Field Ornithology 78:195205.

KuBEL, J. E., AND R. H. YAHNER. 2008. Quality of anthropogenic habitat for Golden-winged Warblers in Central Pennsylvania. Wilson Journal of Ornithology 120:801-812.

MARRA, P. P., AND R. T. Holmes. 1997. Avian removal experiments: do they test for habitat saturation or female availability? Ecology 78:947-952. 
MAŽEIKA, S., P. SUlLIVAN, K. VIERLING. 2009. Experimental and ecological implications of evening bird surveys in stream-riparian ecosystems. Environmental Management 44:789799.

McDonald, J. H. 2009. Handbook of Biological Statistics, 2nd ed. Sparky House Publishing, Baltimore, MD.

MurRAY, B. G., AND F. B. GiLl. 1976. Behavioral interactions of Blue-winged and Goldenwinged Warblers. Wilson Bulletin 88:231-254.

NEWTON, I. 1992. Experiments on the limitations of bird numbers by territorial behaviour. Biological Reviews 67:129-173.

Panjabi, A. O., E. H. Dunn, P. J. Blancher, W. C. Hunter, B. Altman, J. Bart, C. J. Beardmore, H. Berlanga, G. S. Butcher, S. K. Davis, D. W. DEMARESt, R. DetTMers, W. Easton, H. Gomez de Silva Garza, E. E. IÑIgo-Elias, D. N. Pashley, C. J. Ralph, T. D. Rich, K. V. Rosenberg, C. M. Rustay, J. M. Ruth, J. S. WendT, AND T. C. WiLL. 2005. The Partners in Flight handbook on species assessment. Version 2005. Partners in Flight Technical Series No. 3. Rocky Mountain Bird Observatory. Available at: http://www.rmbo.org/pubs/downloads/Handbook2005.pdf.

PARKES, K. C. 1951. The genetics of the Golden-winged x Blue-winged Warbler complex. Wilson Bulletin 63:5-15.

Petrinovich, L., AND T. L. PATTERSOn. 1979. Field studies of habituation: I. Effect of reproductive condition, number of trials, and different delay intervals on responses of the White-crowned Sparrow. Journal of Comparative and Physiological Psychology 93:337350 .

Probst, J. R. 1986. A Review of factors limiting the Kirtland's Warbler on its breeding grounds. American Midland Naturalist 116:87-100.

R DeVelopment Core Team. 2008. R: A Language and Environment for Statistical Computing. R Foundation for Statistical Computing Vienna, Austria.

RAlPH, C. J., J. R. SAUER, AND S. DROEGE, Eds. 1997. Monitoring bird populations by point counts. General Technical Report. PSW-GTR-149. Pacific Southwest Research Station, Forest Service, U.S. Department of Agriculture, Albany, CA.

Rich, T. D., C. J. Beardmore, H. Berlanga, P. J. Blancher, M. S. W. Bradstreet, G. S. Butcher, D. W. Demarest, E. H. Dunn, W. C. Hunter, E. E. IÑigo-Elias, J. A. Kennedy, A. M. Martell, A. O. Panjabi, D. N. Pashley, K. V. Rosenberg, C. M. Rustay, J. S. WeNDT, AND T. C. WILl. 2004. Partners in Flight North American Landbird Conservation Plan. Cornell Lab of Ornithology. Ithaca, NY.

Rimmer, C. C., J. L. Atwood, K. P. McFarland, AND L. R. NAgy. 1996. Population density, vocal behavior, and recommended survey methods for Bicknell's Thrush. Wilson Bulletin 108:639-649.

RoBBins, C. S. 1970. An international standard for a mapping method in bird census work. International Bird Census Committee. Audubon Field Notes 24:722-726. 
ROSENBERG, K. V., AND P. J. BLANCHER. 2005. Setting numerical population objectives for priority landbird species. In: Bird Conservation and Implementation in the Americas: Proceedings of the Third International Partners in Flight Conference, vol.1 (Ralph, C. J., and T. D. Rich, Eds.), pp. 57-67. U.S.D.A., Forest Service, General Technical Report PSW-GTR-191, Albany, CA.

Roth, A. M., AND R. S. LUTZ. 2004. Relationships between territorial male Golden-winged Warblers in managed aspen stands in northern Wisconsin, USA. Forest Science 50:153161.

SAUER, J. R., J. E. Hines, AND J. FAllon. 2008. The North American Breeding Bird Survey, Results and Analysis 1966 - 2007. Version 5.15.2008. USGS Patuxent Wildlife Research Center, Laurel, MD.

SAUer, J. R., B. G. PeterJohn, AND W. A. Link. 1994. Observer differences in the North American Breeding Bird Survey. Auk 111:50-62.

SEWELL, A. 2010. Petition to list the Golden-winged Warbler (Vermivora chrysoptera) as a threatened or endangered species under the U.S. Endangered Species Act. Available at: http://gwwa.org/resources/Petition\%20to\%20List\%20GWWA_comp.pdf.

StRAin, J. G., AND R. L. Mumme. 1988. Effects of food supplementation, song playback, and temperature on vocal territorial behavior of Carolina Wrens. Auk 105:11-16.

Wilson, M. D., B. D. Watts, M. G. Smith, J. P. BredlaU, AND L. W. Seal. 2007. Status Assessment of Golden-winged Warblers and Bewick's Wrens in Virginia. Center for Conservation Biology Technical Report Series, CCBTR-07-02. College of William and Mary, Williamsburg, VA.

ZAR, J. H. 1999. Biostatistical Analysis. Prentice Hall, Upper Saddle River, NJ. 


\section{TABLES AND FigurES}

Table 1. Repeated measures ANOVA table comparing mean detection probability across the 6min survey period with song type, season, and year as main effects.

\begin{tabular}{lrrrrr}
\hline Error: Site $^{\mathrm{a}}$ & DF & Sum of Squares & Mean Squares & F & P \\
\hline Year & 1 & 0.05 & 0.05 & 0.27 & 0.63 \\
Residuals & 4 & 0.71 & 0.18 & & \\
\hline
\end{tabular}

Error: Site:Season ${ }^{\mathrm{b}}$

\begin{tabular}{llllll}
\hline Season & 2 & 0.05 & 0.03 & 0.09 & 0.92 \\
Season x Year & 2 & 0.66 & 0.33 & 1.06 & 0.39 \\
Residuals & 8 & 2.51 & 0.31 & & \\
\hline
\end{tabular}

Error: Site:Season:Song ${ }^{\mathrm{c}}$

\begin{tabular}{lrrrrr}
\hline Song & 1 & 0.38 & 0.38 & 4.45 & 0.05 \\
Song x Season & 2 & 0.15 & 0.08 & 0.90 & 0.43 \\
Song x Year & 1 & 0.00 & 0.00 & 0.05 & 0.83 \\
Residuals & 14 & 1.19 & 0.09 & & \\
\hline & & & & & \\
Error: Within $^{\mathrm{d}}$ & 1 & 0.05 & 0.05 & 0.22 & 0.15 \\
\hline Year & 1 & 0.35 & 0.35 & 1.54 & 0.23 \\
Song x Year & 2 & 0.04 & 0.02 & 0.08 & 0.92 \\
Season x Year & 20 & 4.54 & 0.23 & & \\
Residuals & & & & &
\end{tabular}

${ }^{\mathrm{a}}$ Site was a repeated factor

${ }^{\mathrm{b}}$ Season was a repeated factor nested within Site (Site:Season)

${ }^{\mathrm{c}}$ Song was a repeated factor nested within Season and Site (Site:Season:Song)

${ }^{\mathrm{d}}$ Each within-subjects factor is an independent variable that is manipulated by testing each subject (Site) at each level of the variable 
Table 2. Mean detection probability (\% of known territorial male population) in AM versus PM surveys in 2008 on grazing areas on the Monongahela National Forest, West Virginia.

\begin{tabular}{|c|c|c|c|c|c|c|}
\hline \multirow[b]{2}{*}{ Song Type } & \multirow[b]{2}{*}{ Time of Day } & \multirow[b]{2}{*}{ Season $^{b}$} & \multicolumn{2}{|c|}{ Pre-playback } & \multicolumn{2}{|c|}{ Playback $^{\mathrm{c}}$} \\
\hline & & & $\overline{\mathrm{x}}$ & $\mathrm{SE}$ & $\overline{\mathrm{x}}$ & $\mathrm{SE}$ \\
\hline \multirow[t]{8}{*}{ Type 1} & AM & Early & 65.6 & 14.2 & 76.1 & 8.8 \\
\hline & & Middle & 55.3 & 13.8 & 64.3 & 11.9 \\
\hline & & Late & 38.5 & 10.2 & 57.5 & 10.1 \\
\hline & & All AM & 53.1 & 7.9 & 66.0 & 5.4 \\
\hline & PM & Early & 23.1 & 12.9 & 37.2 & 14.8 \\
\hline & & Middle & 13.3 & 5.1 & 16.1 & 7.0 \\
\hline & & Late & 22.8 & 19.3 & 28.3 & 17.8 \\
\hline & & All PM & 19.8 & 3.2 & 27.2 & 6.1 \\
\hline \multirow[t]{8}{*}{ Type 2} & $\mathrm{AM}$ & Early & 43.8 & 17.1 & 59.9 & 14.9 \\
\hline & & Middle & 63.8 & 8.3 & 72.1 & 5.6 \\
\hline & & Late & 53.5 & 18.5 & 59.7 & 16.3 \\
\hline & & All AM & 53.7 & 5.8 & 63.9 & 4.1 \\
\hline & PM & Early & 14.8 & 7.4 & 26.9 & 3.3 \\
\hline & & Middle & 18.3 & 10.7 & 26.7 & 10.1 \\
\hline & & Late & 18.3 & 8.5 & 23.9 & 8.8 \\
\hline & & All PM & 17.2 & 1.2 & 25.8 & 1.0 \\
\hline
\end{tabular}

$\overline{{ }^{\mathrm{a}} \mathrm{AM}}=\mathrm{Dawn} / 0600-1000 \mathrm{EST}, \mathrm{PM}=1500-2000$

${ }^{\mathrm{b}}$ Early $=10-21$ May, Middle = 22 May-2 June, Late = 3-15 June

${ }^{\mathrm{c}}$ Detection probability for the entire 6-min survey

Table 3. Mean detection probability with and without playback during AM surveys using type 1 and 2 song in 2008 and 2009 on grazing areas on the Monongahela National Forest, West Virginia.

\begin{tabular}{|c|c|c|c|c|c|c|c|c|c|c|c|c|}
\hline \multirow[b]{3}{*}{ Season $^{\mathrm{a}}$} & \multicolumn{6}{|c|}{ Type 1 Survey } & \multicolumn{6}{|c|}{ Type 2 Survey } \\
\hline & \multicolumn{2}{|c|}{ Pre-playback } & \multicolumn{2}{|c|}{ Playback $^{b}$} & \multicolumn{2}{|c|}{$\%$ Increase $^{c}$} & \multicolumn{2}{|c|}{ Pre-playback } & \multicolumn{2}{|c|}{ Playback $^{b}$} & \multicolumn{2}{|c|}{$\%$ Increase $^{c}$} \\
\hline & $\overline{\bar{x}}$ & $\mathrm{SE}$ & $\overline{\overline{\mathrm{x}}}$ & $\mathrm{SE}$ & $\overline{\mathrm{x}}$ & $\mathrm{SE}$ & $\overline{\bar{x}}$ & $\mathrm{SE}$ & $\overline{\bar{x}}$ & $\mathrm{SE}$ & $\overline{\mathrm{x}}$ & $\mathrm{SE}$ \\
\hline Early & 44.0 & 9.1 & 54.2 & 9.0 & 10.2 & 3.4 & 46.1 & 10.2 & 58.9 & 10.6 & 12.9 & 3.7 \\
\hline Middle & 46.4 & 7.8 & 50.7 & 7.9 & 4.4 & 2.6 & 62.0 & 8.3 & 68.8 & 9.2 & 6.9 & 2.9 \\
\hline Late & 39.5 & 7.0 & 50.4 & 8.6 & 10.9 & 4.5 & 41.3 & 10.1 & 54.9 & 9.8 & 13.6 & 4.2 \\
\hline Overall & 43.3 & 2.0 & 51.8 & 1.2 & 8.5 & 2.1 & 49.8 & 6.2 & 60.9 & 4.1 & 11.1 & 2.1 \\
\hline
\end{tabular}

${ }^{\mathrm{a}}$ Early $=10-21$ May, Middle $=22$ May-2 June, Late $=3$-15 June

${ }^{\mathrm{b}}$ Detection probability for the entire 6-min survey

${ }^{\mathrm{c}}$ Increase in detection probability as a result of song playback period 
Table 4. Mean detection probability using type 1 and 2 song considering pre-playback and playback periods independently. Data were collected during AM surveys in 2008 and 2009 on grazing areas on the Monongahela National Forest, West Virginia.

\begin{tabular}{|c|c|c|c|c|c|c|c|c|}
\hline \multirow[b]{3}{*}{ Season $^{\mathrm{a}}$} & \multicolumn{4}{|c|}{ Type 1} & \multicolumn{4}{|c|}{ Type 2} \\
\hline & \multicolumn{2}{|c|}{$\begin{array}{l}\text { Without } \\
\text { Playback }\end{array}$} & \multicolumn{2}{|c|}{$\begin{array}{c}\text { With } \\
\text { Playback }\end{array}$} & \multicolumn{2}{|c|}{$\begin{array}{l}\text { Without } \\
\text { playback }\end{array}$} & \multicolumn{2}{|c|}{$\begin{array}{c}\text { With } \\
\text { Playback }^{\mathrm{b}}\end{array}$} \\
\hline & $\overline{\mathrm{x}}$ & SE & $\overline{\mathrm{x}}$ & SE & $\overline{\mathrm{x}}$ & SE & $\overline{\mathrm{x}}$ & SE \\
\hline Early & 44.0 & 9.1 & 42.9 & 8.0 & 46.1 & 10.2 & 47.5 & 8.8 \\
\hline Middle & 46.4 & 7.8 & 34.1 & 5.9 & 62.0 & 8.3 & 58.1 & 8.5 \\
\hline Late & 39.5 & 7.0 & 33.6 & 5.8 & 41.3 & 10.1 & 44.9 & 9.0 \\
\hline Overall & 43.3 & 2.0 & 36.9 & 3.0 & 49.8 & 6.2 & 50.2 & 4.0 \\
\hline
\end{tabular}

${ }^{\mathrm{a}}$ Early $=10-21$ May, Middle $=22$ May-2 June, Late $=3-15$ June

${ }^{\mathrm{b}}$ Detection probability of 3-min song playback period independent of pre-playback period.

Table 5. Total numbers of responses of male Golden-winged Warblers to 3 mins of type 1 and type 2 song in three time periods $($ Early $=10-21$ May, Middle $=22$ May-2 June, Late $=3-15$ June) during surveys of grazing areas on the Monongahela National Forest, West Virginia in 2008 and 2009.

\begin{tabular}{|c|c|c|c|c|c|c|c|c|c|c|}
\hline \multirow[b]{2}{*}{ Response } & \multicolumn{5}{|c|}{ Type 1} & \multicolumn{5}{|c|}{ Type 2} \\
\hline & Early & Middle & Late & Total $^{\mathrm{a}}$ & $\%$ of all ${ }^{\mathrm{b}}$ & Early & Middle & Late & Total $^{\mathrm{a}}$ & $\%$ of all ${ }^{\mathrm{b}}$ \\
\hline Initiate vocalization & 13 & 4 & 8 & 25 & 23.1 & 16 & 7 & 5 & 28 & 29.8 \\
\hline Initiate type 1 song & 8 & 1 & 5 & 14 & 13.0 & 9 & 4 & 4 & 17 & 18.1 \\
\hline Initiate chipping & 5 & 1 & 0 & 6 & 5.6 & 5 & 1 & 0 & 6 & 6.4 \\
\hline Initiate type 2 song & 0 & 2 & 3 & 5 & 4.6 & 2 & 2 & 1 & 5 & 5.3 \\
\hline Alter vocalization & 22 & 9 & 8 & 39 & 36.1 & 9 & 7 & 6 & 22 & 23.4 \\
\hline Increase song rate & 11 & 7 & 6 & 24 & 22.2 & 3 & 5 & 4 & 12 & 12.8 \\
\hline Mute song & 3 & 2 & 1 & 6 & 5.6 & 3 & 1 & 1 & 5 & 5.3 \\
\hline Shorten song & 5 & 0 & 0 & 5 & 4.6 & 1 & 0 & 0 & 1 & 1.1 \\
\hline Lengthen song & 2 & 0 & 0 & 2 & 1.9 & 2 & 0 & 0 & 2 & 2.1 \\
\hline Switch song type & 1 & 0 & 1 & 2 & 1.9 & 0 & 1 & 1 & 2 & 2.1 \\
\hline Territorial response & 23 & 11 & 10 & 44 & 40.7 & 21 & 17 & 6 & 44 & 46.8 \\
\hline Approach observer & 20 & 10 & 9 & 39 & 36.1 & 17 & 16 & 5 & 38 & 40.4 \\
\hline Territorial display & 3 & 1 & 1 & 5 & 4.6 & 4 & 1 & 1 & 6 & 6.4 \\
\hline Total $^{\mathrm{c}}$ & 58 & 24 & 26 & 108 & 100.0 & 46 & 31 & 17 & 94 & 100.0 \\
\hline
\end{tabular}

${ }^{\mathrm{a}}$ Row totals are summed across season for each response type

${ }^{\mathrm{b}}$ Percentage $=($ Row sum across seasons $) /($ Sum of all responses $) * 100$

${ }^{c}$ Column totals are summed across the three response categories (Initiate vocalization, alter vocalization, and territorial response) 


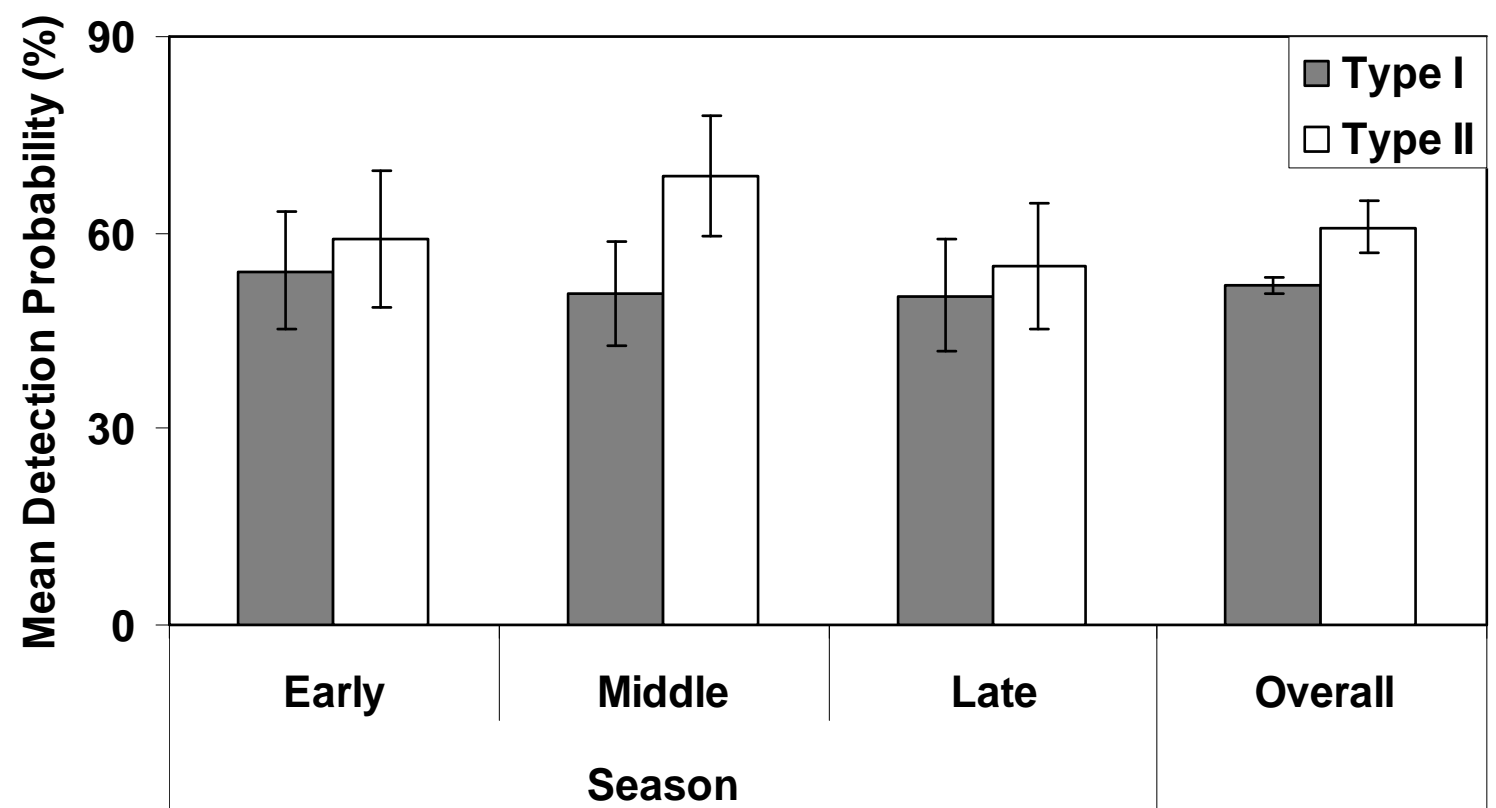

Figure 1. Mean detection probability ( $\pm \mathrm{SE}$ ) using type 1 and type 2 song playback during AM surveys in 2008 and 2009 on grazing areas on the Monongahela National Forest, West Virginia. Detection probability is based on the 6-min survey ( 3 mins of passive listening and 3 mins of song playback) during the early (May 10-21), middle (May 22-June 2), and late (June 3-15) seasons.

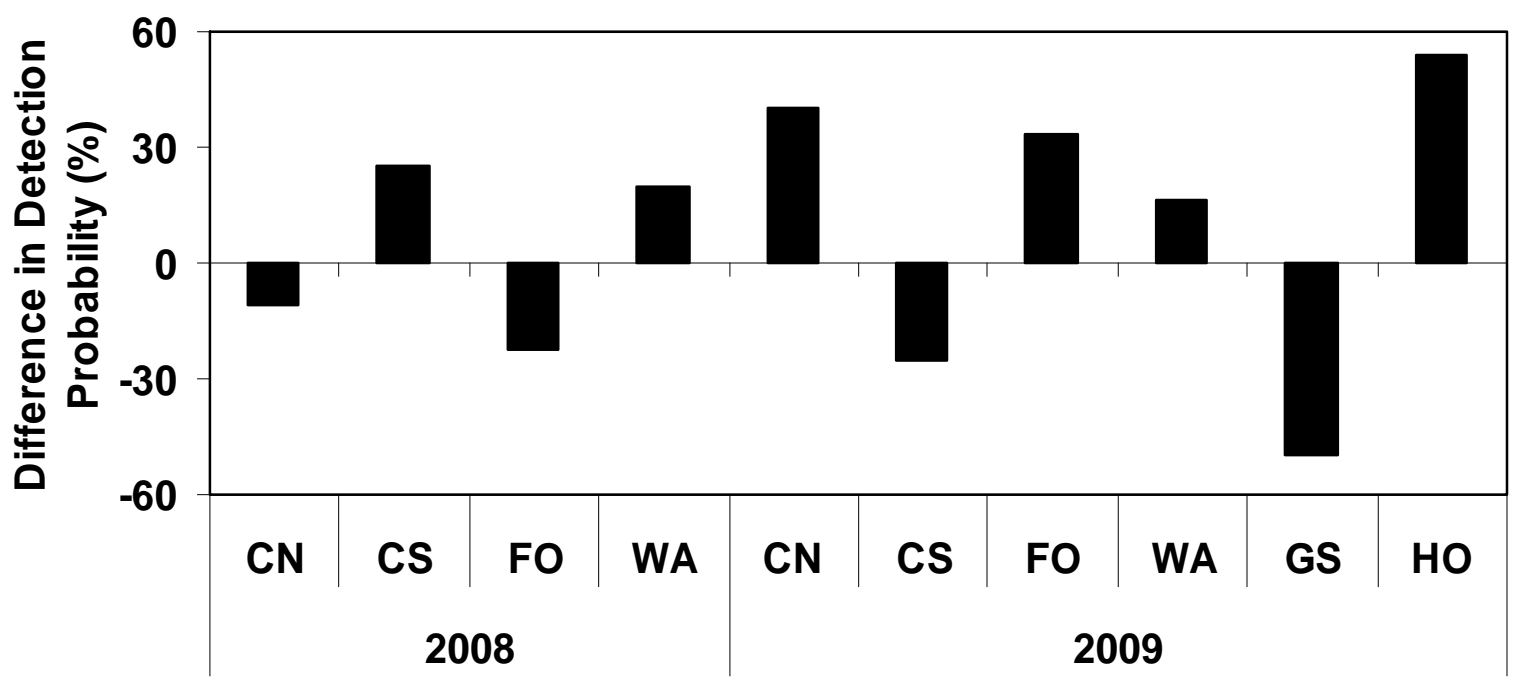

Site

Figure 2. Difference in detection probability by site $(\mathrm{CN}=$ Coberly Sods North, $\mathrm{CS}=$ Coberly Sods South, $\mathrm{FO}=$ Forinash, WA=Washout, GS=Gay/Sharp, $\mathrm{HO}=$ Hoover) between 10-min type 2 surveys and 10-min passive point counts. Y-axis values represent the difference in detection probability (Type 2 - Passive). The difference was not significant (paired $t=0.9, \mathrm{df}=9, P=0.39$ ). 


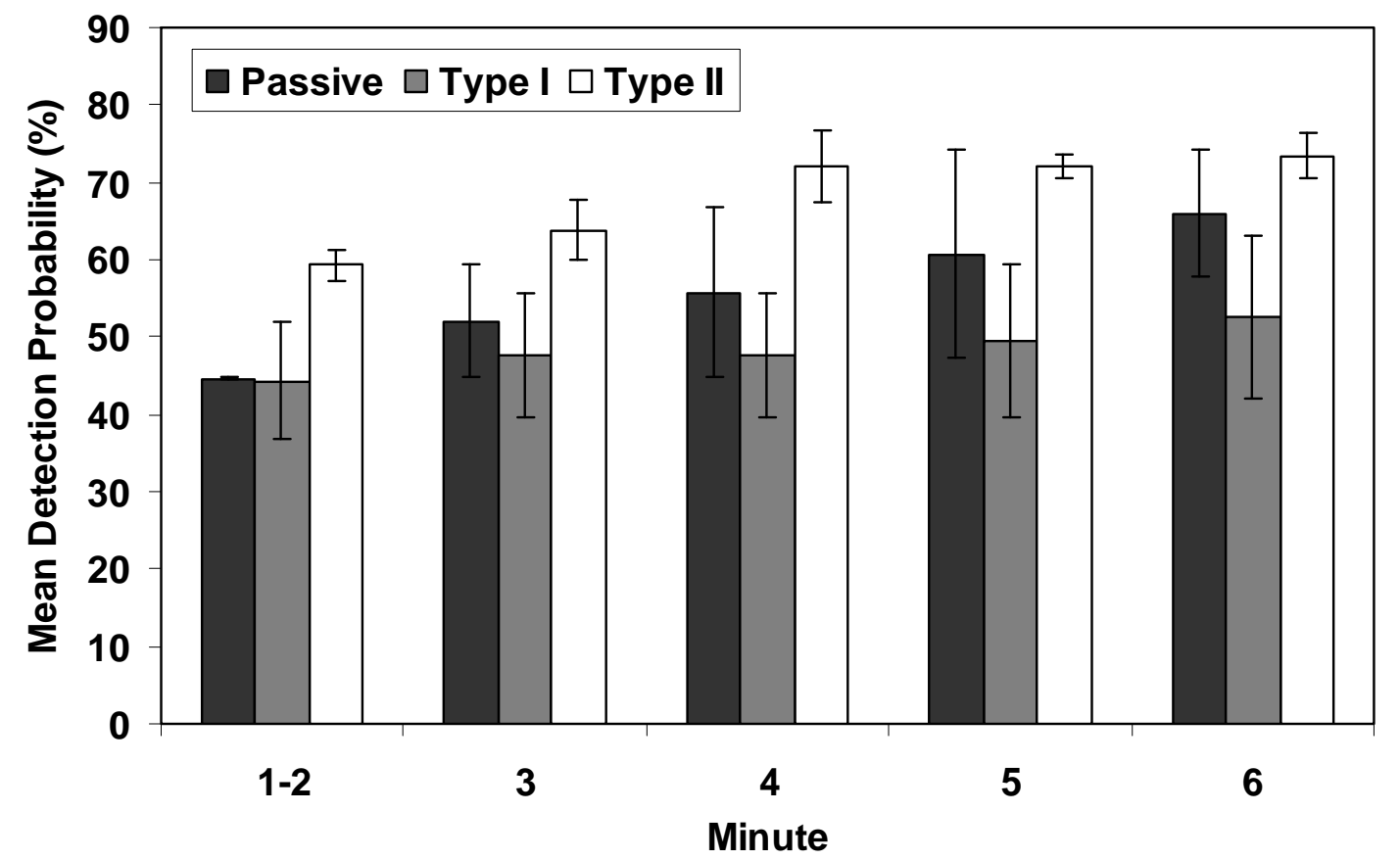

Figure 3. Mean cumulative detection probability $( \pm \mathrm{SE})$ by min during the middle season using type 1 and 2 surveys and passive point counts in 2008 and 2009 on grazing areas on the Monongahela National Forest. Data were pooled across sites and detection probability is the mean of the 2 years. The first 2 mins of the passive point count were grouped as one interval when data were collected.

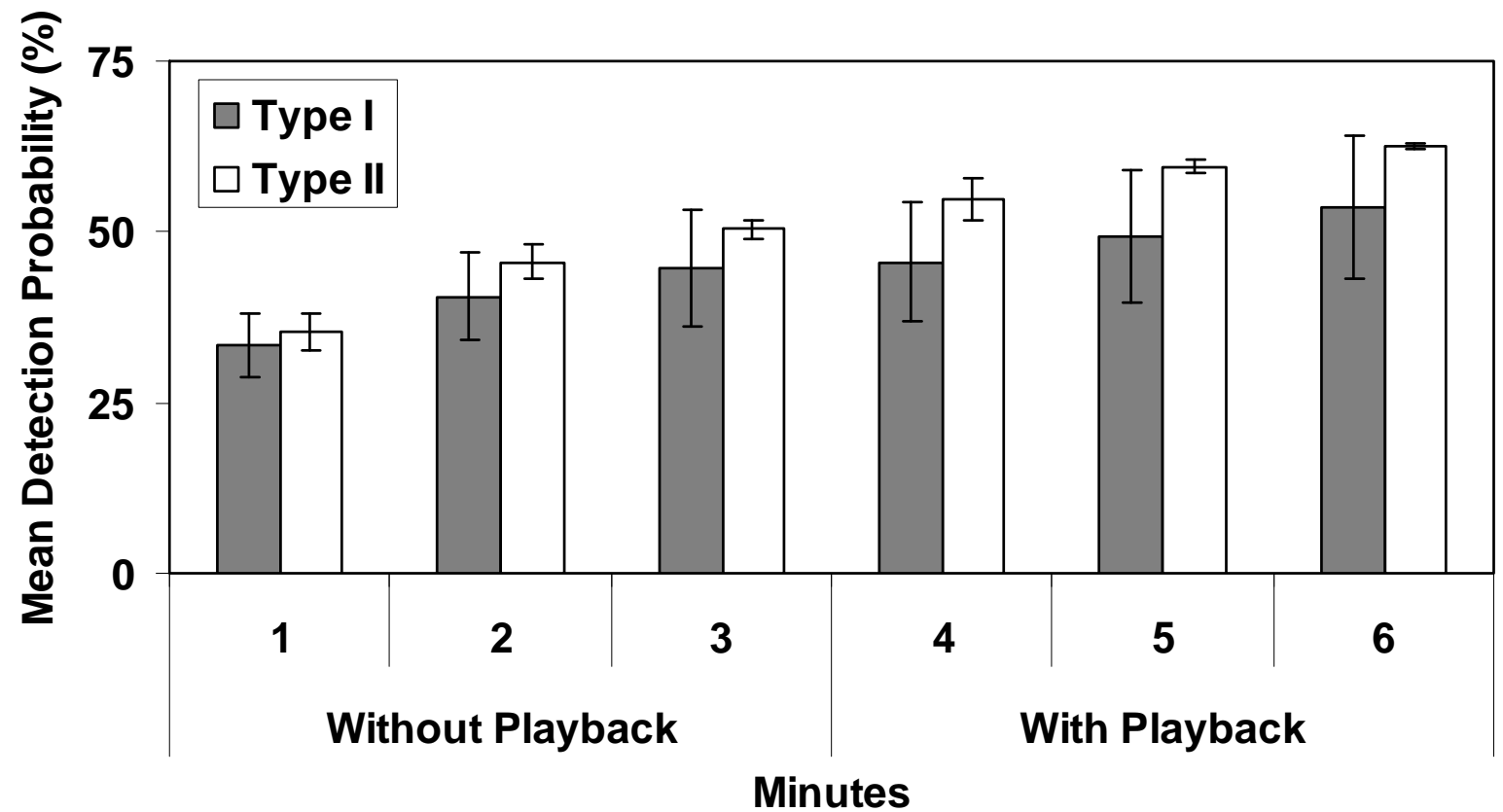

Figure 4. Mean cumulative detection probability ( \pm SE) by min using type 1 and 2 song playback during AM surveys in 2008 and 2009 on grazing areas on the Monongahela National Forest, West Virginia. Data were pooled across sites and seasons and detection probability is the mean of the 2 years. 


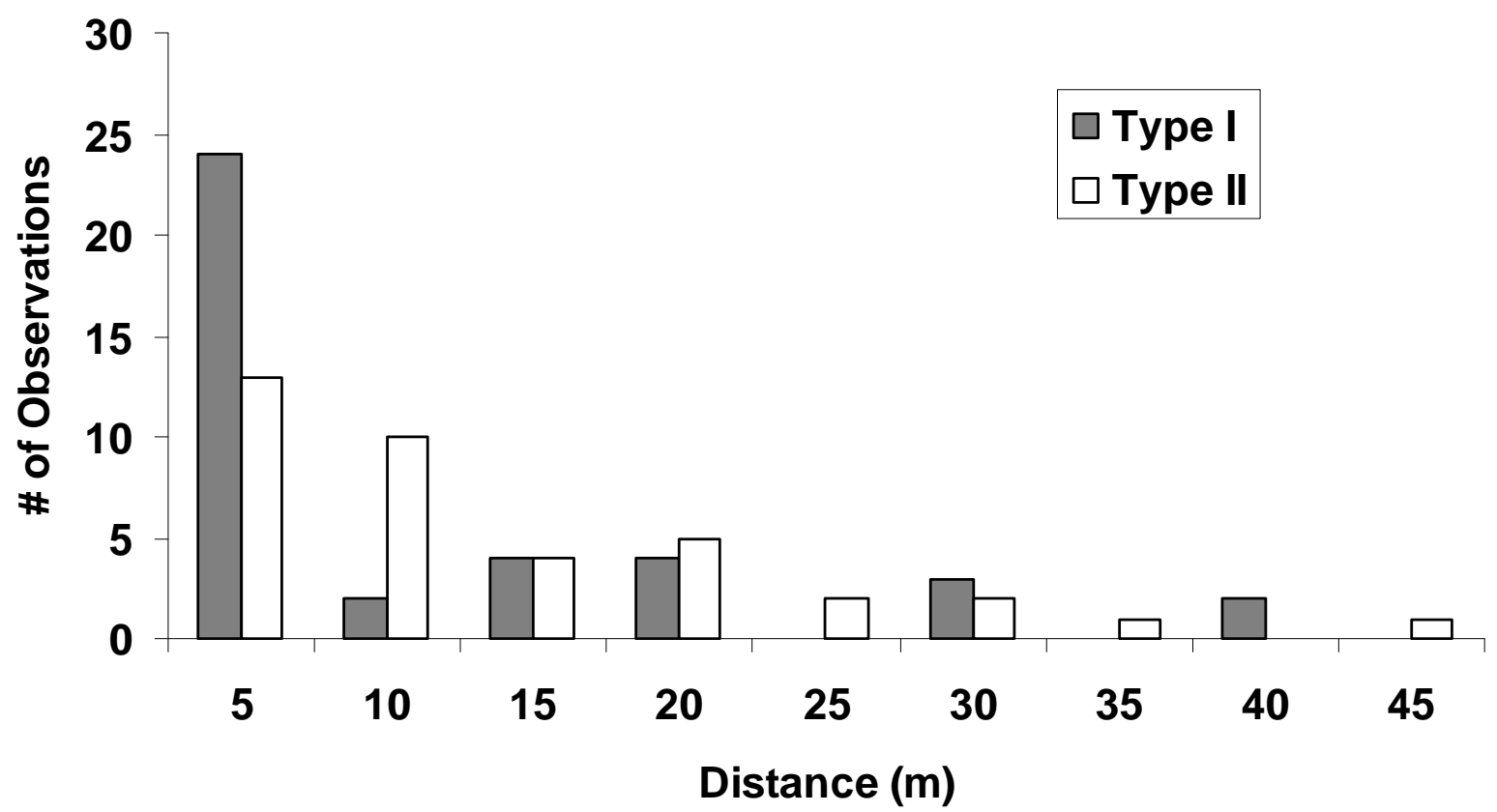

Figure 5. Frequency distribution of distances within which Golden-winged Warblers approached survey stations in response to 3 mins of type 1 or type 2 song playback on grazing areas on the Monongahela National Forest, West Virginia. Data were pooled across season and year. Individuals that did not approach were excluded. 
Appendix 1. Observations of male Golden-winged Warblers with the GOWAP (Type 1) protocol.

\begin{tabular}{|c|c|c|c|c|c|c|c|c|c|c|c|c|c|}
\hline \multirow{2}{*}{$\stackrel{\stackrel{\mathscr{*}}{*}}{\sim}$} & \multirow{2}{*}{$\stackrel{\bar{\Xi}}{\check{\nu}}$} & \multirow{2}{*}{$\stackrel{\varrho}{E}$} & \multirow{2}{*}{ 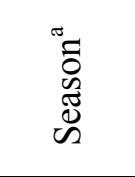 } & \multicolumn{2}{|c|}{$\begin{array}{c}\text { Pre- } \\
\text { playback }^{\mathrm{b}}\end{array}$} & \multicolumn{2}{|c|}{ Playback $^{\mathrm{c}}$} & \multicolumn{2}{|c|}{$\begin{array}{l}\text { Playback } \\
\text { Effect }^{\mathrm{d}}\end{array}$} & \multicolumn{2}{|c|}{ Post-playback $^{\mathrm{e}}$} & \multicolumn{2}{|c|}{$\begin{array}{c}\text { Post-playback } \\
\text { Effect }^{\mathrm{d}}\end{array}$} \\
\hline & & & & $\begin{array}{l}\text { No. } \\
\text { Obs. }\end{array}$ & $\begin{array}{l}\text { \% of } \\
\text { True }^{\mathrm{g}}\end{array}$ & $\begin{array}{l}\text { No. } \\
\text { Obs. }\end{array}$ & $\begin{array}{l}\% \text { of } \\
\text { True }^{\mathrm{g}}\end{array}$ & $\begin{array}{l}\text { Total } \\
\text { Obs. }\end{array}$ & $\begin{array}{l}\% \text { of } \\
\text { True }^{\mathrm{g}}\end{array}$ & $\begin{array}{l}\text { No. } \\
\text { Obs. }\end{array}$ & $\begin{array}{l}\% \text { of } \\
\text { True }^{\mathrm{g}}\end{array}$ & $\begin{array}{l}\text { Total } \\
\text { Obs. }\end{array}$ & $\begin{array}{l}\% \text { of } \\
\text { True }^{\mathrm{g}}\end{array}$ \\
\hline \multirow{9}{*}{ 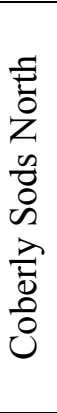 } & \multirow{6}{*}{$\stackrel{\infty}{\stackrel{\overbrace{}}{0}}$} & \multirow[t]{3}{*}{ AM } & Early & 4 & 44.4 & 4 & 44.4 & 6 & 66.7 & 7 & 77.8 & 7 & 77.8 \\
\hline & & & Middle & 8 & 88.9 & 6 & 66.7 & 8 & 88.9 & 9 & 100.0 & 9 & 100.0 \\
\hline & & & Late & 6 & 66.7 & 5 & 55.6 & 6 & 66.7 & 7 & 77.8 & 8 & 88.9 \\
\hline & & \multirow[t]{3}{*}{$\mathrm{PM}$} & Early & 4 & 44.4 & 5 & 55.6 & 6 & 66.7 & 7 & 77.8 & 7 & 77.8 \\
\hline & & & Middle & 1 & 11.1 & 1 & 11.1 & 1 & 11.1 & 3 & 33.3 & 3 & 33.3 \\
\hline & & & Late & 1 & 11.1 & 2 & 22.2 & 2 & 22.2 & 2 & 22.2 & 3 & 33.3 \\
\hline & \multirow{3}{*}{ ㅇํㅇ } & AM & Early & 2 & 40.0 & 3 & 60.0 & 3 & 60.0 & 4 & 80.0 & 4 & 80.0 \\
\hline & & & Middle & 1 & 20.0 & 1 & 20.0 & 1 & 20.0 & 2 & 40.0 & 2 & 40.0 \\
\hline & & & Late & 3 & 60.0 & 2 & 40.0 & 3 & 60.0 & 3 & 60.0 & 3 & 60.0 \\
\hline \multirow{9}{*}{ 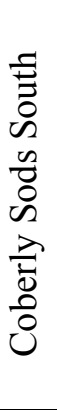 } & \multirow{6}{*}{$\stackrel{\infty}{\stackrel{2}{\circ}}$} & AM & Early & 4 & 100.0 & 3 & 75.0 & 4 & 100.0 & 3 & 75.0 & 4 & 100.0 \\
\hline & & & Middle & 2 & 50.0 & 1 & 25.0 & 3 & 75.0 & 2 & 50.0 & 3 & 75.0 \\
\hline & & & Late & 1 & 25.0 & 1 & 25.0 & 2 & 50.0 & 1 & 25.0 & 2 & 50.0 \\
\hline & & $\mathrm{PM}$ & Early & 1 & 25.0 & 1 & 25.0 & 1 & 25.0 & 2 & 50.0 & 3 & 75.0 \\
\hline & & & Middle & 0 & 0.0 & 0 & 0.0 & 0 & 0.0 & 0 & 0.0 & 0 & 0.0 \\
\hline & & & Late & 0 & 0.0 & 0 & 0.0 & 0 & 0.0 & 1 & 25.0 & 1 & 25.0 \\
\hline & \multirow{3}{*}{ ஓे } & AM & Early & 0 & 0.0 & 0 & 0.0 & 0 & 0.0 & 1 & 25.0 & 1 & 25.0 \\
\hline & & & Middle & 1 & 25.0 & 1 & 25.0 & 1 & 25.0 & 2 & 50.0 & 2 & 50.0 \\
\hline & & & Late & 2 & 50.0 & 1 & 25.0 & 2 & 50.0 & 2 & 50.0 & 2 & 50.0 \\
\hline \multirow{9}{*}{ 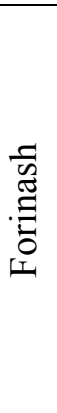 } & \multirow{6}{*}{$\stackrel{\infty}{\bigodot}$} & AM & Early & 7 & 77.8 & 4 & 44.4 & 7 & 77.8 & 7 & 77.8 & 7 & 77.8 \\
\hline & & & Middle & 2 & 22.2 & 3 & 33.3 & 3 & 33.3 & 4 & 44.4 & 4 & 44.4 \\
\hline & & & Late & 2 & 22.2 & 3 & 33.3 & 3 & 33.3 & 4 & 44.4 & 4 & 44.4 \\
\hline & & PM & Early & -- & -- & -- & -- & -- & -- & -- & -- & -- & -- \\
\hline & & & Middle & 2 & 22.2 & 1 & 11.1 & 3 & 33.3 & 3 & 33.3 & 5 & 55.6 \\
\hline & & & Late & 0 & 0.0 & 1 & 11.1 & 1 & 11.1 & 1 & 11.1 & 1 & 11.1 \\
\hline & \multirow{3}{*}{ ஓे } & AM & Early & 3 & 50.0 & 3 & 50.0 & 3 & 50.0 & 3 & 50.0 & 3 & 50.0 \\
\hline & & & Middle & 5 & 83.3 & 3 & 50.0 & 5 & 83.3 & 3 & 50.0 & 5 & 83.3 \\
\hline & & & Late & 1 & 16.7 & 1 & 16.7 & 1 & 16.7 & 1 & 16.7 & 1 & 16.7 \\
\hline & & AM & Early & 2 & 40.0 & 3 & 60.0 & 3 & 60.0 & 3 & 60.0 & 3 & 60.0 \\
\hline & & & Middle & 3 & 60.0 & 2 & 40.0 & 3 & 60.0 & 3 & 60.0 & 3 & 60.0 \\
\hline & $\stackrel{\infty}{0}$ & & Late & 2 & 40.0 & 3 & 60.0 & 4 & 80.0 & 4 & 80.0 & 4 & 80.0 \\
\hline 苛 & ণั & PM & Early & 0 & 0.0 & 1 & 20.0 & 1 & 20.0 & 2 & 40.0 & 2 & 40.0 \\
\hline$\frac{7}{5}$ & & & Middle & 1 & 20.0 & 0 & 0.0 & 1 & 20.0 & 1 & 20.0 & 1 & 20.0 \\
\hline 3 & & & Late & 4 & 80.0 & 3 & 60.0 & 4 & 80.0 & 3 & 60.0 & 4 & 80.0 \\
\hline & & AM & Early & 1 & 16.7 & 2 & 33.3 & 2 & 33.3 & 2 & 33.3 & 2 & 33.3 \\
\hline & 8 & & Middle & 2 & 33.3 & 0 & 0.0 & 2 & 33.3 & 3 & 50.0 & 3 & 50.0 \\
\hline & & & Late & 1 & 16.7 & 0 & 0.0 & 1 & 16.7 & 1 & 16.7 & 2 & 33.3 \\
\hline 를 & & $\mathrm{AM}$ & Early & 1 & 25.0 & 0 & 0.0 & 1 & 25.0 & 2 & 50.0 & 2 & 50.0 \\
\hline$\frac{a}{\pi}$ & 8 & & Middle & 2 & 50.0 & 2 & 50.0 & 2 & 50.0 & 2 & 50.0 & 2 & 50.0 \\
\hline હ্ট் & & & Late & 3 & 75.0 & 2 & 50.0 & 4 & 100.0 & 3 & 75.0 & 4 & 100.0 \\
\hline$\dot{D}$ & & AM & Early & 6 & 46.2 & 8 & 61.5 & 9 & 69.2 & 8 & 61.5 & 9 & 69.2 \\
\hline 8 & 8 & & Middle & 4 & 30.8 & 4 & 30.8 & 5 & 38.5 & 7 & 53.8 & 7 & 53.8 \\
\hline$I$ & $\sim$ & & Late & 3 & 23.1 & 4 & 30.8 & 4 & 30.8 & 8 & 61.5 & 8 & 61.5 \\
\hline
\end{tabular}

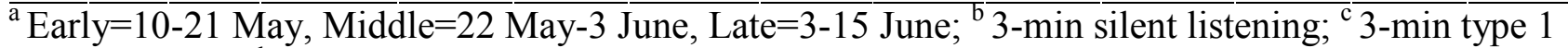
song playback; ${ }^{\mathrm{d}}$ Effect of interval on detection probability; ${ }^{\mathrm{e}}$ All time after 3-min type 1 song playback; ${ }^{\mathrm{f}}$ \# of observations during the interval; ${ }^{\mathrm{g}}$ Proportion of known population detected; ${ }^{\mathrm{h}}$ Total \# of unique individuals detected up to that point. 
Appendix 2. Observations of male Golden-winged Warblers with the Type 2 protocol.

\begin{tabular}{|c|c|c|c|c|c|c|c|c|c|c|c|c|c|}
\hline \multirow{2}{*}{$\stackrel{\mathscr{D}}{\mathrm{n}}$} & \multirow{2}{*}{$\stackrel{\bar{\Xi}}{\doteq}$} & \multirow{2}{*}{$\underset{\Xi}{\Xi}$} & \multirow{2}{*}{ 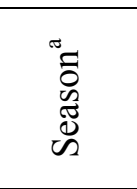 } & \multicolumn{2}{|c|}{$\begin{array}{c}\text { Pre- } \\
\text { playback }^{\mathrm{b}}\end{array}$} & \multicolumn{2}{|c|}{ Playback $^{\mathrm{c}}$} & \multicolumn{2}{|c|}{$\begin{array}{l}\text { Playback } \\
\text { Effect }^{\mathrm{d}}\end{array}$} & \multicolumn{2}{|c|}{$\begin{array}{c}\text { Post- } \\
\text { playback }^{\mathrm{e}}\end{array}$} & \multicolumn{2}{|c|}{$\begin{array}{c}\text { Post-playback } \\
\text { Effect }^{\mathrm{d}}\end{array}$} \\
\hline & & & & No. ${ }^{f}$ & $\begin{array}{l}\text { \% of } \\
\text { True }^{\mathrm{g}}\end{array}$ & $\begin{array}{l}\text { No. } \\
\text { Obs. }\end{array}$ & $\begin{array}{l}\text { \% of } \\
\text { True }^{g}\end{array}$ & $\begin{array}{l}\text { Total } \\
\text { Obs. }\end{array}$ & $\begin{array}{l}\text { \% of } \\
\text { True }^{g}\end{array}$ & No. ${ }^{f}$ & $\begin{array}{l}\% \text { of } \\
\text { True }^{g}\end{array}$ & $\begin{array}{l}\text { Total } \\
\text { Obs. }\end{array}$ & $\begin{array}{l}\text { \% of } \\
\text { True }\end{array}$ \\
\hline \multirow{9}{*}{ 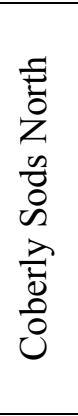 } & \multirow{6}{*}{$\stackrel{\infty}{8}$} & \multirow[t]{3}{*}{$\mathrm{AM}$} & Early & 6 & 66.7 & 7 & 77.8 & 8 & 88.9 & 9 & 100.0 & 9 & 100.0 \\
\hline & & & Middle & 5 & 55.6 & 7 & 77.8 & 7 & 77.8 & 8 & 88.9 & 8 & 88.9 \\
\hline & & & Late & 6 & 66.7 & 5 & 55.6 & 6 & 66.7 & 7 & 77.8 & 8 & 88.9 \\
\hline & & \multirow[t]{3}{*}{ PM } & Early & 2 & 22.2 & 1 & 11.1 & 2 & 22.2 & 4 & 44.4 & 5 & 55.6 \\
\hline & & & Middle & 0 & 0.0 & 2 & 22.2 & 2 & 22.2 & 1 & 11.1 & 2 & 22.2 \\
\hline & & & Late & 2 & 22.2 & 2 & 22.2 & 3 & 33.3 & 1 & 11.1 & 4 & 44.4 \\
\hline & \multirow{3}{*}{ ஓे } & $\mathrm{AM}$ & Early & 4 & 80.0 & 3 & 60.0 & 4 & 80.0 & 3 & 60.0 & 4 & 80.0 \\
\hline & & & Middle & 4 & 80.0 & 4 & 80.0 & 5 & 100.0 & 4 & 80.0 & 6 & 120.0 \\
\hline & & & Late & 3 & 60.0 & 3 & 60.0 & 4 & 80.0 & 3 & 60.0 & 4 & 80.0 \\
\hline \multirow{9}{*}{ 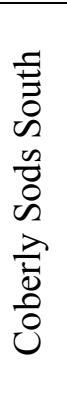 } & \multirow{6}{*}{$\stackrel{\infty}{8}$} & AM & Early & 3 & 75.0 & 1 & 25.0 & 3 & 75.0 & 2 & 50.0 & 4 & 100.0 \\
\hline & & & Middle & 3 & 75.0 & 3 & 75.0 & 3 & 75.0 & 3 & 75.0 & 3 & 75.0 \\
\hline & & & Late & 1 & 25.0 & 1 & 25.0 & 2 & 50.0 & 2 & 50.0 & 2 & 50.0 \\
\hline & & PM & Early & 0 & 0.0 & 1 & 25.0 & 1 & 25.0 & 0 & 0.0 & 1 & 25.0 \\
\hline & & & Middle & 0 & 0.0 & 0 & 0.0 & 0 & 0.0 & 0 & 0.0 & 0 & 0.0 \\
\hline & & & Late & 0 & 0.0 & 0 & 0.0 & 0 & 0.0 & 0 & 0.0 & 0 & 0.0 \\
\hline & \multirow{3}{*}{ \&े } & $\mathrm{AM}$ & Early & 0 & 0.0 & 0 & 0.0 & 0 & 0.0 & 0 & 0.0 & 0 & 0.0 \\
\hline & & & Middle & 0 & 0.0 & 0 & 0.0 & 0 & 0.0 & 3 & 75.0 & 3 & 75.0 \\
\hline & & & Late & 0 & 0.0 & 1 & 25.0 & 1 & 25.0 & 2 & 50.0 & 2 & 50.0 \\
\hline \multirow{9}{*}{ 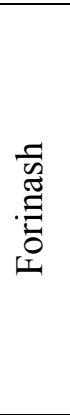 } & \multirow{6}{*}{$\stackrel{\infty}{8}$} & AM & Early & 3 & 33.3 & 5 & 55.6 & 5 & 55.6 & 4 & 44.4 & 6 & 66.7 \\
\hline & & & Middle & 4 & 44.4 & 3 & 33.3 & 5 & 55.6 & 5 & 55.6 & 5 & 55.6 \\
\hline & & & Late & 2 & 22.2 & 1 & 11.1 & 2 & 22.2 & 2 & 22.2 & 2 & 22.2 \\
\hline & & PM & Early & 2 & 22.2 & 3 & 33.3 & 3 & 33.3 & 3 & 33.3 & 3 & 33.3 \\
\hline & & & Middle & 3 & 33.3 & 3 & 33.3 & 4 & 44.4 & 5 & 55.6 & 6 & 66.7 \\
\hline & & & Late & 1 & 11.1 & 2 & 22.2 & 2 & 22.2 & 3 & 33.3 & 3 & 33.3 \\
\hline & \multirow{3}{*}{ \&े } & $\mathrm{AM}$ & Early & 5 & 83.3 & 5 & 83.3 & 6 & 100.0 & 5 & 83.3 & 6 & 100.0 \\
\hline & & & Middle & 5 & 83.3 & 3 & 50.0 & 5 & 83.3 & 3 & 50.0 & 5 & 83.3 \\
\hline & & & Late & 1 & 16.7 & 3 & 50.0 & 3 & 50.0 & 2 & 33.3 & 3 & 50.0 \\
\hline & & $\mathrm{AM}$ & Early & 0 & 0.0 & 1 & 20.0 & 1 & 20.0 & 2 & 40.0 & 2 & 40.0 \\
\hline & & & Middle & 4 & 80.0 & 4 & 80.0 & 4 & 80.0 & 3 & 60.0 & 4 & 80.0 \\
\hline & $\infty$ & & Late & 5 & 100.0 & 5 & 100.0 & 5 & 100.0 & 4 & 80.0 & 5 & 100.0 \\
\hline & స్త & PM & Early & -- & -- & -- & -- & -- & -- & -- & -- & -- & -- \\
\hline$\frac{n}{n}$ & & & Middle & 2 & 40.0 & 1 & 20.0 & 2 & 40.0 & 1 & 20.0 & 2 & 40.0 \\
\hline $3^{\pi}$ & & & Late & 2 & 40.0 & 2 & 40.0 & 2 & 40.0 & 3 & 60.0 & 3 & 60.0 \\
\hline & & $\mathrm{AM}$ & Early & 4 & 66.7 & 4 & 66.7 & 5 & 83.3 & 2 & 33.3 & 5 & 83.3 \\
\hline & 8 & & Middle & 4 & 66.7 & 3 & 50.0 & 4 & 66.7 & 2 & 33.3 & 4 & 66.7 \\
\hline & & & Late & 1 & 16.7 & 1 & 16.7 & 1 & 16.7 & 1 & 16.7 & 1 & 16.7 \\
\hline 彭 & & $\mathrm{AM}$ & Early & 1 & 25.0 & 1 & 25.0 & 1 & 25.0 & 1 & 25.0 & 1 & 25.0 \\
\hline$\frac{\bar{D}}{\lambda}$ & 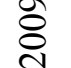 & & Middle & 2 & 50.0 & 2 & 50.0 & 2 & 50.0 & 1 & 25.0 & 2 & 50.0 \\
\hline త్ర & & & Late & 3 & 75.0 & 3 & 75.0 & 4 & 100.0 & 2 & 50.0 & 4 & 100.0 \\
\hline$\overline{0}$ & & AM & Early & 4 & 30.8 & 8 & 61.5 & 8 & 61.5 & 7 & 53.8 & 9 & 69.2 \\
\hline 8 & 8 & & Middle & 11 & 84.6 & 11 & 84.6 & 13 & 100.0 & 11 & 84.6 & 14 & 107.7 \\
\hline I & & & Late & 4 & 30.8 & 4 & 30.8 & 5 & 38.5 & 5 & 38.5 & 5 & 38.5 \\
\hline
\end{tabular}




\section{Chapter 3}

\section{Breeding habitat characteristics of Golden-winged Warblers on high-elevation pasturelands on the Monongahela National Forest, West Virginia}

Formatted in the style of Auk 


\section{Abstract}

Studies of Golden-winged Warbler (Vermivora chrysoptera) breeding habitat are needed to enhance conservation efforts. The high-elevation grazing areas examined here are unique to the published literature because Blue-winged Warblers (V. pinus) were absent, hybrids were rare, and low intensity livestock grazing was and continues to be used as an inexpensive but successful tool for creating Golden-winged Warbler breeding habitat. Mayfield nest success $(52.0 \%)$ is comparable to other reported values for this species and other shrubland nesters. We used classification trees to partition territories from random plots, nests from random plots, and successful from failed nests at microhabitat, macrohabitat, and global scales. Classification trees correctly identified plot types at a rate better than would be expected at random. Vegetation density ( $\geq 38.1 \%$ at territories and $\geq 51.9 \%$ at nests), microhabitat-scale woody vegetation cover ( $\geq 4.5 \%$ at nests), and macrohabitat-scale grass cover (37.5-87.5\% at nests) all emerged in multiple models as important explanatory variables. Over $50 \%$ of nests were $<0.3 \mathrm{~m}$ from a shrub stem. Nests $\geq 0.3 \mathrm{~m}$ from a shrub had $\geq 8.5 \%$ Rubus spp. and $\geq 30.0 \%$ herbaceous microhabitat cover. Global classification trees combined variables from microhabitat and macrohabitat scales to determine if the two spatial scales were similarly important for identifying breeding habitat. No final global models incorporated variables from both scales. Microhabitat and macrohabitat may be the important scales for categorizing nests and territories, respectively. Light grazing pressure can be used to manage habitat for Golden-winged Warblers breeding on high-elevation sites in West Virginia and perhaps elsewhere.

\section{INTRODUCTION}

Several studies have quantified characteristics of Golden-winged Warbler (Vermivora chrysoptera, hereafter Golden-wing) territories (Confer and Knapp 1981, Rossell et al. 2003, Roth and Lutz 2004, Martin et al. 2007) and nests (Demmons 2000, Klaus and Buehler 2001, Confer et al. 2003, Bulluck and Buehler 2008). In areas where Golden-wings and the closely related Blue-winged Warbler (V. pinus, hereafter Blue-wing) are sympatric, habitat characteristics that encourage reproductive isolation of these two species need to be identified (Buehler et al. 2007). Grazing areas in the mountains of central and southern West Virginia present a unique case for research, because Golden-wings and Blue-wings in this region typically are isolated by elevation (Welton 2003, Buehler et al. 2007). To optimize reproductive output 
and enhance conservation efforts for Golden-wings, studies are needed on grazing lands in this region. Ground-nesting passerines in shrublands generally have high rates of mortality (Martin 1993a), and Golden-wings are no exception (Table 1).

Some combination of herbaceous and woody vegetation has repeatedly emerged as an important feature of Golden-wing nest sites and territories, and has been linked with nest survival (Bulluck and Buehler 2008), clutch size, Brown-headed Cowbird (Molothrus ater) parasitism rates, and number of fledglings produced (Confer et al. 2003). These vegetation characteristics often are different between nests, territories, and the surrounding habitat (Klaus and Buehler 2001). Studies of Golden-wing breeding habitat are not in total agreement, but there are some common features, including high herbaceous cover (specifically goldenrod [Solidago spp.], Demmons 2000), few canopy trees (Confer and Knapp 1981, Klaus and Buehler 2001), considerable shrub cover (Confer et al. 2003), and structurally complex, patchy vegetation (Confer 1992, Rossell et al. 2003).

We are aware of no published studies of Golden-wing breeding ecology from actively grazed pasturelands. The habitats studied here are unique to the published literature on Goldenwings, and may be important to conservation efforts for this species because Golden-wings currently are isolated from Blue-wings at these sites. Federal ownership of many grazing areas in this region ensures that pastures will be maintained under the current land use and at a sustainable grazing intensity for a long period of time. Consistency of land use and low grazing intensity provides a somewhat stable, long-term refuge (“arrested succession”, Niering and Goodwin 1974) for Golden-wings and other early successional associates. Furthermore, a relatively low stocking density (1.2-2.4 ha usable forage/animal unit [AU], C. Johnson pers. comm.) allows for the development of a structurally complex habitat able to host a wide variety of avian species. Livestock are not able to denude the pasture to homogeneous grassland, so it develops into a matrix of grasses, forbs, shrubs, saplings, and few trees transitioning to a forested perimeter. This is especially valuable in West Virginia, a state that is predominantly forested. All of this can be accomplished at less expense than other management techniques used to create shrubland habitat. Studies have investigated the response of avian communities to grazing, and results vary by species, grazing intensity, and landscape context (Popotnik and Giuliano 2000, Baldi et al. 2005, Martin and McIntyre 2007). Although most of these studies are not necessarily directly applicable to grazing in eastern North America, there seems to be some agreement that 
low intensity grazing can be used, under certain conditions (e.g., avoid riparian zones, Popotnik and Giuliano 2000), to manage complex early successional habitats beneficial to some species (Martin and McIntyre 2007).

Our objective was to identify habitat characteristics for Golden-wings breeding on actively grazed shrublands and to differentiate these from unoccupied sites. We also were interested in characteristics that may be indicative of successful or failed/depredated nests. We sought to accomplish these at multiple spatial scales: microhabitat, which included variables within $1 \mathrm{~m}$ of the plot center, macrohabitat, which included larger scale variables, and global, which is a combination of both scales. We used a simple analytical technique that can easily translate to on the ground management.

\section{METHODS}

Study area. We conducted our research on six similar grazing areas on the Monongahela National Forest, four near Elkins, Randolph County and two near Marlinton, Pocahontas County, West Virginia, ranging in elevation from about 800 to $1,200 \mathrm{~m}$. Coberly Sods North (40.6 ha) is divided into ungrazed (23.1 ha) and grazed (17.5 ha, 18 AUs in 2009) sections; the ungrazed section has been fenced since 1991. Coberly Sods South (30.2 ha, 21 AUs in 2009) is separated from Coberly Sods North by a gravel US Forest Service (USFS) road. Forinash (21.8 ha, 7 AUs in 2009) was ungrazed from 1993 to 2006, but mowing and grazing resumed in 2007. One study site, "Washout" (5.9 ha) is a privately-owned abandoned pasture just outside of the national forest boundary. Habitat on Washout is similar to the federally owned allotments, although the vegetation is denser and taller in some areas possibly because it has not been grazed for about 40 years (W. Tolin pers. comm.). These four sites were sampled in 2008 and 2009. Study areas in Pocahontas County, Hoover (179.2 ha) and Gay/Sharp (55.6 ha), were only sampled in 2009. Hoover and Gay/Sharp are adjacent and separated by a cattle fence.

Grazing allotments on the Monongahela National Forest generally were active pastures when the land was acquired by the USFS and remain as such today. The USFS leases grazing allotments to the public for low intensity grazing of mostly cattle and a few horses from 15 May to 1 October, thus they are maintained at the current stage of succession primarily by livestock grazing and periodically by mowing. Each allotment is permitted a number of AUs each grazing season, usually 1.2-2.4 ha usable forage/AU, based on total area, forage, type of livestock, and historic land use (C. Johnson pers. comm.). Officials with the USFS may choose to allow or 
deny grazing permits based on the impact of grazing during the previous year(s). For example, in 2009 there were 70 animal units between the Hoover and Gay/Sharp allotments (3.4 ha/AU) but this number will be reduced to 55 units (4.3 ha/AU) in 2010 due to overgrazing (D. Gibson pers. comm.).

All allotments are patchy and structurally complex, comprised of grasses, herbaceous vegetation, and shrub-scrub habitat (predominantly hawthorn [Crataegus spp.] and autumn olive [Elaeagnus umbellata]) primarily towards the fenced edges and transitioning into surrounding large tracts of mostly forest (see Fig. 2 in Chapter 1). Basal area of trees is low across all sites ( $1.7 \mathrm{~m}^{2} / \mathrm{ha}, \mathrm{n}=186$ prism plots). Common plant species include velvet grass (Holcus lanatus), meadow fescue (Festuca elatior), orchard grass (Dactylis glomerata), sweet vernal grass (Anthoxanthum odoratum), goldenrod, common cinquefoil (Potentilla simplex), virgin's bower (Clematis virginiana), raspberry/blackberry (Rubus spp.), multiflora rose (Rosa multiflora), shrubby St. Johnswort (Hypericum prolificum), common elderberry (Sambucus canadensis), white ash (Fraxinus americana), black cherry (Fraxinus americana), and black locust (Robinia pseudoacacia).

Field methods. Between 1 May and 30 June 2008 and 2009, we visited each site nearly every day from pre-dawn ( 0430 EST) to early-afternoon ( 1400). Early morning hours (before 1000) were spent mapping territories and locating nests; sometimes longer if birds were active. During visits to areas with territorial males, we monitored and recorded the locations and behaviors of males and females on high resolution aerial photographs with landmarks and point count stations for reference. To complement spot-mapping in 2009, we conducted 30-min burst sampling, recording a male's location with Garmin GPS 12 and Summit HC handheld GPS units every 3 mins for 10 possible locations per day (Bulluck and Buehler 2008). We also collected coordinates of obvious territorial landmarks (e.g., song perches) opportunistically throughout the season. Territory maps served as a guide for conducting vegetation sampling, so sub-meter accuracy of GPS units was not necessary, although units were typically accurate to $<5 \mathrm{~m}$.

Basic methods and techniques for locating and monitoring nests are outlined in Martin and Geupel (1993) and Martin et al. (1997). Female behavior, such as carrying nest material, chipping, dancing, visiting locations repeatedly, was carefully observed, as these signs may reveal the location of a nest. Any behavior by the female in response to the presence of an observer was quickly noticed and the observer abandoned the position and left the area. After 
locating a nest, flags or stakes were used in conjunction with a distance estimate and compass bearing to relocate the nest; GPS coordinates also were used. Flagging and frequent visits can attract predators to nest locations (Martin and Geupel 1993), so we left at least $10 \mathrm{~m}$ of space between the nest and the flagging. The number of visits to a nest was a compromise between maximizing data precision and minimizing the effect of human disturbance on nest predation and abandonment. Female Golden-wings will readily abandon nests if disturbed, especially during nest construction and egg-laying (Confer et al. 2003).

Clutch size was determined after the onset of incubation by counting the number of eggs in the nest. Number of young produced in each successful nest was the number of nestlings observed one day prior to fledging. A nest was considered successful if at least one chick fledged. Daily survival rates (DSR) were computed based on the Mayfield method (Mayfield 1961). Nest success was calculated based on raising DSR to the $25^{\text {th }}$ power to account for laying, incubating, and nestling stages. Incubation usually lasts 11-12 days, beginning when the ultimate egg is laid (Will 1986, Confer et al. 2003). The nestling period lasts about 8 to 10 days (Will 1986, Ehrlich et al. 1988, Confer 1992) but may take up to 11 days (Confer et al. 2003). Nests in this study generally were not active for more than 25 days, although some were successful in less than 25 days, especially second nest attempts that had fewer than five eggs.

Vegetation data at territories and random plots were collected between 18 June and 15 July (average sampling date $=6$ July). For nests and associated random plots, vegetation data were collected between 12 and 30 June (average sampling date $=22$ June). Data were collected within $1 \mathrm{~m}$ and $11.3 \mathrm{~m}$ radius plots centered on nests $(\mathrm{n}=21)$ and on the approximate geographic center of each male's territory $(n=42)$. At territories with nests, we used the nest plot vegetation to also represent the territory plot. Paired nest plots $(n=21)$ were located $25-50 \mathrm{~m}$ from the nest in a random direction still within the territory. For plots paired with territories $(n=63)$, we continued in a random direction until we were outside of the territory but still within suitable habitat in 2008. In 2009, paired territory plots were placed randomly within suitable unoccupied habitat using the Hawth's Tools (Beyer 2006) extension for ArcMap 9.2 (ESRI 2008). We distinguished between the two types of random plots because those paired with nests were placed in occupied habitat, while paired territory plots were placed in unoccupied habitat.

We sampled vegetation at nests, territories, and random plots associated with each (Table 2) using methods similar to Bulluck and Buehler (2008). Within the $1 \mathrm{~m}$ radius plot, we visually 
estimated percent cover of grasses, forbs, litter, bare ground, woody vegetation, vines and blackberry/raspberry (Rubus spp.). Within the $11.3 \mathrm{~m}$ radius (0.04 ha) plot, we counted the number of snags $\geq 2 \mathrm{~m}$ in height and $\geq 10 \mathrm{~cm}$ in diameter. Basal area was measured using a 10factor prism at plot center. Vegetation density was estimated by placing a density board ( $2 \mathrm{~m}$ tall, $40 \mathrm{~cm}$ wide) on the ground $10 \mathrm{~m}$ from plot center in each of the four cardinal directions and recording how many of the twenty $20 \mathrm{~cm}$ x $20 \mathrm{~cm}$ squares were $>50 \%$ covered by vegetation. Averaging these four values and dividing by the total number of squares on the board yielded a mean percent cover of vegetation at 0-2 $\mathrm{m}$ in height. Litter depth was measured in each cardinal direction $1 \mathrm{~m}$ from plot center and averaged. Across the 0.04 ha plot, we estimated average height of the shrub and sapling layer. We also measured percent cover of grasses, forbs, vines, Rubus, shrubs, saplings ( $1-10 \mathrm{~cm} \mathrm{dbh}$ and $\geq 1 \mathrm{~m}$ in height), and canopy trees $(>10 \mathrm{~cm} \mathrm{dbh})$ based on ocular tube "hits" (James and Shugart 1970) from five points in each cardinal direction along an $11.3 \mathrm{~m}$ transect. Observers recorded the presence of each cover type when looking through the ocular tube straight towards the ground and straight up. Percent cover of each class of vegetation was derived by dividing the number of "hits" for that class by twenty. From these "hits" we also determined dominant species in each category. Distance to forest edge was measured in the field or from 2007 NRCS aerial photographs. Average slope (in degrees) and aspect across a $5 \mathrm{~m}$ radius plot were measured in the field. Aspect was converted to a categorical variable $\left(\right.$ North $=315^{\circ}-44^{\circ}$, East $=45^{\circ}-134^{\circ}$, South $=135^{\circ}-224^{\circ}$, West $\left.=225^{\circ}-314^{\circ}\right)$. Elevation of the center point of each plot was measured from a $30 \mathrm{~m}$ resolution digital elevation model in ArcMap 9.2 (ESRI 2008).

We measured additional habitat characteristics at nest and paired nest plots to assess the fine scale structure that is required for Golden-wings to nest (Table 2). Most of the variables were based on BBIRD Field Protocols (Martin et al. 1997). We measured height from the ground to the rim of the nest and recorded the species and height of the substrate in which the nest was placed. Overhead cover was an estimate of the percent of the nest obscured by vegetation from $1 \mathrm{~m}$ above the nest site. Plant species or other substrates primarily responsible for concealing the nest also were recorded. Several characteristics of the nearest shrub were recorded, including species, height, maximum width, width perpendicular to maximum width, distance from the nest to the nearest branch and central stem (at $10 \mathrm{~cm}$ above the ground), and the number of stems at $10 \mathrm{~cm}$ above the ground. We also noted presence of other objects near 
the nest that could serve as perches for the adults, such as fencerows or other vegetation. Finally, nest orientation was defined as the direction towards which the nest cup tilted or the direction adults took to enter or leave the nest. Nest orientation was converted to a categorical variable in the same way as aspect. Nest height to rim, supporting and concealing substrates, overhead cover, and nest orientation do not apply to random plots and were not measured.

Statistical analysis. Previous studies of habitat characteristics associated with Goldenwing nests, territories, and song perches have used traditional analytical approaches such as regression (Klaus and Buehler 2001, Confer et al. 2003, Martin et al. 2007), analysis of variance (Rossell 2001, Confer et al. 2003), t-tests (Bulluck and Buehler 2008), and the nonparametric signed ranks test (Rossell et al. 2003). We chose to use a powerful yet simple analytical technique, recursive partitioning (often referred to as classification and regression trees or CART), which splits groups based on optimal grouping variables. Recursive partitioning is a robust nonparametric technique that explores differences between response variables by repeatedly splitting the data into optimally homogeneous subsets based on the levels of explanatory variables (De'ath and Fabricius 2000). In contrast with parametric models, recursive partitioning is designed to work with data having multiple structures rather than a single dominant structure (Vayssieres et al. 2000). Classification and regression trees are not new (Breiman et al. 1984) and have been used in a variety of disciplines from agriculture (e.g., Ferraro et al. 2009) to mammalian (e.g., Edalgo et al. 2009) and avian ecology (Dellinger et al. 2007). De'ath and Fabricius (2000) demonstrated the utility of this technique for complex ecological datasets, complementing and even surpassing traditional statistical methods. Easily interpretable binary decision trees can be used to guide habitat management and may reveal features important to successful nesting needing further scrutiny.

We used CART to identify habitat characteristics that distinguished territories from random plots, nests from random plots, and successful from unsuccessful nests. The experimental unit was each individual nest, territory, or random plot. CART analyses were completed using the R Language and Environment for Statistical Computing Version 2.8.1 (R Development Core Team 2008) and package mvpart.

Final CART models were selected by cross-validation (CV) for all classification tree analyses. CV involves dividing the data into $n$ equal sized subsets then constructing the tree with $n-1$ subsets. The error is determined by testing the tree with the excluded subset. This is 
repeated until all subsets have been excluded and tested by the tree. We ran a series of 5010 fold CVs and selected the modal tree size using the 1-SE rule (Breiman et al. 1984, De'ath and Fabricius 2000), where the smallest tree with an estimated error within one standard error of the minimum CV error is considered the best tree. This decision rule can result in much smaller trees, with minimal increase in the estimated error rate over the minimum CV error (at most $<1$ SE, De'ath and Fabricius 2000). Representative CVs are shown in the results, using the most frequently occurring tree size. Longer tree branches indicate more homogeneous groupings. Since the main objective of this analysis was to describe characteristics of nests (successful and failed) and territories and to partition these into optimally homogeneous groups, we did not divide the data into independent training and testing subsets. Sample size also prohibited our ability to test the predictive power of the trees; however, future data collection and compilation of standardized data that has been collected across the Golden-wing's range will permit this type of analysis. Small sample sizes can potentially be problematic for classification tree analysis, since later splits are based on fewer cases than initial ones and identification of predictive factors becomes increasingly difficult (Vayssieres et al. 2000).

Another study (Dellinger et al. 2007) used K values to assess the performance of CART models, where $\mathrm{K}$ is the ratio of observed classification improvement (compared to random classification) to perfect classification improvement (again, compared to random classification). Values for $\mathrm{K}$ are the same as the amount of variation explained by the tree if a balanced sample is used (i.e., 21 nests and 21 random points). Only the comparison of successful and failed nests was not balanced (11 successful and 10 failed), but the slight imbalance caused the amount of variation explained and the $\mathrm{K}$ value to be almost identical, so we chose to present the amount of variation explained.

Explanatory variables were organized into three spatial scales for model building: microhabitat (variables collected at the $1 \mathrm{~m}$ radius plot level and fine-scale characteristics collected at nests), macrohabitat (variables collected at the 0.04 ha plot level or larger), and global (all variables, Table 2). For comparison of territory and paired plots, we initially used only the 2008 data for the macrohabitat and global models because ocular tube measurements (a macrohabitat variable) were not collected at territory centers in 2009. Because none of the ocular tube percent cover estimates were retained in these trees, we repeated the analysis with data from both years and excluded ocular tube measurements from the models. The microhabitat 
model differentiating between territories and paired random plots included data collected in 2008 and 2009 .

\section{RESULTS}

Territories. We measured habitat characteristics at 63 territories (21 nests and 42 territory centers) in 2008 and 2009. An equal number of paired territory plots ( $n=28$ in 2008 and $\mathrm{n}=35$ in 2009) were sampled. Means and standard errors for attributes measured are provided (Tables 3). Ocular tube percent cover estimates (Table 3) are based on territory centers sampled in $2008(\mathrm{n}=28)$ and nests $(\mathrm{n}=21)$, since vegetation sampling at territories was altered in 2009 and we did not have those data at territory centers. All other estimates are based on the full dataset $(n=63)$ from 2008 and 2009.

Territories versus random. The microhabitat model to separate territory and paired random plots (Fig. 1) explained relatively little of the variation in the data (47.6\%, Table 2). The low amount of variation explained, the relatively high model misclassification rate, and the high $\mathrm{CV}$ error (Table 2) also attest to the difficulty in partitioning territories from random plots based on the variables used, although the tree was more effective than random classification and than the macrohabitat and global models. Litter depth was the most important splitting variable, followed by woody cover on the left hand side of the tree. If litter depth was $\geq 1.4 \mathrm{~cm}$, litter, vine, and forb cover followed as splitting variables in that order. There were six terminal nodes, four classified as territories and the remaining two as paired plots. Most territories $(60.3 \%)$ had $\geq 1.4 \mathrm{~cm}$ of litter but $<5.1 \%$ of litter cover. Using the 10 -fold CV method with this tree, $78.5 \%$ of territory centers and $71.4 \%$ of random plots were classified correctly.

The macrohabitat model (Fig. 2) explained the least variation in the data (28.6\%) of any tree. Other diagnostic statistics (Table 2) revealed that this tree performed poorly, albeit better than random classification. There were two terminal nodes, one each for territories and paired random plots, with vegetation density as the splitting variable. Although diagnostic statistics suggest poor classification, only two territory centers had a vegetation density score of $<38.1 \%$. Using 10-fold CV, $96.8 \%$ of territories and $31.7 \%$ of random plots were classified correctly. Even the tree with the minimum CV error did not include more splits.

The global tree was identical to the macrohabitat model using the 1-SE tree selection rule. Vegetation density again was used as the splitting variable. Although the microhabitat model performed better than the macrohabitat model in terms of the diagnostic statistics we 
presented, the macrohabitat model was the smallest possible tree within 1-SE of the minimum $\mathrm{CV}$ error, so the model using vegetation density as the sole splitting variable was chosen. If selecting the model with the minimum CV error, four microhabitat and four macrohabitat variables were used to grow a tree with 14 terminal nodes.

Nests. We monitored 7 nests in 2008 and 14 in 2009 for 271 exposure days across a 46day interval (earliest egg 13 May, latest fledgling 27 June). Nests were located at all sites (Coberly Sods North=3, Coberly Sods South=2, Forinash=6, Gay/Sharp=1, Hoover=3, Washout=6). Two-thirds of all nests were discovered during construction, one during egg laying, five during incubation, and one during the nestling phase. Average complete clutch size and number of fledglings per successful nest were $4.4 \pm 0.2$ and $4.0 \pm 0.3$, respectively. There was no evidence of double-brooding or cowbird parasitism, although cowbirds were frequently detected during point counts. Three nests were abandoned (one after the first egg was laid, 14.3\%), 7 depredated (33.3\%), and 11 successful (52.4\%). No nests were trampled by livestock, although the vegetation surrounding one nest was disturbed by cattle and subsequently the nest was predated. Mayfield (1961) nest success was 52.0\% when excluding a nest that was abandoned after the first egg was laid. Of 65 territorial male Golden-wings observed, $60 \%$ were assumed to be paired at some point during the season (all with female Golden-wings), equating to a $53.8 \%$ nest discovery rate if all females observed nested.

Habitat characteristics were measured at all nests (Tables 3 and 4). Sixteen of 21 nests were supported by Rubus spp., Solidago spp., or both. Eight nests had a woody stem in the substrate; including Crataegus spp. (3), autumn olive (2), shrubby St. Johnswort (1), multiflora rose (Rosa multiflora, 1), and common elderberry (Sambucus canadensis, 1). Nine plant species were observed as primary nest substrates, typically species with firm stems. Crataegus spp. often was the nearest shrub species $(66.7 \%)$ at nests, although this species more often was the nearest shrub at paired nest plot centers $(81.0 \%)$. Nests were always built at a point of transition or edge between dense vegetation and an opening, including fencerows, livestock paths and browse lines, and even recently mowed strips.

Nests versus random. At the microhabitat scale, only one variable distinguished nests from random points (Fig. 3). Distance to the nearest central shrub stem or trunk explained $52.4 \%$ of the variation in the data and the tree had a CV error of 0.57 and a model misclassification rate of $23.8 \%$ (Table 2). Using the 10 -fold CV method with this tree, $52.4 \%$ of 
nests and all random plots were classified correctly. No random plots were within $0.31 \mathrm{~m}$ of a shrub trunk, while nests were essentially split down the middle for this explanatory variable. One outlying nest was built far from a shrub trunk $(9.9 \mathrm{~m})$, and this nest was unsuccessful. We grew a larger tree to investigate further potential splits and found that 9 out of the 10 nests farther than $0.31 \mathrm{~m}$ from the nearest central shrub stem had $\geq 8.5 \%$ Rubus cover within $1 \mathrm{~m}$ of the nest. Six out of nine of these nests had $\geq 30.0 \%$ forb cover.

Partitioning nests and random points at the macrohabitat scale resulted in a tree with three terminal nodes (Fig. 4). Grass cover across the 0.04 ha plot and vegetation density were used as splitting variables. Only one nest had $<37.5 \%$ grass cover, and of the remaining 20, 18 had relatively dense vegetation ( $\geq 51.9 \%)$. Classification of nests and random points at the macrohabitat scale resulted in slightly more variation explained (57.1\%) than the microhabitat model (52.4\%). CV error was 0.922 performing less effectively than the microhabitat model at predicting the excluded subsets. Using the 10 -fold CV method with this tree, $85.7 \%$ of nests and $71.4 \%$ of random plots were classified correctly.

The global model for partitioning nests and random points was identical to the microhabitat model (Fig. 3), indicating there are no similarly important explanatory variables at the two different scales based on our data. An overgrown tree (the largest possible tree) incorporated macrohabitat variables only in the last split of a tree with five terminal nodes. This tree, which is not presented because it did not meet our tree selection criteria, was essentially an extension of the tree in Figure 3, where the right-hand node was split using 2 microhabitat variables (Rubus and forb cover) and lastly percent grass cover across the 0.04 ha plot.

Successful versus failed nests. A tree constructed to group successful and failed nests at the microhabitat scale had three terminal nodes, two dominated by successful nests and one by failed nests (Fig. 5). Eighty percent of the variation in the data was explained by this tree, although the tree did not perform as well as some of the other trees at predicting data subsets (CV Error=1.34). Successful nests tended to have some woody substrate $(\geq 4.5 \%)$ within a $1 \mathrm{~m}$ radius circle. Of the nests that fell below this threshold, 75\% were differentiated by an eastward facing tilt or opening to the nest. Nests facing north, south, or west tended to be unsuccessful. Four unsuccessful nests disturbed by predators were dropped from the tree at this split because we were unable to assign a value for nest orientation. With this tree, all but two nests (one of each successful and failed) were classified correctly. 
In the $\mathrm{CV}$ for the macrohabitat model to partition successful and failed nests, two competing models emerged and we made an exception to our decision rule by selecting the tree with the minimum CV error. The first tree was more frequently chosen based on the 1-SE rule for selecting tree size (Breiman et al. 1984), but had only two terminal nodes, so its descriptive capabilities were lacking. A five leaved tree was occasionally chosen using the 1-SE rule. This latter tree size (five terminal nodes) was chosen when the error rate of the former tree (two terminal nodes) exceeded the minimum CV error by more than 1-SE. We chose to display the five-leaved tree (Fig. 6) because it was sometimes selected using the 1-SE rule (it always had the minimum CV error) and we required a more descriptive model. Classification of successful and failed nests at the macrohabitat scale resulted in the highest amount of variance explained $(90 \%$, Table 2). CV relative error was higher than all trees (CV Error $=1.38$ ). At this tree size, $90 \%$ of failed and $100 \%$ of successful nests were classified correctly. Sample size is certainly an issue with a tree of this many terminal nodes; however, a considerable portion of successful nests ( $82 \%)$ follow the right-hand splits down the entire tree. Following the right-hand splits resulted in a group of nests with $<87.5 \%$ grass cover, shrub layer $\geq 1.9 \mathrm{~m}$ tall, and $<17.5 \%$ vine cover.

The global model to group successful and failed nests was identical to the microhabitat model (Fig. 5). Even an overgrown tree size did not incorporate macrohabitat variables. Based on data collected, habitat characteristics at the two different scales do not interact as important predictors of successful or failed nests. Two global models, one partitioning nests and random

plots and the other successful and failed nests, suggest that the microhabitat scale contains more important grouping variables than the macrohabitat scale.

\section{Discussion}

Golden-wing habitat is a complex patchy mosaic of dense vegetation broken by openings, characterized by grasses and herbaceous vegetation interspersed with shrubs and young trees of varying heights adjacent to a forested edge (Confer 1992, Buehler et al. 2007). Habitats used by Golden-wings breeding on high-elevation grazing areas in West Virginia were similar to habitats used in other studies (e.g., Confer 1992, Klaus and Buehler 2001, Rossell et al. 2003, Bulluck and Buehler 2008). Consequently, vegetation density and woody and grass cover each emerged in multiple classification trees as important defining characteristics of Golden-wing breeding habitat on our study sites. Specific habitat parameters for best management practices have yet to surface, despite multiple studies, probably because Golden-wings breed in a variety of early 
successional habitat types, including regenerating aspen (Populus spp.) clearcuts (Roth and Lutz 2004), reclaimed surface mines (Bulluck and Buehler 2008), wetlands (Rossell et al. 2003), utility rights-of-way (Kubel and Yahner 2008), and active grazing areas, among others.

Territory habitat. Models distinguishing between territories and random plots did not perform as well as models partitioning nests and random plots or successful and failed nests at all three scales based on our data. Difficulty in creating homogenous groups using CART models is likely the result of habitat variation within territories which might be overcome by measuring multiple samples within each territory. Paired territory plots were randomly placed in unoccupied habitat that appeared to observers to be suitable for breeding Golden-wings, so we would expect variability when placing a plot within a broadly defined stratum ("suitable unoccupied habitat").

It is interesting that litter depth and cover would be included in the microhabitat model. Litter depth and cover are important aspects of nest sites for some birds, usually grassland species like Henslow's Sparrow (Ammodramus henslowii, Herkert 1994), Dickcissel (Spiza americana, Hughes et al. 1999), Lark Sparrow (Chondestes grammacus, Lusk et al. 2003), Bobolink (Dolichonyx oryzivorus), and Eastern Meadowlark (Sturnella magna, Warren and Anderson 2005), even affecting nest success (Hughes et al. 1999, Lusk et al. 2003). Nests of Red-winged Blackbirds (Agelaius phoeniceus) can have deep litter accumulations (LeClerc 1982) but decreased litter cover (Warren and Anderson 2005) in West Virginia. Similarly, Golden-wing territories often had deeper litter but less litter cover than random plots. Litter cover is probably most important to Golden-wings for construction and concealment of nests (Confer 1992), but why it should be a distinguishing feature of territories is unclear.

We would expect macrohabitat features to be more important than fine-scale microhabitat characteristics for differentiating between occupied and unoccupied habitat, since a territory should support all of the activities required for successful reproduction. These activities might occur in a variety of conditions and locations across the territory (e.g., foraging, Ficken and Ficken 1968; or singing, Highsmith 1989, Rossell 2001), or they could be localized and require specific habitat features (e.g., nesting; Confer et al. 2003, Bulluck and Buehler 2008). Almost all territories had relatively dense vegetation ( $\geq 38.1 \%$ ), while paired random plots exhibited more variation. One terminal node of the macrohabitat tree contained $96.8 \%$ of all territories, while the terminal node grouping the most territories in the microhabitat model contained $60.3 \%$. 
At both scales, our estimates of herbaceous vegetation cover at territories (Table 3) were similar to the $69 \%$ cover reported by Confer et al. (2003), although the methodology differed and grasses appear to be grouped with forbs in that study. If percent cover for forbs and grasses are combined from our data at the $1 \mathrm{~m}$ scale, the average cover at territories was $65.9 \pm 3.1 \%$. At the 0.04 ha scale, where vegetation classes were independent and do not sum to $100 \%$, forb and grass cover at territories were $73.6 \pm 2.4 \%$ and $58.3 \pm 3.8 \%$, respectively.

The global model for partitioning between territory centers and random plots was identical to the macrohabitat model using the 1-SE tree selection criteria. Though the microhabitat model outperformed the macrohabitat model in terms of some of the diagnostic statistics presented (variation explained, misclassification rate), the global model was identical to the macrohabitat model because the macrohabitat model was smaller than the microhabitat model yet still within $1 \mathrm{SE}$ of the minimum CV error. Synthesis of all territory models suggests that most territories tended to have litter $\geq 1.4 \mathrm{~cm}$ deep, yet covering $<5.1 \%$ of the ground, and dense vegetation ( $\geq 38.1 \%$ ). We would expect vegetation density and amount of litter to be related, as more vegetation would create more litter; however, more vegetation might also occupy more ground cover and possibly obscure the view of an observer estimating litter cover.

Nesting habitat. Most Golden-wing nests have a tall, firm stem supporting the nest that is used by the adults for perching upon arrival at the nest (Confer 1992). Nests at the Queen's University Biological Station in Ontario had considerably more woody stems $(22.8 \pm 1.9)$ than random points $(15.6 \pm 2.3)$ within a $2 \mathrm{~m}$ by $1 \mathrm{~m}$ area (Demmons 2000). In our study, partitioning of nest and paired nest plots at the microhabitat scale was influenced by the 8 of 21 nests that were supported by a shrub stem. Nests not supported by a shrub stem were typically built near a shrub or some other tall, rigid vegetation (e.g., Rubus spp.) or structure (a cow fence in one case) that could serve as a perch before nest entry. The nest that was farthest from a shrub (9.9 m) was built on the edge of a large patch of Rubus that likely served the same purpose as a shrub. Similarly, among nests not built directly adjacent to a shrub ( $\geq 0.31 \mathrm{~m}$ away), there tended to be more Rubus and forb cover. On two different occasions, we observed females carrying nesting material to a shrub adjacent to the nest being built and then dropping the material to the ground practically on top of the nest without ever leaving the upper branches of the shrub, almost as if stock piling nest material (K. Aldinger pers. obs.). Nearby shrubs often were used for perching 
before adults entered the nest, and if an observer was sighted by an adult, one or both of the parents would remain in the shrub until the intruder retreated.

An adjacent shrub may be an important aspect of Golden-wing nest sites, perhaps for nest entry, substitution of parents at the nest, or vigilance against predators. Breitwisch et al. (1989) reviewed some strategies, such as predator distraction, active defense, and partitioning of nest visits, behind parental vigilance at nests of Northern Mockingbirds (Mimus polyglottos), which may be applicable here. While Golden-wings may not engage in active defense, shrubs near the nest site would provide a vantage point for distracting predators, alerting a mate of the other mate's presence, or ensuring safe, undetected nest entry. With (1994) showed the hazard of nesting near shrubs for a grassland species, the McCown's Longspur (Calcarius mccownii), which had high rates of predation, presumably from Thirteen-lined Ground Squirrels (Spermophilus tridecemlineatus) that were taking advantage of the cover. In shrubland habitat, Demmons (2000) also hypothesized that dense vegetation surrounding Golden-wing nest sites may attract small mammalian predators (Edalgo et al. 2009). Hauber and Russo (2000) asserted that tall perch $(>2 \mathrm{~m})$ proximity correlated with higher rates Brown-headed Cowbird parasitism of ground-nesting Song Sparrows (Melospiza melodia). Proximal perches at Golden-wing nests in our study averaged $2.0 \pm 0.3 \mathrm{~m}$ in height, but there was no evidence of cowbird parasitism even though cowbirds were abundant and other studies have shown high parasitism rates among Golden-wing nests (Will 1986, Confer 1992, Confer et al. 2003, Kubel and Yahner 2008). This could be due to the low abundance of inconspicuous Golden-wings relative to other more common and conspicuous species like Field Sparrows (Spizella pusilla), Indigo Buntings (Passerina cyanea), and Chestnut-sided Warblers (Dendroica pensylvanica). Barber and Martin (1997) suggested cowbirds could be attracted to conspicuous species and that high abundances of these species could increase the probability of parasitism among coexisting species. We have no data on cowbird parasitism rates for other species on our study sites, but if cowbirds are attracted to common and conspicuous species, we did not document an affect on Golden-wings. Not only are Golden-wing nests well concealed (Confer 1992), but males tend to vocalize relatively infrequently, especially after pair formation and as the season progresses (Highsmith 1989, Confer 1992, Kubel and Yahner 2007). There is evidence to suggest that a structure, usually a nearby shrub, is a common characteristic of Golden-wing nest sites, and this nearby structure 
does not seem to reduce nesting success (With 1994) or increase cowbird parasitism (Hauber and Russo 2000) as occurs in other species.

Results from the model comparing nests to random points at the macrohabitat scale emphasize the importance of open areas surrounding nest sites. Studies have consistently found that a large proportion of a Golden-wing nest site is covered by herbaceous (grasses, forbs, or both) vegetation (Confer 1992, Confer et al. 2003, Bulluck and Buehler 2008). Bulluck and Buehler (2008) found average grass and forb cover at Golden-wing nest sites to be $70.2 \%$ and $79.1 \%$, respectively, across a circular 0.04 ha plot. Our data are similar (grass $=65.5 \pm 4.7 \%$, forbs $=77.6 \pm 3.2 \%$ ), using the same scale and methodology. Even though $95 \%$ of nest sites had grass cover $\geq 37.5 \%$ across the 0.04 ha plot, $90 \%$ of these had relatively dense vegetation $(\geq 51.9 \%)$. The patchiness of these habitats is a likely explanation. Grasses contribute to vegetation density and can be under other types of vegetation like shrubs and saplings. This translates to a high diversity of vegetation types (woody, Rubus, grasses, vines, and forbs), as even herbaceous undergrowth is not shaded by the patchy mid-story layer of shrubs. Non-nest sites having low grass cover are likely characterized by a homogeneous cover of other plants that effectively replace pioneering grasses and eliminate the patchy structure that Golden-wings seem to prefer for breeding (Confer 1992, Rossell et al. 2003). Similarly, Martin et al. (2007) suggested that some aspen stands were not suitable for Golden-wings because the conditions limited ground cover (grasses and forbs) development.

Implications of vegetation density and nest concealment on nests are not totally clear. Demmons (2000) found that successful Golden-wing nests were more visible (30.05 $\pm 4.12 \%)$ than failed ones $(23.08 \pm 3.31 \%)$, perhaps due to higher abundances of small, cover-loving mammalian predators at less visible depredated nests. Nests on grazing areas were on average less visible and showed the opposite trend (successful $=10.2 \pm 4.8 \%$, failed $=21.7 \pm 9.0 \%$ ) compared to those in Demmons (2000), who measured visibility from five locations rather than just overhead. There are tradeoffs to building nests in dense vegetation: nests with the most cover may deter some predators (total-foliage hypothesis, Martin 1993b), but certain predators like small mammals also could be more active and abundant in densely vegetated patches (Stapp and Van Horne 1997). Edalgo et al. (2009) found that trails of white-footed mice (Peromyscus leucopus) in old field habitats had structurally complex vegetation and greater shrub cover than randomly selected trails. Our CART models did not isolate vegetation density or nest 
concealment as an important predictor of nest fate, but nests in general were characterized by dense vegetation $(69.0 \pm 3.5 \%)$ and low visibility $(15.7 \pm 5.0 \%)$. Vegetation density was an important explanatory variable in three other trees, however.

Based on our data, microhabitat characteristics were more important than macrohabitat characteristics for differentiating Golden-wing nests from paired random points. If there was some interaction wherein variables from both scales were both highly important, we might expect a tree to incorporate variables from both scales. Synthesis of the micro- and macrohabitat models suggests that a combination of a nearby shrub or suitable replacement like Rubus (within about $4 \mathrm{~m}$ ), open grassy areas (at least about $37.5 \%$ cover within $11.3 \mathrm{~m}$ of the nest), and moderately dense vegetation (at least about 50\% obstructed view at $10 \mathrm{~m}$ ) are important indicators of Golden-wing nest sites.

Successful and failed nests. Small sample size limited the power of the models partitioning successful and failed nests. However, there is certainly information to be gleaned from the primarily descriptive models. Only one nest with $\geq 4.5 \%$ woody cover within a $1 \mathrm{~m}$ radius circle failed, and five of the seven successful nests in this group had a woody stem supporting the nest. Essentially, the first split is a product of plots having very little or no woody cover (mostly failed nests and some successful nests) versus plots where the nest was supported by a shrub or there were several shrub stems nearby. Only two successful nests had no woody cover in the $1 \mathrm{~m}$ radius plot, and these nests were built in patches of Rubus, a potential surrogate for woody substrate. However, Bulluck and Buehler (2008) found that Golden-wing nests with a woody stem in the substrate had marginally lower daily survival rates (DSR) than nests without a woody stem, although they admit that the presence of a woody stem may not significantly affect DSR. Demmons (2000) discovered that woody vegetation density (successful $=22.7 \pm 2.4$ stems, failed $=22.8 \pm 3.3$ stems) immediately surrounding the nest had no effect on nesting success of Golden-wings breeding in a patchy matrix of forest and agricultural fields in southeastern Ontario.

In our study, when woody cover was $<4.5 \%$ and the nest was oriented towards the east, all nests were successful, although only three nests met these criteria. Conversely, five of six nests facing north, south, or west failed. Four depredated nests were excluded from the tree at this split because we were unable to assign a value for nest orientation at these disturbed nests. Similarly in a subset of nests of the macrohabitat model, two successful nests were characterized 
by south or east facing plots and four unsuccessful nests by plots that faced north or west. Other studies have demonstrated that certain nest orientations may be favorable for regulating microclimate factors like wind and solar radiation (Burton 2007), especially among cavitynesting species (Ardia et al. 2006) and those breeding in harsh environments (Hartman and Oring 2003). Golden-wing nests on our study areas may face east to take advantage of solar radiation in the morning when mean low temperatures are around $7^{\circ} \mathrm{C}$ in May and $12^{\circ} \mathrm{C}$ in June. Burton (2007) found that ground nesting birds at mid-latitudes often orient their nests toward the east for warmth in the morning and shade in the afternoon. There can be considerable variation in preferred nest orientation among species (Burton 2007), and the implications on survival are not always consistent (Högstedt 1978, Lloyd and Martin 2004).

For the analysis of successful and failed nests at the macrohabitat scale, we chose the tree with the minimum CV error rather than the smallest tree within 1-SE of the minimum because we required a more descriptive tree than one with only two terminal nodes differentiated by the amount of grass cover within the 0.04 ha plot. Although this tree may overfit the data and might perform poorly as a predictive model, some interesting patterns emerged. Eighty-two percent of successful nests follow the right-hand splits down the length of the tree, making this tree easy to follow even given the number of terminal nodes. Conversely, a variety of conditions led to unsuccessful nests. Amount of grass cover was the most important splitting variable, as it for differentiating between nests and random points. Almost all nests had $\geq 37.5 \%$ grass cover across the 0.04 ha plot, but apparently there could be a maximum threshold as there were no successful nests with $\geq 87.5 \%$ grass cover. A homogeneous patch of pasture grasses could not only make the nest more conspicuous and lack the structural characteristics desired for nest construction (i.e., rigid stems, edges; Confer 1992), but also might be more easily disturbed by livestock grazing. The variation in habitat characteristics among unsuccessful nests is evidence of an array of environmental conditions in these study sites that could lead to failure. Conversely, similarity among most successful nests is evidence of a limited set of habitat characteristics that may predispose nests to be successful. Some publications have failed to show a definitive relation between nest-site selection and nest survival (e.g., Wilson and Gende 2000, Siepielski et al. 2001), even specifically among Golden-wings (Bulluck and Buehler 2008). 
Whether partitioning nests and random points or successful and unsuccessful nests, it appears that microhabitat characteristics may be more meaningful than larger scale factors at explaining differences between plots. Our reasoning for this conclusion is that a model incorporating variables from both scales (micro- and macrohabitat, see Table 2) used only variables from the microhabitat suite following the 1-SE tree selection rule. This is not to say that broader scale features are not important for identifying nest sites or more specifically successful or unsuccessful nests, but according to our data and analytical technique, fine scale habitat characteristics may be of more importance. Broad-scale characteristics could prove to be more important across different habitats and regions, but our data were limited to a single habitat type. Synthesis of findings from analyses at both scales might direct our attention toward east facing nests with some woody cover within a $1 \mathrm{~m}$ radius circle (at least $4.5 \%$ ), not too much grass cover within $11.3 \mathrm{~m}(<87.5 \%)$, a moderately tall shrub layer $(\geq 1.9 \mathrm{~m})$, and some vine cover within $11.3 \mathrm{~m}(<17.5 \%)$. None of the global models used variables from both scales following the 1-SE tree selection rule.

Conservation implications. Two years of data collection suggest that these highelevation grazing allotments provide quality breeding habitat for Golden-wings. Reproductive parameters are comparable to, and in some cases greater than, values from other studies across the Golden-wing's range (Will 1986, Confer 1992, Canterbury et al. 1996, Klaus and Buehler 2001, Confer et al. 2003, Reed et al. 2007, Bulluck and Buehler 2008, Kubel and Yahner 2008). Our Mayfield nest success (52.0\%) fell near the middle of other published values (Table 1). Productivity was relatively high at 2.44 young per nest compared to other studies that ranged from 0.57 (Kubel and Yahner 2008) to 3.65 young per nest (Klaus and Buehler 2001). Although based on one year of data, return rates by adults (7/13 males, $5 / 5$ females) and juveniles (3/15) may bolster reproductive output by ensuring multiple years of productivity for most adults while a considerable proportion of their nestlings returned the following year to breed and pioneer new habitat patches (K. Aldinger, unpubl. data). Nest parasitism by Brown-headed Cowbirds was not observed on the allotments, another testament to the value of these habitats despite findings that cowbirds often are more abundant in agricultural settings (Thompson et al. 2000). Most likely due to elevation (Buehler et al. 2007, R. Tallman pers. comm.), no territorial Blue-wings and only one hybrid occurred each year on the study sites. Few locales experience allopatry, although it occurs in central West Virginia and the Cumberland Mountains, Tennessee (Welton 
2003, Bulluck 2007) due to elevation and in Manitoba due to latitude (Vallender et al. 2009). The reduction in competition and lost reproductive output could be critical for persistence of both Golden-wings and Blue-wings in the Appalachian region. Although genetic introgression may be occurring on high-elevation pasturelands in central West Virginia (see Vallender et al. 2009), we rarely observed stereotypic hybrids or individuals displaying phenotypic characteristics of Blue-wings. Low-intensity grazing can be an inexpensive and minimal-effort management tool on high-elevation pasturelands in West Virginia, and potentially elsewhere, to encourage breeding of Golden-wings in isolation from their Blue-winged counterparts.

Specific management prescriptions for Golden-wings will strive to create a complex, patchy mosaic of grasses, forbs, Rubus, shrubs, saplings, few canopy trees, and a forested edge. Transitional areas between dense vegetation and open areas are important for nesting, and can be accomplished with such practices as grazing, mowing, or prescribed fire. Golden-wing nests were within $1.4 \pm 0.5 \mathrm{~m}$ of a shrub, with successful nests being closer still $(0.8 \pm 0.4 \mathrm{~m})$, and shrubs averaged $2.0 \pm 0.3 \mathrm{~m}$ in height. The overall shrub layer generally was about $3 \mathrm{~m}$ in height. Habitat managers may not need to wait years for a substantial shrub layer to develop though, because fast growing Rubus served as a tall, rigid substrate at nests where shrubs were farther away. Vegetation was relatively dense at most territories ( $\geq 38.1 \%)$ and nests $(\geq 51.9 \%)$, and was neither completely open nor overcrowded. Grasses (37.5-87.5\% cover across 0.04 ha), forbs ( $75 \%$ cover across $0.04 \mathrm{ha}$ ), and woody vegetation (at least $4.5 \%$ cover near the nest site and $\sim 30-40 \%$ shrub/sapling cover across 0.04 ha) were important components of Golden-wing territories and nest sites and need to be distributed in an overlapping, structurally complex manner.

\section{LiTERATURE CiTED}

Ardia, D. R., J. H. Pérez, E. D. Clotfelter. 2006. Nest box orientation affects internal temperature and nest site selection by Tree Swallows. Journal of Field Ornithology 77:339-344.

Baldi, A., P. Batary, and S. Erdos. 2005. Effects of grazing intensity on bird assemblages and populations of Hungarian grasslands. Agriculture, Ecosystems and Environment 108:251263.

Beyer, H. L. 2006. Hawth's Analysis Tools for ArcGIS. Version 3.27. Available at http://www.spatialecology.com/htools.

Breiman, L., J. H. Friedman, R. A. Olshen, and C. G. Stone. 1984. Classification and regression trees. Wadsworth International Group, Belmont, California. 
Breiman, L., J. H. Friedman, R. A. Olshen, and C. G. Stone. 1984. Classification and regression trees. Wadsworth International Group, Belmont, California.

Breitwisch, R., N. Gottleib, and J. Zaias. 1989. Behavioral differences in nest visits between male and female Northern Mockingbirds. Auk 106:659-665.

Buehler, D. A., A. M. Roth, R. Vallender, T. C. Will, J. L. Confer, R. A. Canterbury, S. B. Swarthout, K. V. Rosenberg, and L. P. Bulluck. 2007. Status and conservation priorities of Golden-winged Warbler (Vermivora chrysoptera) in North America. Auk 124:14391445.

Bulluck, L. P. 2007. Golden-winged Warbler (Vermivora chrysoptera) demographics and habitat use and the potential effects of land use change on Golden-winged and Cerulean (Dendroica cerulean) in the Cumberland Mountains of Tennessee. Ph.D. dissertation, University of Tennessee, Knoxville, TN.

Bulluck, L. P., and D. A. Buehler. 2008. Factors influencing Golden-winged Warbler (Vermivora chrysoptera) nest-site selection and nest survival in the Cumberland Mountains of Tennessee. Auk 125:551-559.

Burton, N. H. K. 2007. Intraspecific latitudinal variation in nest orientation among groundnesting passerines: A study using published data. Condor 109:441-446.

Canterbury, R. A., D. M. Stover, and J. J. Kotesovec Jr. 1996. Population ecology of Goldenwinged Warblers in southern West Virginia. West Virginia Division of Natural Resources, Elkins, WV.

Confer, J. L. 1992. Golden-winged Warbler (Vermivora chrysoptera). In The Birds of North America, no. 20 (Poole, A., P. Steenheim, and F. Gill, Eds.). Academy of Natural Sciences, Philadelphia, PA and American Ornithologists' Union, Washington, D.C.

Confer, J. L., J. L. Larkin, and P. E. Allen. 2003. Effects of vegetation, interspecific competition, and brood parasitism on Golden-winged Warbler (Vermivora chrysoptera) nesting success. Auk 120:138-144.

Confer, J. L., and K. Knapp. 1981. Golden-winged Warblers and Blue-winged Warblers: The relative success of a habitat specialist and a generalist. Auk 98:108-114.

De'ath, G. and K. A. Fabricius. 2000. Classification and regression trees: A powerful yet simple technique for ecological data analysis. Ecology 81:3178-3192.

Dellinger, R. L., P. B. Wood, P. D. Keyser, and G. Seidel. 2007. Habitat partitioning of four sympatric thrush species at three spatial scales on a managed forest in West Virginia. Auk 124:1425-1438.

Demmons, T. D. 2000. Nest site selection and nest predation patterns at forest-field edges. M.S. thesis, Queen's University, Kingston, Ontario, Canada.

Edalgo, J. A., H. M. McChesney, J. P. Love, J. T. Anderson. 2009. Microhabitat use by whitefooted mice Peromyscus leucopus in forested and old-field habitats occupied by Morrow's honeysuckle Lonicera morrowii. Current Zoology 55:111-122. 
Ehrlich, P. R., D. S. Dobkin, and D. Wheye. 1988. The birder's handbook: A field guide to the natural history of North American birds. Simon and Schuster, New York, NY.

ESRI. 2008. ArcGIS Version 9.2. 380 New York St, Redlands, CA 92373-8100.

Ferraro, D. O., D. E. Rivero, and C. M. Ghersa. 2009. An analysis of the factors that influence sugarcane yield in Northern Argentina using classification and regression trees. Field Crops Research 112:149-157.

Ficken, M. S., and R. W. Ficken. 1968. Ecology of Blue-winged Warblers, Golden-winged Warblers and some other Vermivora. American Midland Naturalist 79:311-319.

Frech, M. H., and J. L. Confer. 1987. The Golden-winged Warbler: Competition with the Bluewinged Warbler and habitat selection in portions of southern, central, and northern New York. Kingbird 37:65-72.

Hartman, C. A., and L. W. Oring. 2003. Orientation and microclimate of Horned Lark nests: The importance of shade. Condor 105:158-163.

Hauber, M. E., and S. A. Russo. 2000. Perch proximity correlates with higher rates of cowbird parasitism of ground nesting Song Sparrows. Wilson Bulletin 112:150-153.

Highsmith, R. T. 1989. The singing behavior of Golden-winged Warblers. Wilson Bulletin 101: 36-50.

Högstedt, G. 1978. Orientation of the entrance in Tawny Pipit Anthus campestris nests. Ornis Scandinavica 9:193-196.

Hughes, J. P., R. J. Robel, K. E. Kemp, and J. L. Zimmerman. 1999. Effects of habitat on Dickcissel abundance and nest success in Conservation Reserve Program fields in Kansas. Journal of Wildlife Management 63:523-529.

James, F. C., and H. H. Shugart, Jr. 1970. A quantitative method of habitat description. Audubon Field Notes 24:727-736.

Klaus, N. A., and D. A. Buehler. 2001. Golden-winged Warbler breeding habitat characteristics and nest success in clearcuts in the southern Appalachian Mountains. Wilson Bulletin 113:297-301.

Kubel, J. E., and R. H. Yahner. 2007. Detection probability of Golden-winged Warblers during point counts with and without playback recordings. Journal of Field Ornithology 78:195205.

Kubel, J. E., and R. H. Yahner. 2008. Quality of anthropogenic habitat for Golden-winged Warblers in Central Pennsylvania. Wilson Journal of Ornithology 120:801-812.

LeClerc, M. G. 1982. Bird communities and vegetation structure of reclaimed surface mines in West Virginia. M.S. thesis, West Virginia University, Morgantown, WV.

Lloyd, J. D., and T. E. Martin. 2004. Nest-site preference and maternal effects on offspring growth. Behavioral Ecology 15:816-823. 
Lusk, J. J., K. S. Wells, F. S. Guthery, S. D. Fuhlendorf. 2003. Lark Sparrow (Chondestes grammacus) nest-site selection and success in a mixed-grass prairie. Auk 120:120-129.

Martin, K. J., R. S. Lutz, and M. Worland. 2007. Golden-winged Warbler habitat use and abundance in northern Wisconsin. Wilson Journal of Ornithology 119:523-532.

Martin, T. E. 1993a. Nest predation among vegetation layers and habitat types: Revising the dogmas. American Naturalist 141:897-913.

Martin, T. E. 1993b. Nest predation and nest sites: New perspectives on old patterns. BioScience 43:523-532.

Martin, T. E., C. J. Conway, W. M. Hochachaka, P. Allen, and W. Jenkins. 1997. BBIRD field protocols. U.S.G.S. Biological Resources Division, Montana Cooperative Wildlife Research Unit, University of Montana, Missoula. Available at http://www.umt.edu/bbird/protocol/veg.htm.

Martin, T. E., and G. R. Geupel. 1993. Nest-monitoring plots: Methods for locating nests and monitoring success. Journal of Field Ornithology 64:507-519.

Martin, T. G., and S. McIntyre. 2007. Impacts of livestock grazing and tree clearing on birds of woodland and riparian habitats. Conservation Biology 21:504-514.

Mayfield, H. 1961. Nesting success calculated from exposure. Wilson Bulletin 73:255-261.

Niering, W. A., and R. H. Goodwin. 1974. Creation of relatively stable shrublands with herbicides: Arresting "succession" on rights-of-way and pastureland. Ecology 55:784795.

Popotnik, G. J., and W. M. Giuliano. 2000. Response of birds to grazing of riparian zones. Journal of Wildlife Management 64:976-982.

R Development Core Team. 2008. R: A Language and Environment for Statistical Computing. R Foundation for Statistical Computing, Vienna, Austria.

Reed, L. P, R. Vallender, and R. J. Robertson. 2007. Provisioning rates by Golden-winged Warblers. Wilson Journal of Ornithology 119:350-355.

Rossell, C. R. 2001. Song perch characteristics of Golden-winged Warblers in a mountain wetland. Wilson Bulletin 113:246-248.

Rossell, C. R., S. C. Patch, and S. P. Wilds. 2003. Attributes of Golden-winged Warbler territories in a mountain wetland. Wildlife Society Bulletin 31:1099-1104.

Roth, A. M., and R. S. Lutz. 2004. Relationships between territorial male Golden-winged Warblers in managed aspen stands in northern Wisconsin, USA. Forest Science 50:153161.

Siepielski, A. M., A. D. Rodewald, and R. H. Yahner. 2001. Nest site selection and nesting success of the Red-eyed Vireo in central Pennsylvania. Wilson Bulletin 113:302-307. 
Stapp, P., and B. Van Horne. 1997. Response of deer mice (Peromyscus maniculatus) to shrubs in shortgrass prairie: Linking small-scale movements and the spatial distribution of individuals. Functional Ecology 11:644-651.

Thompson, F. R. III, S. K. Robinson, T. M. Donovan, J. Faaborg, D. R. Whitehead. 2000. Biogeographic, landscape, and local factors affecting cowbird abundance and host parasitism levels. Pages 271-279 in Ecology and management of cowbirds (Cooke T., S. K. Robinson, S. I. Rothstein, S. G. Sealy, J. N. M. Smith, Eds.). University of Texas Press, Austin, TX.

Vallender, R., S.L. Van Wilgenburg, L.P. Bulluck, A. Roth, R. Canterbury, J. Larkin, R. Fowlds, and I.J. Lovette. 2009. Extensive rangewide mitochondrial introgression indicates substantial cryptic hybridization in the Golden-winged Warbler (Vermivora chrysoptera). Avian Conservation and Ecology 4:4. Available at http://www.ace-eco.org/vol4/iss2/art4/

Vaysseires, M. P., R. E. Plant, and B. H. Allen-Diaz. 2000. Classification trees: An alternative non-parametric approach for predicting species distributions. Journal of Vegetation Science 11:679-694.

Warren, K. A., and J. T. Anderson. 2005. Grassland songbird nest-site selection and response to mowing in West Virginia. Wildlife Society Bulletin 33:285-292.

Welton, M. 2003. Status and distribution of the Golden-winged Warbler in Tennessee. Migrant 74:61-82.

Will, T. C. 1986. The behavioral ecology of species replacements: Blue-winged and Goldenwinged warblers in Michigan. Ph.D. dissertation, University of Michigan, Ann Arbor, MI.

Wilson, R. R., and R. J. Cooper. 1998. Acadian Flycatcher nest placement: Does placement influence reproductive success? Condor 100:673-679.

With, K. A. 1994. The hazards of nesting near shrubs for a grassland bird, the McCown's Longspur. Condor 96:1009-1019. 


\section{TABLES AND FIGURES}

Table 1. Summary of Golden-winged Warbler nesting demographics.

\begin{tabular}{|c|c|c|c|c|c|c|c|c|}
\hline State & Habitat & $\mathrm{N}$ & Years & $\begin{array}{l}\% \text { Nest } \\
\text { success }\end{array}$ & $\begin{array}{c}\text { Clutch } \\
\text { size }\end{array}$ & Productivity $^{\mathrm{a}}$ & $\begin{array}{c}\% \\
\text { parasitized }\end{array}$ & Authors \\
\hline MI & $\begin{array}{l}\text { Tamarack } \\
\text { swamps, } \\
\text { successional } \\
\text { fields, } \\
\text { overgrown } \\
\text { cuttings }\end{array}$ & 13 & $\begin{array}{l}1981- \\
1983\end{array}$ & $85^{b}$ & 4.69 & 3.30 & 31 & Will 1986 \\
\hline NY & $\begin{array}{l}\text { Old fields, } \\
\text { young forests }\end{array}$ & 12 & $\begin{array}{l}1990- \\
1991\end{array}$ & -- & 4.80 & 2.00 & 35 & Confer 1992 \\
\hline WV & $\begin{array}{l}\text { Reclaimed } \\
\text { surface mines, } \\
\text { cutover forests }\end{array}$ & 347 & $\begin{array}{l}1987- \\
1996\end{array}$ & 61 & 4.80 & 3.22 & 0 & $\begin{array}{l}\text { Canterbury et al. } \\
1996\end{array}$ \\
\hline ON & $\begin{array}{l}\text { Deciduous } \\
\text { forest mixed } \\
\text { with } \\
\text { agricultural } \\
\text { fields and } \\
\text { swamps }\end{array}$ & 49 & $\begin{array}{l}1998- \\
1999\end{array}$ & 44 & -- & -- & 2 & Demmons 2000 \\
\hline $\mathrm{NC}$ & $\begin{array}{l}\text { Forest } \\
\text { regeneration } \\
\text { areas }\end{array}$ & 23 & $\begin{array}{l}1997- \\
1998\end{array}$ & 73 & 4.50 & 3.65 & 0 & $\begin{array}{l}\text { Klaus and } \\
\text { Buehler } 2001\end{array}$ \\
\hline NY & $\begin{array}{l}\text { Old fields, } \\
\text { young forests }\end{array}$ & 69 & $\begin{array}{l}1988- \\
1994\end{array}$ & 38 & 4.39 & $1.00-2.30^{\mathrm{c}}$ & 30 & $\begin{array}{l}\text { Confer et al. } \\
2003\end{array}$ \\
\hline $\mathrm{ON}$ & $\begin{array}{l}\text { Abandoned } \\
\text { farmland, } \\
\text { swamps, }\end{array}$ & 6 & 2004 & -- & 5.00 & -- & -- & Reed et al. 2007 \\
\hline ON & $\begin{array}{l}\text { second growth } \\
\text { forest, rocky } \\
\text { outcrops }\end{array}$ & 55 & $\begin{array}{l}2001- \\
2003\end{array}$ & $56^{\mathrm{b}}$ & 5.06 & -- & -- & $\begin{array}{l}\text { Vallender et al. } \\
2007\end{array}$ \\
\hline PA & $\begin{array}{l}\text { Patch clearcuts, } \\
\text { utility ROWs }\end{array}$ & 39 & $\begin{array}{l}2002- \\
2003\end{array}$ & $20-46^{\mathrm{d}}$ & 4.00 & $0.57-2.38^{\mathrm{d}}$ & 15 & $\begin{array}{l}\text { Kubel and } \\
\text { Yahner } 2008\end{array}$ \\
\hline TN & $\begin{array}{l}\text { Reclaimed } \\
\text { surface mines }\end{array}$ & 102 & $\begin{array}{l}2003- \\
2006\end{array}$ & 49 & 4.30 & -- & 3 & $\begin{array}{l}\text { Bulluck and } \\
\text { Buehler } 2008\end{array}$ \\
\hline WV & $\begin{array}{l}\text { Active grazing } \\
\text { areas }\end{array}$ & 21 & $\begin{array}{l}2008- \\
2009\end{array}$ & 52 & 4.40 & 4.00 & 0 & $\begin{array}{l}\text { Aldinger and } \\
\text { Wood (unpubl.) }\end{array}$ \\
\hline
\end{tabular}

${ }^{a}$ Average number of fledglings across all nests (successful or unsuccessful)

${ }^{b}$ Nest success is the proportion of successful nests, all other estimates based on Mayfield (1961)

${ }^{c}$ Lower number is from parasitized nests and higher number is from unparasitized nests

${ }^{\mathrm{d}}$ Lower number is from utility ROWs and higher number is from patch clearcuts 
Table 2. Classification tree models by scale and variables included in initial models using data from 2008-2009 in Randolph and Pocahontas counties, WV.

\begin{tabular}{|c|c|c|c|c|c|c|c|c|c|}
\hline \multirow{2}{*}{ Variable } & \multicolumn{3}{|c|}{ Territory vs random } & \multicolumn{3}{|c|}{ Nest vs random } & \multicolumn{3}{|c|}{ Successful vs failed } \\
\hline & Micro & Macro & Global & Micro & Macro & Global & Micro & Macro & Global \\
\hline \multicolumn{10}{|c|}{ Visual \% cover estimate $(1 \mathrm{~m})$} \\
\hline Litter & $\mathrm{X}$ & & $\mathrm{X}$ & $\mathrm{X}$ & & $\mathrm{X}$ & $\mathrm{X}$ & & $\mathrm{X}$ \\
\hline Grass & X & & $X$ & X & & $X$ & X & & $X$ \\
\hline Bare & $\mathrm{X}$ & & $\mathrm{X}$ & $\mathrm{X}$ & & $\mathrm{X}$ & $\mathrm{X}$ & & $\mathrm{X}$ \\
\hline Forb & $\mathrm{X}$ & & $\mathrm{X}$ & $\mathrm{X}$ & & $\mathrm{X}$ & $\mathrm{X}$ & & $\mathrm{X}$ \\
\hline Woody & $\mathrm{X}$ & & $\mathrm{X}$ & $\mathrm{X}$ & & $\mathrm{X}$ & $\mathrm{X}$ & & $\mathrm{X}$ \\
\hline Vine & $\mathrm{X}$ & & $\mathrm{X}$ & $\mathrm{X}$ & & $\mathrm{X}$ & $\mathrm{X}$ & & $\mathrm{X}$ \\
\hline Rubus & $\mathrm{X}$ & & $\mathrm{X}$ & $\mathrm{X}$ & & $\mathrm{X}$ & $\mathrm{X}$ & & $\mathrm{X}$ \\
\hline \multicolumn{10}{|c|}{ Ocular tube $\%$ cover estimate $(11.3 \mathrm{~m})$} \\
\hline Grass & & & & & $\mathrm{X}$ & $\mathrm{X}$ & & $\mathrm{X}$ & $\mathrm{X}$ \\
\hline Forb & & & & & $\mathrm{X}$ & $\mathrm{X}$ & & $\mathrm{X}$ & $\mathrm{X}$ \\
\hline Vine & & & & & $\mathrm{X}$ & $\mathrm{X}$ & & $\mathrm{X}$ & $\mathrm{X}$ \\
\hline Rubus & & & & & $\mathrm{X}$ & $\mathrm{X}$ & & $\mathrm{X}$ & $\mathrm{X}$ \\
\hline Shrub & & & & & $\mathrm{X}$ & $\mathrm{X}$ & & $X$ & $\mathrm{X}$ \\
\hline Sapling & & & & & $\mathrm{X}$ & $\mathrm{X}$ & & $\mathrm{X}$ & $\mathrm{X}$ \\
\hline Canopy & & & & & $\mathrm{X}$ & $\mathrm{X}$ & & $\mathrm{X}$ & $\mathrm{X}$ \\
\hline Elevation (m) & & $\mathrm{X}$ & $\mathrm{X}$ & & $\mathrm{X}$ & $\mathrm{X}$ & & $X$ & $\mathrm{X}$ \\
\hline Slope $\left(^{\circ}\right)$ & & $\mathrm{X}$ & $\mathrm{X}$ & & $\mathrm{X}$ & $\mathrm{X}$ & & $\mathrm{X}$ & $\mathrm{X}$ \\
\hline Aspect $(\mathrm{N}, \mathrm{E}, \mathrm{S}, \mathrm{W})$ & & $\mathrm{X}$ & $\mathrm{X}$ & & $\mathrm{X}$ & $\mathrm{X}$ & & $X$ & $\mathrm{X}$ \\
\hline Litter depth $(\mathrm{cm})$ & $\mathrm{X}$ & & $\mathrm{X}$ & $\mathrm{X}$ & & $\mathrm{X}$ & $\mathrm{X}$ & & $\mathrm{X}$ \\
\hline Basal area (m2/ha) & & $\mathrm{X}$ & $\mathrm{X}$ & & $\mathrm{X}$ & $\mathrm{X}$ & & $\mathrm{X}$ & $\mathrm{X}$ \\
\hline Snag count & & $\mathrm{X}$ & $\mathrm{X}$ & & $\mathrm{X}$ & $\mathrm{X}$ & & $\mathrm{X}$ & $\mathrm{X}$ \\
\hline Edge distance $(\mathrm{m})$ & & $\mathrm{X}$ & $\mathrm{X}$ & & $\mathrm{X}$ & $\mathrm{X}$ & & $\mathrm{X}$ & $\mathrm{X}$ \\
\hline Vegetation density (\%) & & $\mathrm{X}$ & $\mathrm{X}$ & & $\mathrm{X}$ & $\mathrm{X}$ & & $X$ & $\mathrm{X}$ \\
\hline Ht. of sapling layer (m) & & $\mathrm{X}$ & $\mathrm{X}$ & & $\mathrm{X}$ & $\mathrm{X}$ & & $\mathrm{X}$ & $\mathrm{X}$ \\
\hline Ht. of shrub layer (m) & & $\mathrm{X}$ & $\mathrm{X}$ & & $\mathrm{X}$ & $\mathrm{X}$ & & $\mathrm{X}$ & $\mathrm{X}$ \\
\hline \multicolumn{10}{|c|}{ Nest microhabitat characteristics } \\
\hline Distance to shrub ste & & & & $\mathrm{X}$ & & $\mathrm{X}$ & $\mathrm{X}$ & & $\mathrm{X}$ \\
\hline Distance to shrub br & (m) & & & $\mathrm{X}$ & & $\mathrm{X}$ & $\mathrm{X}$ & & $\mathrm{X}$ \\
\hline Shrub Height (m) & & & & $\mathrm{X}$ & & $\mathrm{X}$ & $\mathrm{X}$ & & $\mathrm{X}$ \\
\hline Max Shrub Width (n & & & & $\mathrm{X}$ & & $\mathrm{X}$ & $\mathrm{X}$ & & $\mathrm{X}$ \\
\hline Shrub Width Perpen & $\operatorname{lar}(\mathrm{m})$ & & & $\mathrm{X}$ & & $\mathrm{X}$ & $\mathrm{X}$ & & $\mathrm{X}$ \\
\hline \# shrub stems@10 & & & & $\mathrm{X}$ & & $\mathrm{X}$ & $\mathrm{X}$ & & $\mathrm{X}$ \\
\hline Height to nest rim (c & & & & & & & $\mathrm{X}$ & & $\mathrm{X}$ \\
\hline Nest substrate ht. (cr & & & & & & & $\mathrm{X}$ & & $\mathrm{X}$ \\
\hline Overhead cover $(\%)$ & & & & & & & $\mathrm{X}$ & & $\mathrm{X}$ \\
\hline Nest orientation $(\mathrm{N}, \mathrm{I}$ & & & & & & & $\mathrm{X}$ & & $\mathrm{X}$ \\
\hline Tree selection rule ${ }^{\mathrm{a}}$ & 1-SE & $1-\mathrm{SE}$ & $1-\mathrm{SE}$ & $1-\mathrm{SE}$ & $1-\mathrm{SE}$ & $1-\mathrm{SE}$ & 1-SE & MIN & $1-\mathrm{SE}$ \\
\hline$\%$ variation explained & 47.6 & 28.6 & 28.6 & 52.4 & 57.1 & 52.4 & 80.0 & 90.0 & 80.0 \\
\hline Misclass rate (\%) & 26.2 & 35.7 & 35.7 & 23.8 & 21.4 & 23.8 & 9.5 & 4.8 & 9.5 \\
\hline $\mathrm{CV}$ error & 0.91 & 0.78 & 0.79 & 0.57 & 0.91 & 0.57 & 1.34 & 1.38 & 1.34 \\
\hline
\end{tabular}

${ }^{a}$ Tree selection rules are 1-SE (smallest tree within $1 \mathrm{SE}$ of the minimum CV error) and minimum (MIN; tree with the smallest $\mathrm{CV}$ error overall). 
Table 3. Means and standard errors for vegetation variables measured during 2008-2009 in Randolph and Pocahontas counties, WV.

\begin{tabular}{|c|c|c|c|c|c|c|c|c|c|c|c|c|}
\hline \multirow[b]{2}{*}{ Variable } & \multicolumn{2}{|c|}{$\begin{array}{l}\text { Territory } \\
(n=63)\end{array}$} & \multicolumn{2}{|c|}{$\begin{array}{l}\text { Paired territory } \\
\qquad(\mathrm{n}=63)\end{array}$} & \multicolumn{2}{|c|}{$\begin{array}{c}\text { Nest } \\
(\mathrm{n}=21)\end{array}$} & \multicolumn{2}{|c|}{$\begin{array}{l}\text { Paired nest } \\
(\mathrm{n}=21)\end{array}$} & \multicolumn{2}{|c|}{$\begin{array}{l}\text { Successful nest } \\
(\mathrm{n}=11)\end{array}$} & \multicolumn{2}{|c|}{$\begin{array}{l}\text { Failed nest } \\
\qquad(\mathrm{n}=10)\end{array}$} \\
\hline & $\overline{\mathrm{x}}$ & SE & $\overline{\mathrm{x}}$ & SE & $\overline{\mathrm{x}}$ & SE & $\overline{\mathrm{x}}$ & $\mathrm{SE}$ & $\overline{\mathrm{x}}$ & $\mathrm{SE}$ & $\overline{\mathrm{x}}$ & $\mathrm{SE}$ \\
\hline \multicolumn{13}{|c|}{ Visual $\%$ cover estimate $(1 \mathrm{~m})$} \\
\hline Litter & 9.2 & 1.4 & 12.8 & 1.9 & 10.0 & 2.6 & 13.6 & 3.3 & 11.7 & 3.2 & 8.1 & 4.1 \\
\hline Grass & 23.8 & 2.4 & 20.5 & 2.5 & 21.2 & 3.8 & 25.3 & 5.4 & 15.1 & 3.6 & 27.9 & 6.6 \\
\hline Bare & 2.8 & 0.5 & 7.4 & 2.0 & 2.1 & 0.6 & 5.5 & 2.3 & 2.5 & 0.8 & 1.8 & 1.1 \\
\hline Forb & 42.1 & 2.6 & 46.5 & 2.8 & 37.5 & 4.0 & 31.0 & 6.1 & 40.1 & 5.6 & 34.6 & 5.8 \\
\hline Woody & 3.9 & 0.9 & 2.3 & 0.6 & 6.5 & 2.2 & 2.9 & 1.0 & 9.1 & 3.3 & 3.5 & 2.6 \\
\hline Vine & 2.9 & 0.8 & 1.3 & 0.5 & 3.5 & 1.5 & 1.4 & 0.7 & 3.4 & 1.9 & 3.7 & 2.5 \\
\hline Rubus & 15.3 & 2.1 & 9.4 & 1.9 & 19.2 & 4.0 & 20.3 & 6.5 & 18.1 & 6.4 & 20.4 & 5.0 \\
\hline \multicolumn{13}{|c|}{ Ocular tube $\%$ cover estimate $(11.3 \mathrm{~m})^{\mathrm{a}}$} \\
\hline Grass & 58.3 & 3.8 & 63.3 & 4.8 & 65.5 & 4.7 & 55.0 & 5.9 & 60.9 & 5.4 & 70.5 & 7.9 \\
\hline Forb & 73.6 & 2.4 & 75.2 & 2.5 & 77.6 & 3.2 & 73.8 & 3.5 & 76.4 & 4.0 & 79.0 & 5.4 \\
\hline Vine & 16.3 & 3.2 & 10.7 & 3.6 & 14.5 & 3.8 & 11.9 & 4.1 & 11.8 & 4.1 & 17.5 & 6.7 \\
\hline Rubus & 39.8 & 3.7 & 29.8 & 4.5 & 36.2 & 5.9 & 36.2 & 6.8 & 34.1 & 7.7 & 38.5 & 9.3 \\
\hline Shrub & 33.5 & 2.7 & 27.9 & 4.4 & 35.7 & 3.6 & 32.6 & 4.0 & 37.7 & 3.5 & 33.5 & 6.5 \\
\hline Sapling & 5.6 & 1.3 & 3.4 & 1.1 & 3.8 & 1.8 & 9.3 & 2.9 & 4.1 & 3.1 & 3.5 & 1.5 \\
\hline Canopy & 7.4 & 2.0 & 16.0 & 4.8 & 6.7 & 2.3 & 5.7 & 2.3 & 6.8 & 3.5 & 6.5 & 3.1 \\
\hline Elevation (m) & 928.7 & 11.3 & 945.9 & 13.6 & 923.8 & 19.2 & 920.8 & 19.0 & 914.6 & 22.4 & 933.9 & 32.9 \\
\hline Slope $\left(^{\circ}\right)$ & 12.0 & 0.9 & 13.9 & 1.1 & 14.6 & 1.9 & 16.6 & 2.7 & 16.0 & 2.5 & 13.1 & 3.1 \\
\hline Litter depth (cm) & 3.0 & 0.2 & 2.2 & 0.2 & 3.2 & 0.3 & 3.8 & 0.7 & 3.3 & 0.5 & 3.1 & 0.5 \\
\hline Basal area (m2/ha) & 0.8 & 0.2 & 2.2 & 0.5 & 1.1 & 0.3 & 1.4 & 0.5 & 1.1 & 0.5 & 1.0 & 0.4 \\
\hline Snag count & 0.8 & 0.6 & 6.0 & 3.3 & 1.2 & 1.2 & 6.0 & 3.8 & 0.0 & 0.0 & 2.5 & 2.5 \\
\hline Edge distance (m) & 33.4 & 2.5 & 34.5 & 2.9 & 31.3 & 4.0 & 35.4 & 5.3 & 29.5 & 6.1 & 33.3 & 5.4 \\
\hline Vegetation density (\%) & 65.8 & 2.3 & 55.0 & 3.3 & 69.0 & 3.5 & 65.9 & 5.1 & 64.0 & 4.3 & 74.5 & 5.2 \\
\hline Ht. of sapling layer (m) & 2.9 & 0.3 & 2.4 & 0.4 & 3.1 & 0.5 & 2.8 & 0.6 & 3.3 & 0.7 & 2.8 & 0.8 \\
\hline Ht. of shrub layer (m) & 3.2 & 0.2 & 3.1 & 0.2 & 3.1 & 0.2 & 3.4 & 0.2 & 3.4 & 0.3 & 2.7 & 0.2 \\
\hline
\end{tabular}

${ }^{\mathrm{a}}$ These variables were not measured in 2009 at territory centers and paired territory plots, so values presented are based on sample sizes of 43 territories ( $n=22$ territories and $n=21$ nests) and 29 paired territories collected. 
Table 4. Means and standard errors for nest microhabitat characteristics collected at nests $(n=21)$ and paired nest points $(\mathrm{n}=21)$ during 2008-2009 in Randolph and Pocahontas counties, WV.

\begin{tabular}{|c|c|c|c|c|c|c|c|c|}
\hline \multirow{2}{*}{$\begin{array}{l}\text { Nest microhabitat } \\
\text { characteristics }\end{array}$} & \multicolumn{2}{|c|}{$\begin{array}{c}\text { Nest } \\
(\mathrm{n}=21)\end{array}$} & \multicolumn{2}{|c|}{$\begin{array}{l}\text { Paired nest } \\
(\mathrm{n}=21)\end{array}$} & \multicolumn{2}{|c|}{$\begin{array}{l}\text { Successful } \\
(\mathrm{n}=11)\end{array}$} & \multicolumn{2}{|c|}{$\begin{array}{l}\text { Failed } \\
(\mathrm{n}=10)\end{array}$} \\
\hline & $\overline{\mathrm{x}}$ & SE & $\overline{\mathrm{x}}$ & SE & $\overline{\mathrm{x}}$ & SE & $\overline{\mathrm{x}}$ & SE \\
\hline $\begin{array}{l}\text { Distance to nearest shrub stem } \\
(\mathrm{m})\end{array}$ & 1.4 & 0.5 & 3.1 & 0.7 & 0.8 & 0.4 & 2.1 & 0.9 \\
\hline $\begin{array}{l}\text { Distance to nearest shrub } \\
\text { branch }(\mathrm{m})\end{array}$ & 0.9 & 0.4 & 1.8 & 0.6 & 0.5 & 0.3 & 1.4 & 0.9 \\
\hline Shrub ht. (m) & 2.0 & 0.3 & 3.1 & 0.4 & 1.8 & 0.4 & 2.2 & 0.4 \\
\hline Max shrub width (m) & 1.8 & 0.4 & 3.5 & 0.6 & 1.5 & 0.4 & 2.1 & 0.7 \\
\hline $\begin{array}{l}\text { Shrub width perpendicular to } \\
\max (\mathrm{m})\end{array}$ & 1.5 & 0.3 & 3.0 & 0.6 & 1.3 & 0.4 & 1.8 & 0.6 \\
\hline \# of shrub stems@10 cm & 4.0 & 1.1 & 2.5 & 0.6 & 4.7 & 1.9 & 3.2 & 1.1 \\
\hline Ht. to nest $\operatorname{rim}(\mathrm{cm})$ & 11.9 & 0.8 & -- & -- & 11.9 & 1.0 & 11.9 & 1.4 \\
\hline Nest substrate ht. $(\mathrm{cm})$ & 90.0 & 5.7 & -- & -- & 94.2 & 9.0 & 85.4 & 6.9 \\
\hline Overhead cover $(\%)$ & 84.3 & 5.0 & -- & -- & 89.8 & 4.8 & 78.3 & 9.0 \\
\hline
\end{tabular}




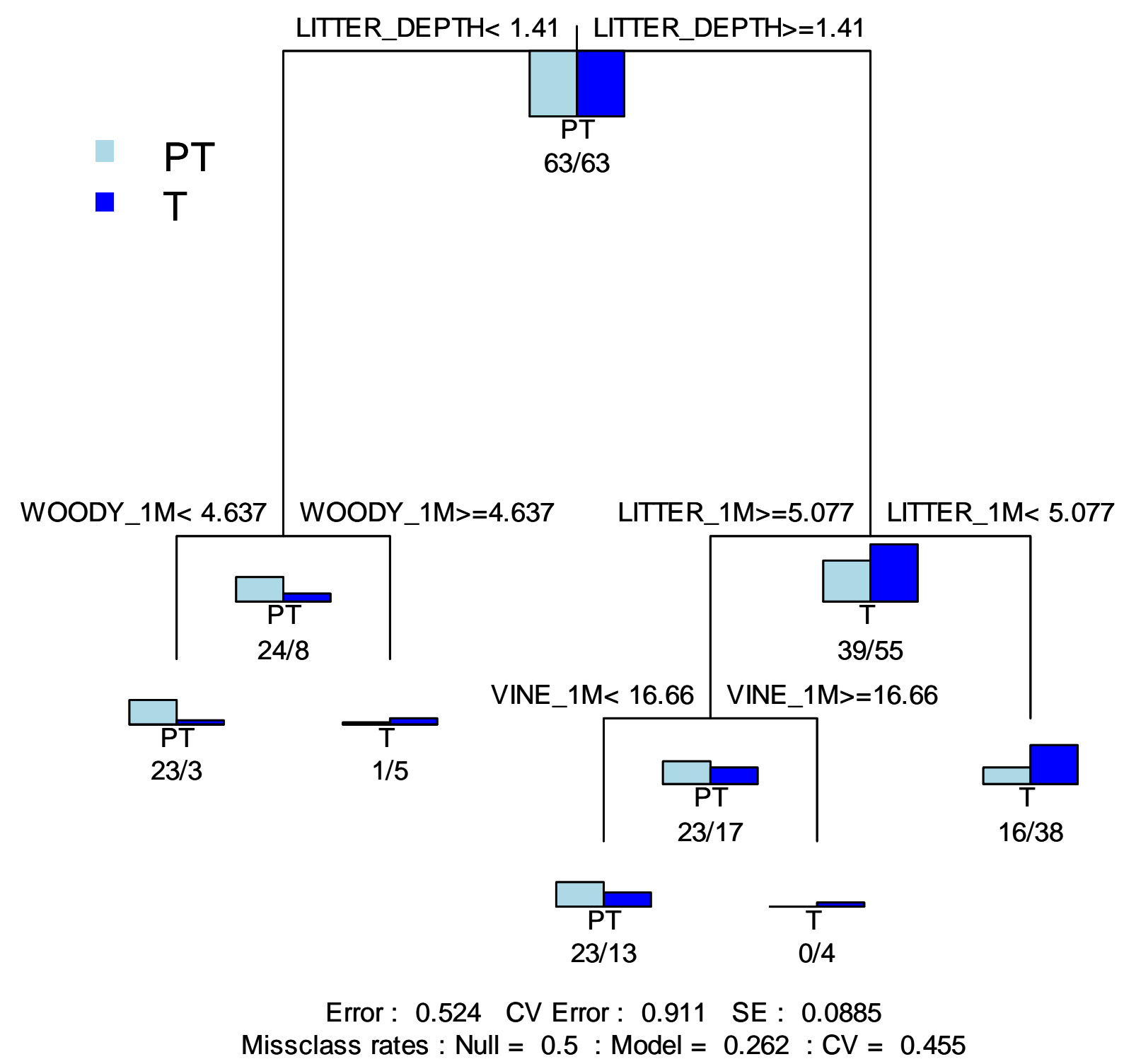

Figure 1. Classification tree for microhabitat characteristics at Golden-winged Warbler territories $(\mathrm{n}=63)$ and paired territory plots $(\mathrm{n}=63)$ during 2008-2009 in Randolph and Pocahontas counties, West Virginia. Letters below the histogram at each terminal node for all trees signify the dominant type (e.g., $\mathrm{PT}=$ =paired territory, $\mathrm{T}=$ territory center) and values represent the number of cases for that type at each node (\#PT/\#T). 


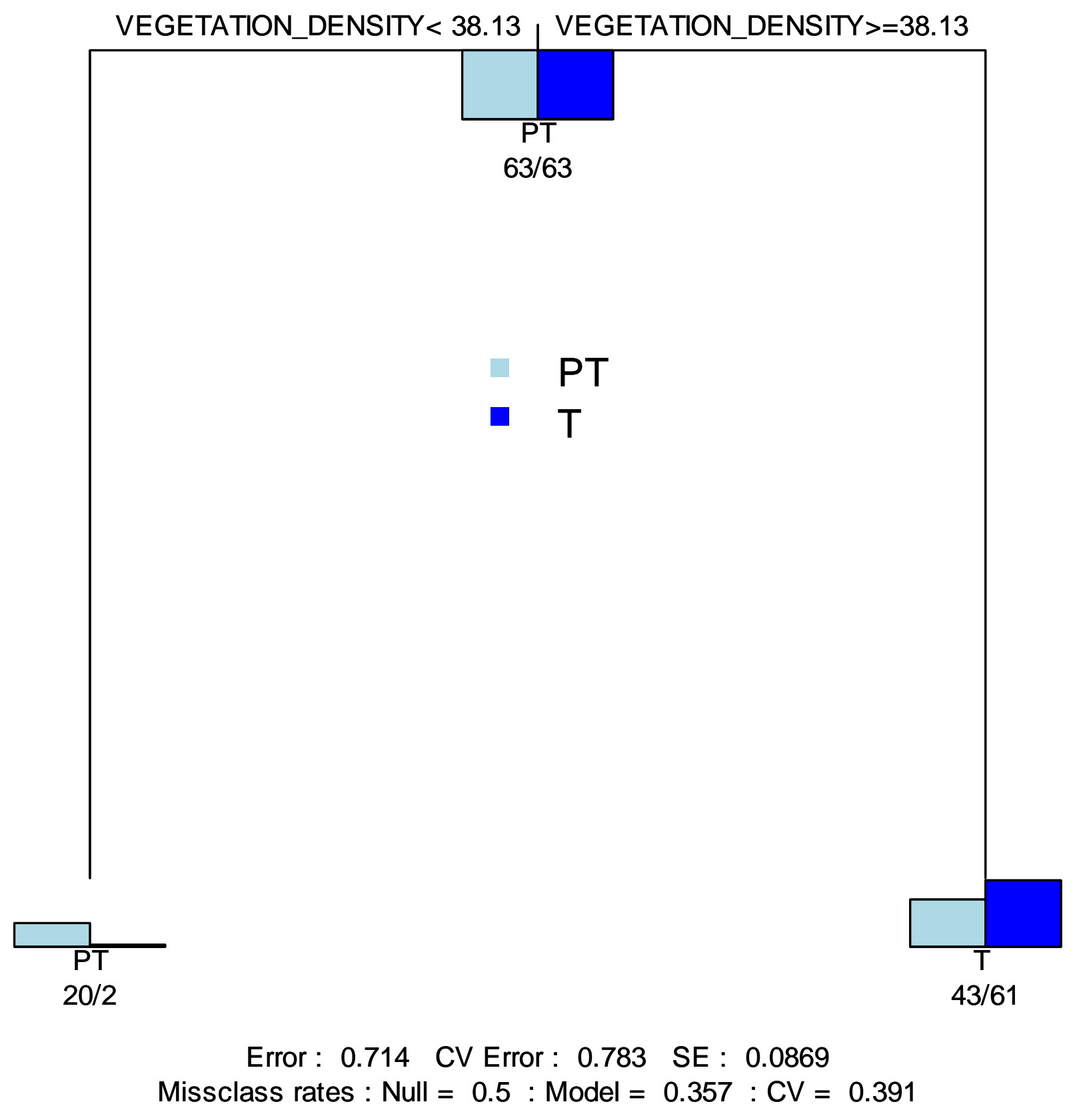

Figure 2. Classification tree for macrohabitat characteristics at Golden-winged Warbler territories ( $\mathrm{T} ; \mathrm{n}=63)$ and paired territory plots $(\mathrm{PT} ; \mathrm{n}=63)$ during 2008 and 2009 in Randolph and Pocahontas counties, West Virginia. 


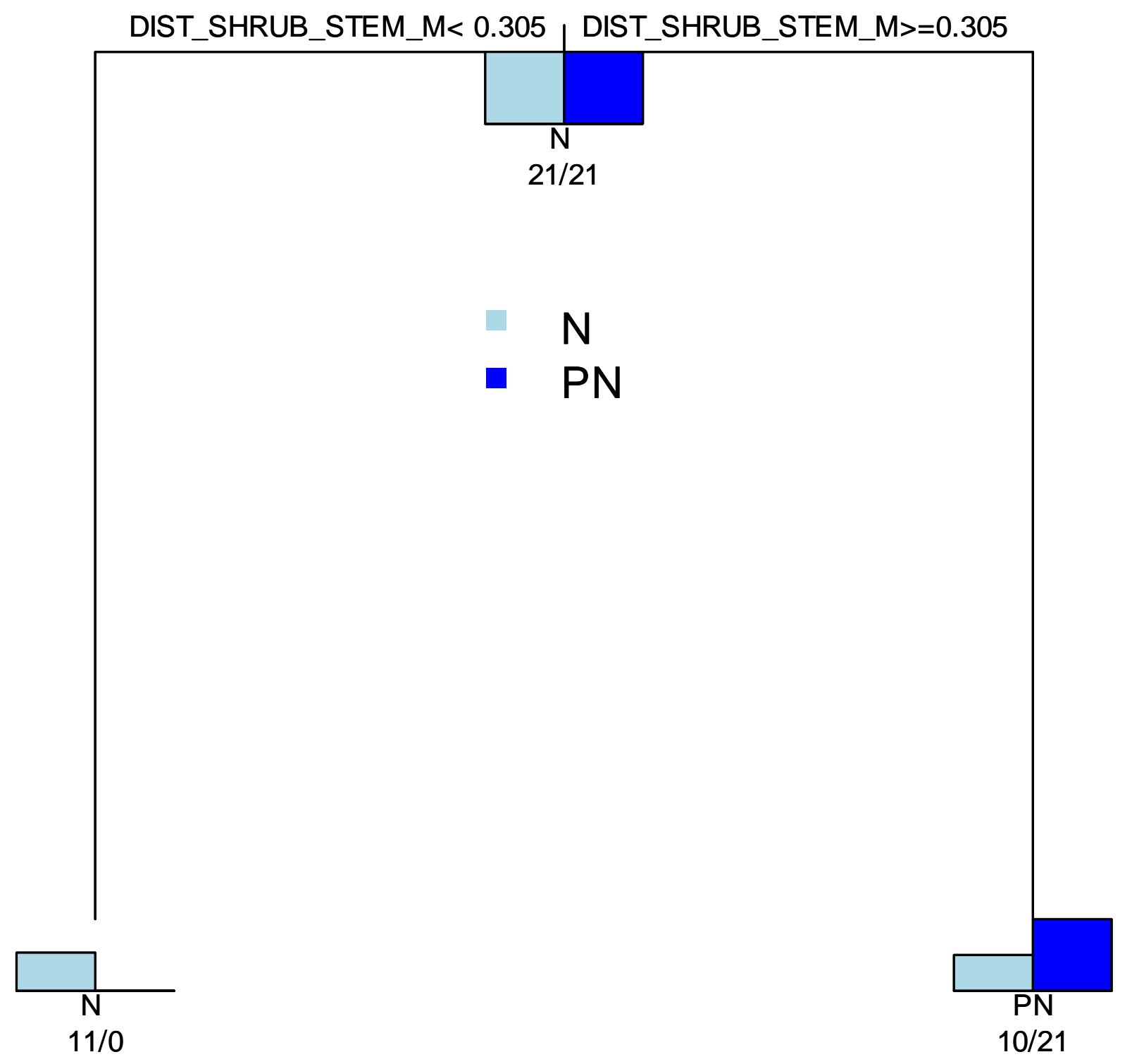

\section{Error : 0.476 CV Error : 0.576 SE : 0.14 \\ Missclass rates $:$ Null $=0.5:$ Model $=0.238: \mathrm{CV}=0.288$}

Figure 3. Classification tree for microhabitat characteristics at nests $(\mathrm{N} ; \mathrm{n}=21)$ and their associated random plots (PN; $\mathrm{n}=21)$ during 2008-2009 in Randolph and Pocahontas counties, WV. 


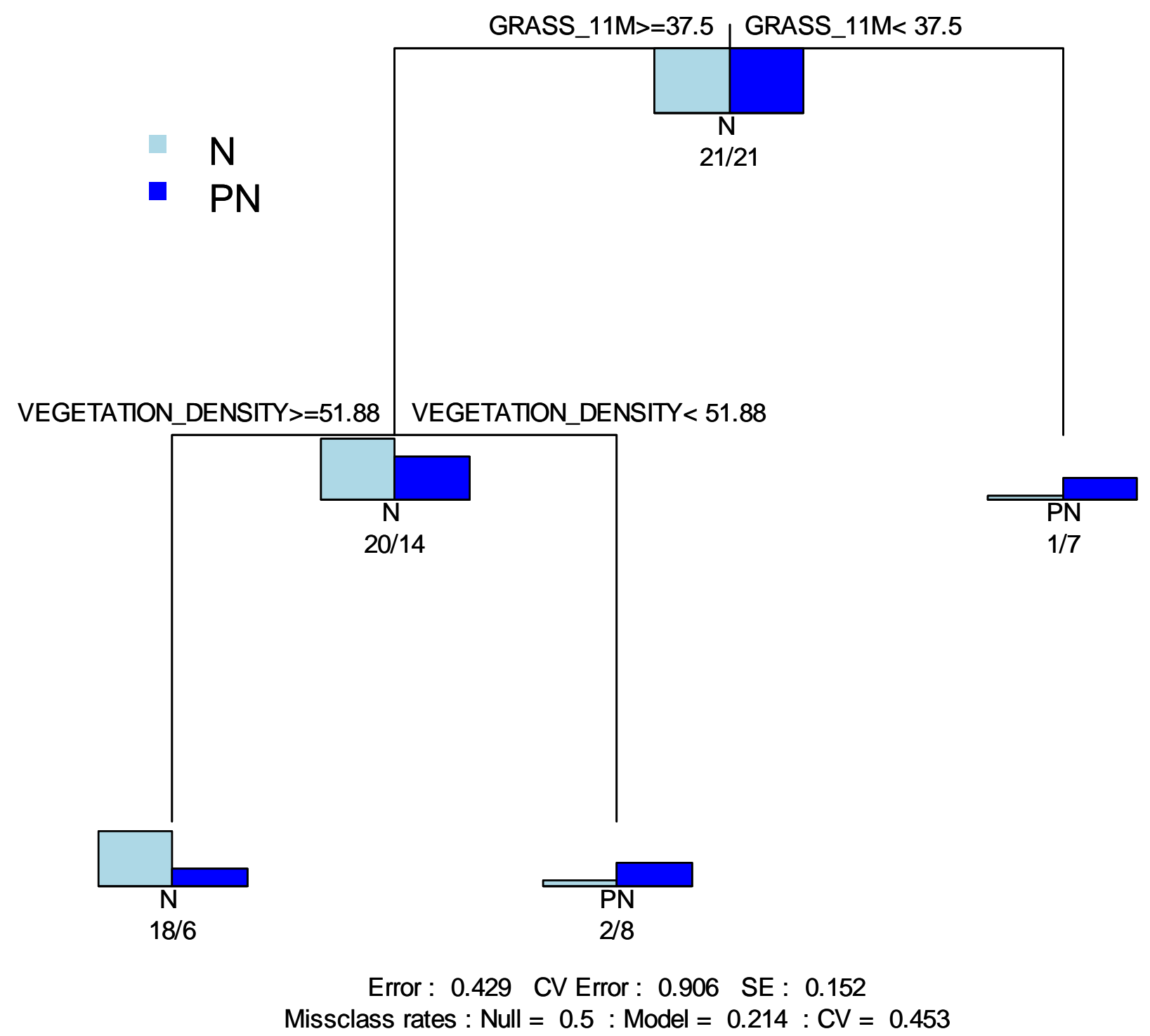

Figure 4. Classification tree for macrohabitat characteristics at nests $(\mathrm{N} ; \mathrm{n}=21)$ and their associated random plots (PN; $\mathrm{n}=21$ ) during 2008-2009 in Randolph and Pocahontas counties, WV. 


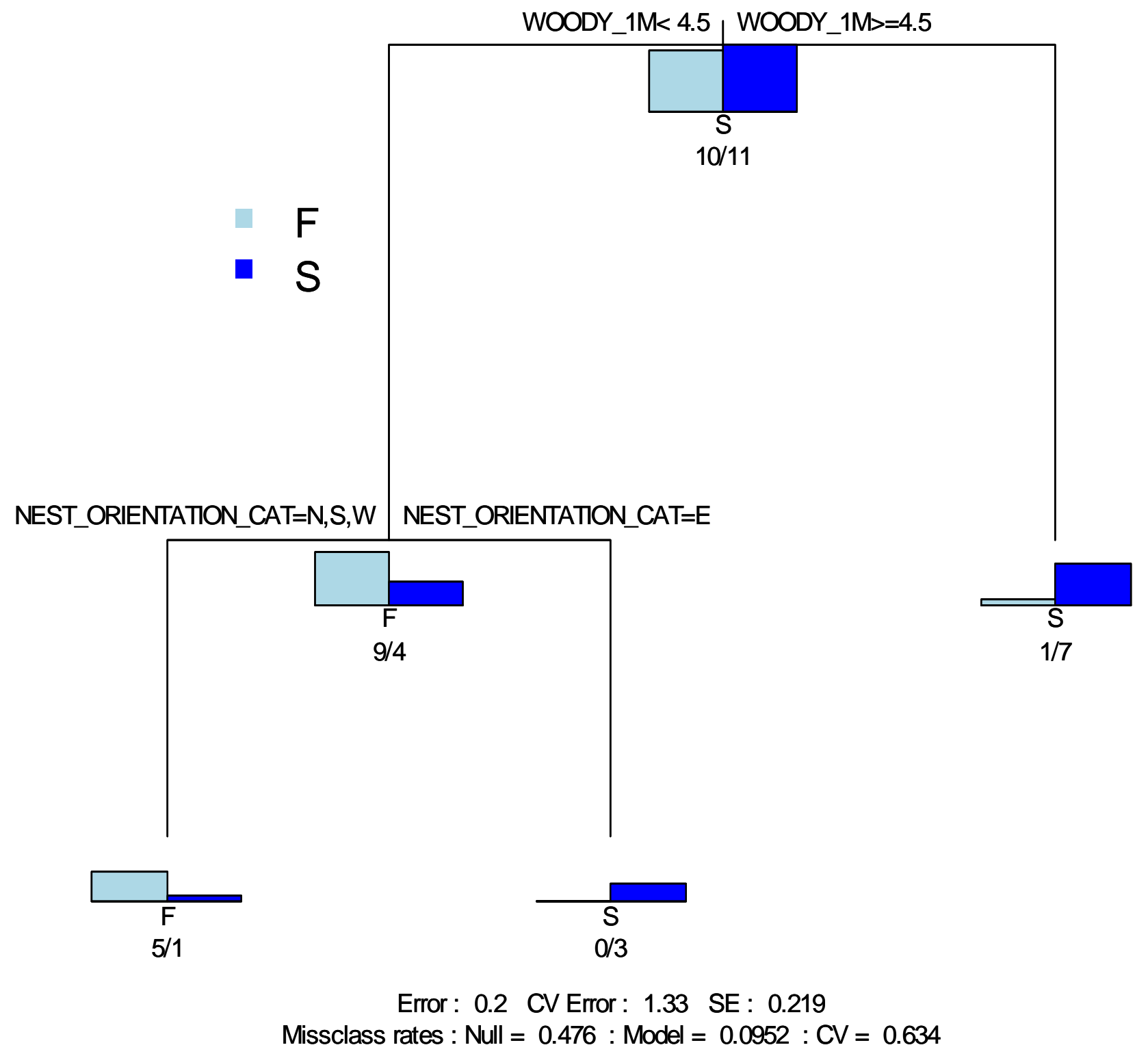

Figure 5. Classification tree for microhabitat characteristics at nests $(n=21)$ during 2008-2009 in Randolph and Pocahontas counties, WV. Letters below histograms signify successful (S) and failed (F) nests. 


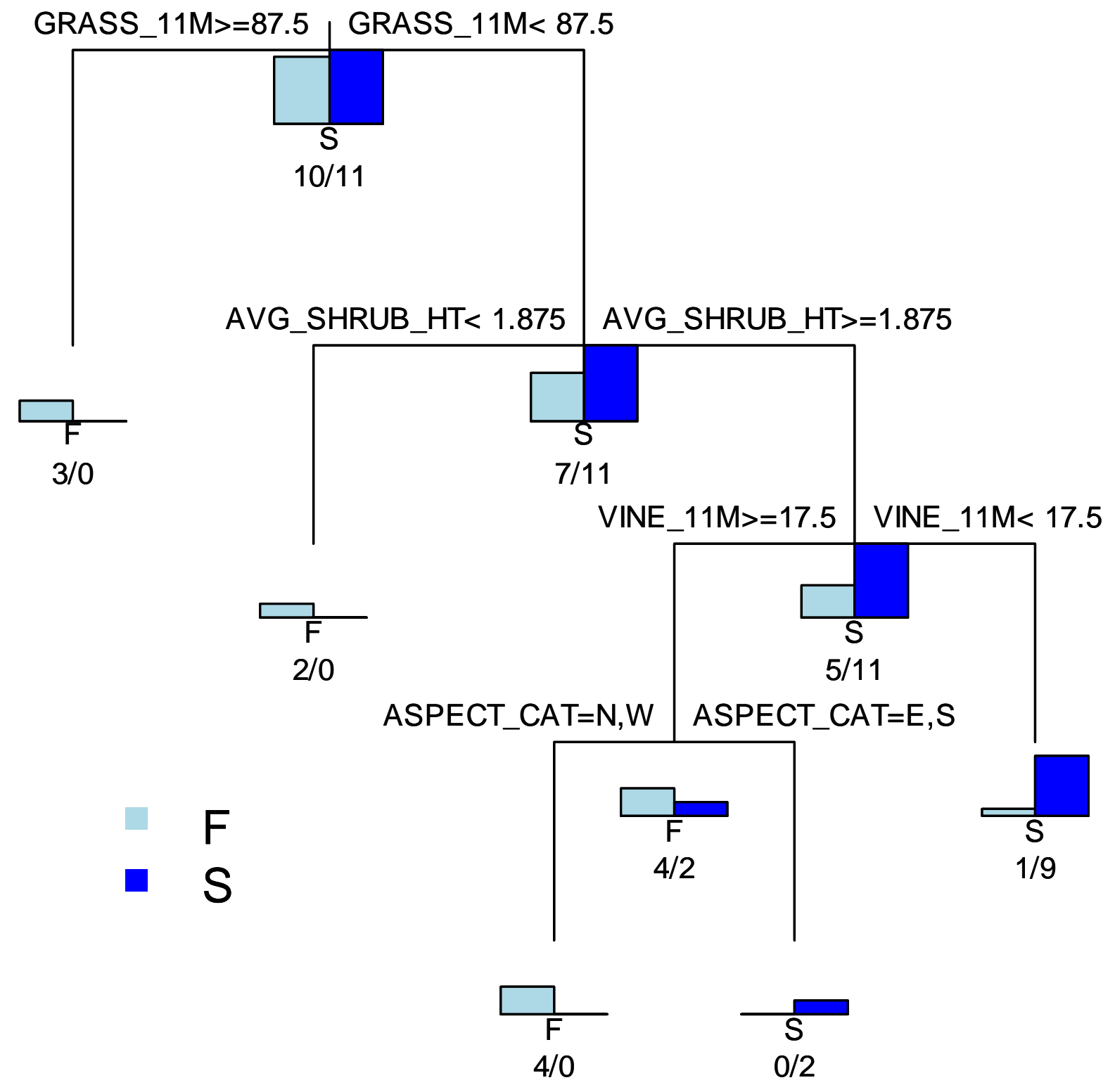

Error : 0.1 CV Error : 1.48 SE : 0.204

Missclass rates : Null $=0.476:$ Model $=0.0476: \mathrm{CV}=0.707$

Figure 6. Classification tree for macrohabitat characteristics at successful $(\mathrm{S} ; \mathrm{n}=11)$ and failed nests (F; n=10) during 2008-2009 in Randolph and Pocahontas counties, WV. We selected the tree with the minimum $\mathrm{CV}$ error rather the smallest tree within 1-SE of the minimum $\mathrm{CV}$ error. 